\title{
Effect of the Support and Its Surface Modifications in Cobalt-Based Fischer-Tropsch Synthesis
}

\author{
Rajesh Munirathinam,*i) Doan Pham Minh, and Ange Nzihou \\ Université de Toulouse, IMT-Mines Albi, UMR CNRS 5302, Centre RAPSODEE, Campus Jarlard, Albi F-81013 Cedex 09, France
}

\begin{abstract}
Support effects in heterogeneous catalysis are evolving as an important field of investigation to optimize catalyst properties. The cobalt-based Fischer-Tropsch (FT) catalysts usually consist of metallic cobalt nanocrystallites dispersed on a support material. The present review surveys the progress that has been made over the last couple of decades in the area of the effect of the support and its surface modifications in cobalt-based FT synthesis. Different catalyst supports such as alumina, silica, titania, niobia, zirconia, zeolite, ceria, carbon-based materials, silicon carbide, aluminum phosphate, hydrotalcite, metal-organic frameworks, and metal foams are discussed and compared with classical supports like alumina or silica wherever permitted. Properties such as metal-support interactions, the support-induced size and morphology of the cobalt nanocrystallites (textural properties of the support), changes in the electronic properties of the cobalt clusters, and the acid/base nature of the support are examined, and wherever possible the activity and/or selectivity in FT synthesis is discussed. This review also summarizes findings on new and promising supports for FT catalysts. Guidance for support modifications and choice of the support as functions of the product selectivity in the FT process is also proposed.

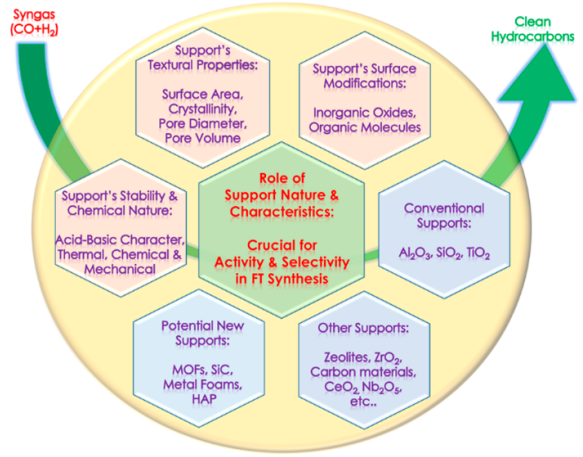

\section{INTRODUCTION}

Limited petroleum reserves have called for the strengthening of research activities on Fischer-Tropsch (FT) synthesis. ${ }^{1}$ It aims to produce synthetic fuels and value-added chemicals from synthesis gas (syngas, containing mainly $\mathrm{CO}$ and $\mathrm{H}_{2}$ ) obtained from non-petroleum resources such as coal, natural gas, biomass, and wastes. Cobalt ${ }^{2}$ and iron $^{3}$ are the most widely used metal catalysts in FT synthesis. Cobalt catalysts are preferred over iron catalysts for the low-temperature FT synthesis because of their increased stability, significant resistance toward oxidation by the steam formed during the course of the FT reaction, poor activity in the water-gas shift reaction, and increased selectivity for long-chain linear paraffins. ${ }^{4,5}$ The overall FT reaction that yields straight-chain alkane (paraffin) products is represented by the simplified eq 1 :

$$
n \mathrm{CO}+(2 n+1) \mathrm{H}_{2} \rightarrow \mathrm{C}_{n} \mathrm{H}_{2 n+2}+n \mathrm{H}_{2} \mathrm{O} \quad(n \geq 1)
$$

Industrially used cobalt-based FT catalysts (Co catalysts) with cobalt loadings in the range of $10-30$ wt \% are usually supported on alumina $\left(\mathrm{Al}_{2} \mathrm{O}_{3}\right)$, silica $\left(\mathrm{SiO}_{2}\right)$, or titania $\left(\mathrm{TiO}_{2}\right)^{6,7}$ The use of other supports such as carbon-based supports, ${ }^{8}$ mesoporous materials (SBA-15, MCM-41), ${ }^{9}$ zirconia $\left(\mathrm{ZrO}_{2}\right),{ }^{10}$ niobia $\left(\mathrm{Nb}_{2} \mathrm{O}_{5}\right),{ }^{11}$ ceria $\left(\mathrm{CeO}_{2}\right){ }^{12}$ zeolites, ${ }^{13}$ and $\mathrm{SiC}^{14}$ has also been reported in the literature. The Co catalysts are often promoted with noble metals $(\mathrm{Ru}$, $\mathrm{Pt}, \mathrm{Re}$, and Pd in the range of $0.05-1$ wt \%) to enhance the reducibility of cobalt oxide particles, to improve cobalt dispersion, inhibit catalyst deactivation, increase the number of hydrogen activation sites, and consequently augment the intrinsic reactivity of active sites. ${ }^{15}$ In addition, transition metal oxides such as zirconia, chromia, and manganese oxides and some rare-earth metal oxides such as lanthanum oxide, ceria, and thorium oxide have also been employed as structural promoters (in the range of $1-10 \mathrm{wt} \%$ ) to improve the dispersion of the active phase and its stability, consequently leading to increased catalytic activity. ${ }^{16}$ Because of the overlapping effects of structural promoters that influence the formation and stability of the active phase, textural promoters, and electronic promoters that affect elementary steps involved in each turnover on the catalyst, it is difficult to precisely define the function of a promoter. ${ }^{16}$

The support is a porous refractory oxide that is thermally stabilized at elevated temperatures to secure the strength and stability of the material. Generally, increasing the calcination temperature of the support leads to the formation of a more inert surface with reduced surface area, creation of larger pores, and condensation of surface hydroxyl groups. The effect of the support is an important field of investigation in heterogeneous catalysis. ${ }^{17}$ The primary functions of the support are to disperse the active metal, yield a high surface area of the catalytic phase, and provide mechanical strength and thermal stability to the active phase. Furthermore, the support's chemical nature also influences several important properties such as the reducibility of metal precursors, heat and mass transfer in an exothermic or diffusion-limited reaction, the 
electronic state of the active metal, diffusion of reagents and reaction products, and the stability of the active phase against morphological change during the reaction. ${ }^{18,19}$

The textural properties of the support, such as the surface area, pore structure, and surface chemistry, greatly affect cobalt dispersion. For example, high-surface-area supports provide high cobalt dispersion and most likely give rise to highly active FT catalysts, with the condition that there are no detrimental metal-support interactions that yield catalytically inactive species. ${ }^{20}$ The acidity of the support is known to play a role in determining the selectivity for methane, short-chain hydrocarbons, or long-chain hydrocarbons. ${ }^{21}$ Since the FT reaction is exothermic, the support also plays an important role in dissipating heat and thereby reducing the temperature gradients, especially in fixed-bed reactors. Therefore, the choice of the carrier material is of vital importance in FT synthesis. ${ }^{22}$ Comparison of the site activities of Co catalysts on different supports in FT synthesis is not straightforward, most likely because of the great variability of intrinsic textural properties among the different support materials and catalyst testing conditions. For example, a study of $\mathrm{CO}$ hydrogenation over cobalt catalysts supported on different carriers (3 wt \% Co loading) at $1 \mathrm{~atm}$ and $225{ }^{\circ} \mathrm{C}$ displayed specific activities for $\mathrm{CO}$ hydrogenation in the following order: $\mathrm{Co} / \mathrm{TiO}_{2}>\mathrm{Co} /$ $\mathrm{SiO}_{2}>\mathrm{Co} / \mathrm{Al}_{2} \mathrm{O}_{3}>\mathrm{Co} / \mathrm{C}>\mathrm{Co} / \mathrm{MgO}^{22}$ On the contrary, another study ${ }^{2}$ showed that the turnover frequency for CO conversion on Co catalysts (dispersion range, i.e., fraction of surface atoms, of 0.01-0.12) was independent of the support $\left(\mathrm{Al}_{2} \mathrm{O}_{3}, \mathrm{SiO}_{2}, \mathrm{TiO}_{2}, \mathrm{SiO}_{2}\right.$-modified $\mathrm{TiO}_{2}$, and $\left.\mathrm{MgCr}_{2} \mathrm{O}_{4}\right)$ under typical FT reaction conditions $\left(20\right.$ bar and $200{ }^{\circ} \mathrm{C}$ ). In a different study, ${ }^{23}$ the cobalt site activity for $\mathrm{CO}$ conversion and methane selectivity remained unaffected by the identity of the support $\left(\mathrm{Al}_{2} \mathrm{O}_{3}, \mathrm{SiO}_{2}\right.$, and $\left.\mathrm{TiO}_{2}\right)$; however, modifying the support with $\mathrm{Y}_{2} \mathrm{O}_{3}, \mathrm{MgO}$, or $\mathrm{ZnO}$ (by coating) reduced the site activity, thus demonstrating the importance of the nature of the interface between the support and the metal.

Research concerning the development of new catalyst carriers and their surface modifications to support cobalt has been active over the last couple of decades to decode the effect of the support in FT synthesis. Although results about support effects have been summarized partly in general reviews, $5,19,24,25$ a general review specifically on this topic is still missing, probably because of the complexity of the effect of the support on the catalytic behavior and the difficulty of comparing supports subjected to different experimental conditions. Rytter and Holmen ${ }^{26}$ attempted to discuss the impact of alumina and aluminates in FT synthesis, but the discussion was limited only to $\gamma-\mathrm{Al}_{2} \mathrm{O}_{3}, \alpha-\mathrm{Al}_{2} \mathrm{O}_{3}$, magnesium aluminate, and nickel aluminate.

During the last decades, much research work has been devoted to the valorization of biomass and wastes using thermal conversion processes (pyrolysis, gasification). Biomass and waste-derived syngas generally contain complex and variable pollutants, including particulate matter, tars, sulfurcontaining compounds, nitrogen-containing compounds, halide-containing compounds, and even metals. Purification of this syngas is difficult because of the variable nature of biomass and wastes as pyrolysis/gasification feedstocks. Thus, the valorization of this biomass- and waste-derived syngas via catalytic processes such as FT synthesis needs new catalysts that are highly resistant to pollutants. ${ }^{27,28}$ A survey of the latest developments on FT synthesis catalysts appears pertinent at this point.
In this review, we attempt to examine the state of the art on support effects, including most of the supports used in FT synthesis from research publications over the last two decades. Supports that have been surface-modified by the introduction of inorganic oxide and organic precursors before impregnation of the cobalt metal precursors are also surveyed in this review.

\section{ALUMINA-SUPPORTED CATALYSTS}

Alumina $\left(\mathrm{Al}_{2} \mathrm{O}_{3}\right)$ is the most commonly used carrier material in industry because of its low cost, good thermal and mechanical stability, and ability to yield a highly dispersed active phase. $\mathrm{Al}_{2} \mathrm{O}_{3}$ can be obtained in different crystallographic forms, i.e., $\gamma-\mathrm{Al}_{2} \mathrm{O}_{3}, \theta-\mathrm{Al}_{2} \mathrm{O}_{3}$, and $\alpha-\mathrm{Al}_{2} \mathrm{O}_{3}$ derived from boehmite or $\eta-\mathrm{Al}_{2} \mathrm{O}_{3}$ resulting from bayerite. ${ }^{29} \gamma-\mathrm{Al}_{2} \mathrm{O}_{3}$ is the most employed support in FT catalysts. $\mathrm{Al}_{2} \mathrm{O}_{3}$ is known to interact with cobalt ions and yield a well-dispersed active phase. As a result of metal-support interactions that arise from the diffusion of cobalt ions into alumina lattice sites of octahedral or tetrahedral geometry (forming $\mathrm{CoAl}_{2} \mathrm{O}_{4}$ species) during calcination, the reducibility of the catalysts is hindered, and a portion of the metal ions remain catalytically inactive. ${ }^{30}$ Complete diffusion of cobalt ions into lattice sites (tetrahedral) is attained only at low concentrations (i.e., ca. $\leq 2 \mathrm{wt} \% \mathrm{Co}$ ), and the percentage of cobalt ions interacting with the carrier decreases with increasing cobalt loading and decreasing calcination temperature. ${ }^{11}$ A study of cobalt catalysts supported on $\mathrm{Al}_{2} \mathrm{O}_{3}, \mathrm{SiO}_{2}$, and $\mathrm{TiO}_{2}$ showed that the metalsupport interactions affect the reduction of cobalt species, and the strengths of such interactions for different supports decrease in the order $\mathrm{Al}_{2} \mathrm{O}_{3}>\mathrm{TiO}_{2}>\mathrm{SiO}_{2}{ }^{32}$ The varied metal-support interactions give rise to differences in reducibility and dispersion of the active phase on different supports, consequently affecting the specific activity of cobaltbased FT catalysts. Cobalt reducibility is one of the major limitations of $\mathrm{Al}_{2} \mathrm{O}_{3}$-supported cobalt $\mathrm{FT}$ catalysts that arise from the detrimental metal-support interactions. It is circumvented in most cases by promotion with a noble metal such as $\mathrm{Ru}, \mathrm{Re}, \mathrm{Pt}$, or $\mathrm{Pd}$, which has been discussed in several reviews. ${ }^{5,15,16}$ In the following sections, the effects of the textural properties and crystalline phase of alumina, surface modification of alumina by different metal oxides and organic molecules, and the acid/base properties of alumina on the catalytic activity/selectivity in FT synthesis are discussed.

2.1. Effect of the Textural Properties and Crystalline Phase of the Alumina Support. Textural properties such as surface area, pore volume, pore size distribution, and crystalline phase of alumina are known to influence the activity/selectivity in Co-based FT synthesis through varied degrees of Co reducibility or formation of a cobalt aluminate phase. ${ }^{24,25}$ The support pore size plays a role in controlling the size of cobalt $\left(\mathrm{Co}_{3} \mathrm{O}_{4}\right)$ particles, with the formation of small particles in narrow pores and large particles in wide pores. ${ }^{33-36}$ Borg et al. ${ }^{35}$ showed that the degree of Co reduction increased with increasing catalyst pore size and $\mathrm{Co}_{3} \mathrm{O}_{4}$ particle size. Furthermore, they observed positive correlations between the cobalt particle size and the $\mathrm{C}_{5+}$ selectivity and between the catalyst pore size and the $\mathrm{C}_{5+}$ selectivity, with small variations in the cobalt site-time yields related to the chemical purity of the catalyst samples. Low-surface-area alumina $\left(\alpha-\mathrm{Al}_{2} \mathrm{O}_{3}\right)$ was found to display better $\mathrm{C}_{5+}$ selectivity compared with highsurface-area alumina $\left(\gamma-\mathrm{Al}_{2} \mathrm{O}_{3}\right) \cdot{ }^{36,37} \mathrm{~A}$ macroporous-structured (MPS) $\mathrm{Al}_{2} \mathrm{O}_{3}$ support synthesized from $\mathrm{Al}_{2} \mathrm{O}_{3}$ nanoparticles using polystyrene beads as a sacrificial agent seemed to 

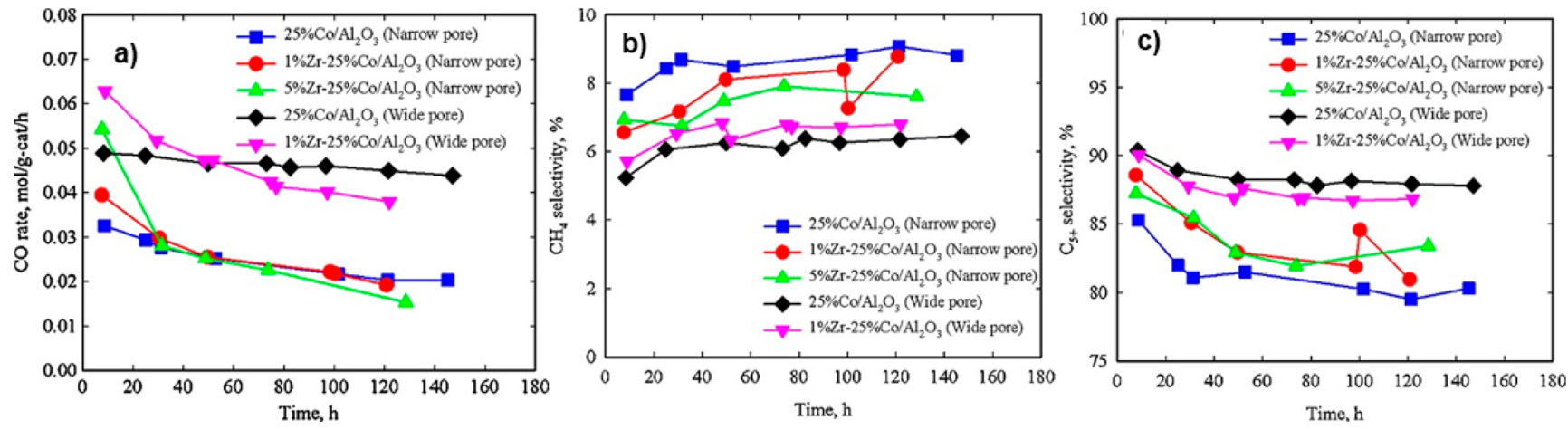

Figure 1. Effect of $\mathrm{Zr}$ loading and pore size on (a) CO rate, (b) $\mathrm{CH}_{4}$ selectivity, and (c) $\mathrm{C}_{5+}$ selectivity. Reaction conditions: $220{ }^{\circ} \mathrm{C}, 22$ bar, $\mathrm{H}_{2} /$ $\mathrm{CO}=2.1, X_{\mathrm{CO}}=49-51 \%$. Adapted with permission from ref 49. Copyright 2014 Elsevier.

combine the advantages of $\alpha-\mathrm{Al}_{2} \mathrm{O}_{3}$ and $\gamma-\mathrm{Al}_{2} \mathrm{O}_{3}$ as support materials, with activity and selectivity comparable to those of $\mathrm{Co} / \gamma-\mathrm{Al}_{2} \mathrm{O}_{3}$ and $\mathrm{Co} / \alpha-\mathrm{Al}_{2} \mathrm{O}_{3}$, respectively. ${ }^{38}$ Vosoughi et al. ${ }^{39}$ demonstrated the synthesis of mesoporous alumina using Pluronic F127 as a structure-directing agent that contributed to a high surface area and large pore volume and pore diameter of the support. The structure of the thus-prepared support collapsed upon impregnation with aqueous cobalt nitrate solution, but shifting the impregnation medium from aqueous to organic (ethanol or acetone) reinstated the textural stability of the mesoporous alumina. The cobalt catalyst supported on mesoporous alumina revealed higher CO conversion (8.3\%), higher hydrocarbon yield (18\%), and lower $\mathrm{CH}_{4}$ selectivity (2.6\%) compared with its counterpart supported on $\gamma-\mathrm{Al}_{2} \mathrm{O}_{3}$. In a more detailed study, different alumina phases $(\delta$-, $\theta$-, and $\left.\alpha-\mathrm{Al}_{2} \mathrm{O}_{3}\right)$ prepared by thermal treatment of small-pore (11-19 $\mathrm{nm})$ and medium-pore $(21-36 \mathrm{~nm}) \gamma-\mathrm{Al}_{2} \mathrm{O}_{3}$ were charged with a constant Co loading (12 wt \%) containing cobalt particle sizes in the range of $8-10 \mathrm{~nm} .{ }^{40}$ It was found that the medium-pore catalysts were reduced at lower temperatures and also exhibited higher selectivity for $\mathrm{C}_{5+}$ compared with the small-pore catalysts $\left(12 \mathrm{wt} \% \mathrm{Co}, 210{ }^{\circ} \mathrm{C}, 20 \mathrm{bar}, \mathrm{H}_{2} / \mathrm{CO}=2\right)$. In addition, higher $\mathrm{C}_{5+}$ selectivity was observed for $\delta$ - and $\alpha$ $\mathrm{Al}_{2} \mathrm{O}_{3}$ phases compared with $\theta$ - and $\gamma-\mathrm{Al}_{2} \mathrm{O}_{3}$, with $\alpha-\mathrm{Al}_{2} \mathrm{O}_{3}$ giving the highest selectivity. The site-time yield for cobalt supported on alumina did not vary systematically with the support variations investigated. These studies clearly established the role of textural properties of the support in controlling the particle size, reducibility, activity, and selectivity of the catalyst in FT synthesis.

2.2. Effect of Surface Modifications on the Alumina Support. Modification of the alumina surface is one of the options to weaken the interaction between the alumina support and the cobalt oxides, thereby limiting or suppressing the direct $\mathrm{Co}-\mathrm{Al}$ interactions and helping to increase the reducibility of cobalt particles. Precoating of cobalt aluminate on the surface of common alumina $\left(\gamma-\mathrm{Al}_{2} \mathrm{O}_{3}\right)$ exhibited higher cobalt specific activity, higher $\mathrm{C}_{5+}$ selectivity, higher $\mathrm{C}_{5+}$ spacetime yields, and lower methane selectivity than conventional catalysts in the FT synthesis. ${ }^{41}$ The enhanced catalytic performance was ascribed to the formation of the more active hexagonal close-packed (hcp) Co phase on the aluminatemodified alumina-supported cobalt catalysts, as opposed to the face-centered cubic (fcc) phase, which was supported on unmodified alumina. In addition, the modified catalysts exhibited lower reduction temperatures and a more intense bridged $\mathrm{CO}$ adsorption mode that generally yields long-chain hydrocarbons. In the following sections, both inorganic oxides and organic molecules that have been used to prevent the direct interaction of cobalt with the support are discussed.

2.2.1. Surface Modifications with Inorganic Oxides. 2.2.1.1. Modification with Magnesia and Barium Oxide. Studies have shown that modification of $\gamma-\mathrm{Al}_{2} \mathrm{O}_{3}$ with magnesia $(\mathrm{MgO})$ increased the reducibility of cobalt oxide, positively impacting the catalytic activity in $\mathrm{CO}$ hydrogenation. ${ }^{42,43}$ It was found that the addition of small amounts of magnesia to $\gamma$ $\mathrm{Al}_{2} \mathrm{O}_{3}$ improved the activity of cobalt catalysts in FT synthesis. However, larger amounts of magnesia ( $>0.8 \mathrm{wt} \%)$ restrained the reduction of the catalysts because of the formation of a $\mathrm{MgO}-\mathrm{CoO}$ phase, consequently decreasing the activity and increasing the methane and $\mathrm{CO}_{2}$ selectivity. ${ }^{42} \mathrm{~A} \mathrm{Mg}$ (10 wt $\%)$-modified $\alpha-\mathrm{Al}_{2} \mathrm{O}_{3}\left(\mathrm{MgAl}_{2} \mathrm{O}_{4}-\alpha-\mathrm{Al}_{2} \mathrm{O}_{3}\right)$ support prepared by incipient wetness impregnation of $\gamma-\mathrm{Al}_{2} \mathrm{O}_{3}$ with $\mathrm{Mg}\left(\mathrm{NO}_{3}\right)_{2}$ and calcination in air at $1140{ }^{\circ} \mathrm{C}$ for $10 \mathrm{~h}$ displayed better mechanical strength compared with unmodified $\alpha-\mathrm{Al}_{2} \mathrm{O}_{3}$, making it more suitable to operate in slurry or fluidized-bed reactors. ${ }^{44}$ The reduction of $\mathrm{CoO}$ to $\mathrm{Co}^{0}$ decreased with increasing $\mathrm{Mg}$ loading ( $\geq 1 \mathrm{wt} \%$ ), consequently impacting negatively both the catalytic activity and selectivity. The negative effect of $\mathrm{Mg}$ was attributed to a chemical/site (electronic) effect similar to that observed for alkali metals ( $\mathrm{Na}, \mathrm{K}$, and $\mathrm{Li}$ ), in which case the surface $\mathrm{H}$ concentration was decreased and $\mathrm{CO}$ adsorption and dissociation were increased. $^{45}$

Cobalt catalysts supported on barium modified $\gamma-\mathrm{Al}_{2} \mathrm{O}_{3}$ displayed improved cobalt reducibility when barium is added in smaller amounts $(\leq 2 \mathrm{wt} \%)$ and thus led to more cobalt active sites on the catalyst surface. ${ }^{46}$ These catalysts tested in a continuously stirred tank reactor presented higher $\mathrm{CO}$ conversion (ca. $36 \%$ versus $32 \%$ ) and $\mathrm{C}_{5+}$ selectivity (ca. $83 \%$ versus $80 \%$ ) compared to unmodified catalyst in FT synthesis ( 2 wt $\% \mathrm{Ba}, 15$ wt \% Co, 10 bar, $235^{\circ} \mathrm{C}$ and $\mathrm{H}_{2} / \mathrm{CO}$ $=2$ ). On the contrary, catalysts with high $\mathrm{BaO}$ loadings showed negative effects on the activity and selectivity for high hydrocarbons owing to low cobalt reducibility. Therefore, choosing the right amount of the modifying material is necessary to gain improvement in the catalytic performance.

2.2.1.2. Modification with Zirconia. A cobalt catalyst supported on a zirconium-modified $\gamma-\mathrm{Al}_{2} \mathrm{O}_{3}$ support displayed a decrease in the content of the $\mathrm{CoAl}_{2} \mathrm{O}_{4}$ spinel phase with increasing zirconium loading $(0.5-15 \mathrm{wt} \%)$ on the $\gamma-\mathrm{Al}_{2} \mathrm{O}_{3}$ support, resulting from minimization of the direct metalsupport interactions. ${ }^{47} \mathrm{Zr}$ addition improved the $\mathrm{CO}$ hydrogenation activity and $\mathrm{C}_{5+}$ selectivity of the $\mathrm{Co} / \gamma-\mathrm{Al}_{2} \mathrm{O}_{3}$ catalyst 
in FT synthesis ( 15 wt \% Co, $230{ }^{\circ} \mathrm{C}, 10$ bar, $\mathrm{H}_{2} / \mathrm{CO}=2$ ). The enhanced catalytic performance was attributed to an increase in the number and reducibility of cobalt active sites. On the contrary, Rohr et al. ${ }^{48}$ reported that modification of the $\mathrm{Al}_{2} \mathrm{O}_{3}$ (boehmite phase) support with $\mathrm{Zr}$ (3-10 wt \%) improved neither the reducibility nor the dispersion of cobalt, which might be ascribed to the different pretreatment conditions of the support and catalyst preparation. Nevertheless, both the activity and selectivity for higher hydrocarbons increased compared with the unmodified catalysts (520 wt $\% \mathrm{Co}, 245^{\circ} \mathrm{C}, 5$ bar, $\left.\mathrm{H}_{2} / \mathrm{CO}=9\right)$. $\mathrm{Ma}$ and co-workers ${ }^{49}$ systematically studied the impact of the $\mathrm{Zr}$ loading (1-5 wt \%) and pore size $\left(10.8\right.$ and $25 \mathrm{~nm}$ ) of the $\mathrm{Al}_{2} \mathrm{O}_{3}$ support in cobaltbased $\mathrm{FT}$ synthesis at a $\mathrm{CO}$ conversion level of ca. 50\% (25 wt $\% \mathrm{Co}, 220{ }^{\circ} \mathrm{C}, 22 \mathrm{bar}, \mathrm{H}_{2} / \mathrm{CO}=2.1$ ) (Figure 1a). They found that the cobalt site density of wide-pore catalysts increased by $25-55 \%$ compared with narrow pore catalysts. The catalytic test results indicated that Zr-modified alumina supports significantly improved the activity per gram of catalyst $\left(\mathrm{g}_{\text {cat }}\right)$, but the catalyst deactivation rate was increased. Furthermore, the pore size (wide or narrow) and loading of $\mathrm{Zr}$ promoter (1-5 wt \%) did not change the cobalt intrinsic activity. However, addition of $\mathrm{Zr}\left(1-5\right.$ wt \%) decreased the $\mathrm{CH}_{4}$ selectivity and increased the $\mathrm{C}_{5+}$ selectivity for the narrow-pore $25 \% \mathrm{Co} / \mathrm{Al}_{2} \mathrm{O}_{3}$ catalyst, whereas the opposite trend was observed with the wide-pore Co catalyst (Figure $1 \mathrm{~b}, \mathrm{c}$ ). The differences in the selectivity trends were attributed to the variances in the pore size and cobalt distribution.

2.2.1.3. Modification with Titania. Surface modification of $\gamma-\mathrm{Al}_{2} \mathrm{O}_{3}$ with small quantities of titanium $(0.2-0.5$ wt \% Ti$\mathrm{Al}_{2} \mathrm{O}_{3}$ ) was found to reduce direct detrimental metal-support interactions and stabilize the grain boundary of $\mathrm{Al}_{2} \mathrm{O}_{3}-\mathrm{TiO}_{2}$, consequently altering the density of surface acidic sites, which in turn led to a homogeneous size distribution of cobalt clusters with increased reducibility. ${ }^{50}$ Cobalt catalysts supported on $\mathrm{Ti}-\mathrm{Al}_{2} \mathrm{O}_{3}$ displayed high $\mathrm{CO}$ conversion (ca. $50 \%$ vs $34 \%$ ) and $\mathrm{C}_{5+}$ selectivity ( $80 \%$ vs $76 \%$ ) compared with their counterparts on unmodified alumina (20 wt \% Co, 240 ${ }^{\circ} \mathrm{C}, 20 \mathrm{bar}, \mathrm{H}_{2} / \mathrm{CO}=2$ ). The enhanced activity of the Timodified FT catalyst was ascribed to the suppressed aggregation of cobalt clusters and the better reducibility of $\mathrm{Co}_{3} \mathrm{O}_{4}$ particles. $\alpha-\mathrm{Al}_{2} \mathrm{O}_{3}$ supports usually have low specific surface area, and in the direction of improving the specific surface area, Liu et al. ${ }^{51}$ demonstrated the preparation of a hierarchical composite material, titania/carbon nanotubes $/ \alpha$ $\mathrm{Al}_{2} \mathrm{O}_{3}$ (TiCNTA), consisting of $\mathrm{TiO}_{2}$-modified multiwall carbon nanotubes (CNTs) decorating a macroscopic host structure of $\alpha-\mathrm{Al}_{2} \mathrm{O}_{3}$. The composite material exhibited a moderate specific surface area and very open porous structure as well as a strong interaction with the deposited cobalt phase, which in turn significantly improved the dispersion of cobalt nanoparticles and the mass diffusion during the FT reaction. The catalyst supported on TiCNTA showed higher cobalt time yield (6.6 vs 4.2$)$ and $\mathrm{C}_{5+}$ selectivity ( $95 \%$ vs $92 \%$ ) compared with its counterpart on the unmodified support, CNTs $/ \alpha$ $\mathrm{Al}_{2} \mathrm{O}_{3}\left(10\right.$ wt $\left.\% \mathrm{Co}, 200{ }^{\circ} \mathrm{C}, 20 \mathrm{bar}, \mathrm{H}_{2} / \mathrm{CO}=2\right)$. The catalyst also exhibited higher stability compared with other traditional FT synthesis catalysts as a function of time on stream, which was attributed to the medium interaction between the $\mathrm{TiO}_{2}$ and cobalt NPs. Such stable catalysts will be very useful in application to the biomass-to-liquid process, where some impurities that could be detrimental to the catalyst life cycle are present.
2.2.1.4. Modification with Lanthanum. Lanthanummodified alumina $\left(\gamma-\mathrm{Al}_{2} \mathrm{O}_{3}\right.$ preimpregnated with lanthanum nitrate before cobalt addition) was reported to influence the dispersion of the metallic cobalt phase, but the extent of its influence depends on its loading. ${ }^{52}$ At low $\mathrm{La}^{3+}$ loadings (La/ $\mathrm{Al}$ atomic ratio $\leq 0.026$ ), the presence of La had little effect on the structure of the cobalt catalyst or the $\mathrm{CO}$ hydrogenation activity, but the selectivity for long-chain hydrocarbons and olefinic products increased with increasing La content (10 wt $\% \mathrm{Co}, 185{ }^{\circ} \mathrm{C}, 1$ bar, $\left.\mathrm{H}_{2} / \mathrm{CO}=3\right)$. At higher $\mathrm{La}^{3+}$ loadings $(\mathrm{La} / \mathrm{Al}$ atomic ratio $>0.026)$, the turnover frequency (TOF) for $\mathrm{CO}$ hydrogenation was decreased, probably because of the formation of a La-Co mixed oxide, which eventually decreased the amount of catalytically active cobalt phase. Cai et al. ${ }^{53}$ demonstrated the preparation of lanthana-modified alumina supports by both impregnation and coprecipitation. They found that cobalt catalysts on the modified supports displayed better reducibility and that more $\mathrm{CO}$ molecules were adsorbed on cobalt species, which in turn led to higher activity and lower methane selectivity than with their counterparts on the unmodified support in FT synthesis. Brabant and co-workers systematically studied the effect of the La/Co ratio on the structure of alumina-supported cobalt catalysts in FT synthesis by varying the amount of $\mathrm{La}(0,5,10,25,20 \mathrm{wt} \%)$ preimpregnated on alumina. ${ }^{54}$ They found that impregnation of the support with $10 \mathrm{wt} \%$ lanthanum reduced the concentration of barely reducible cobalt aluminate and also maximized the cobalt metal dispersion. At similar conversions in FT synthesis ( 10 wt $\% \mathrm{Co}, 220^{\circ} \mathrm{C}, 20$ bar, $\mathrm{H}_{2} / \mathrm{CO}=2$ ), lower selectivity for methane and higher selectivity for heavy hydrocarbons were obtained for cobalt catalysts on lanthanummodified supports. Nevertheless, they displayed higher deactivation rates after several hours of time on stream (60 h) compared with cobalt catalysts on unmodified alumina. They speculated that sintering and the formation of inert carbon phases were possible reasons for catalyst deactivation.

2.2.1.5. Modification with Phosphorus. The chemical modification of $\gamma-\mathrm{Al}_{2} \mathrm{O}_{3}$ with phosphorus is widely used in hydrotreatment reactions. The strong affinity between $\mathrm{Al}$ and $\mathrm{P}$ leads to the formation of $\mathrm{AlPO}_{4}$, which is known to weaken the metal-support interaction, enhance the reducibility of metal precursors, and stabilize the active phase. ${ }^{55}$ The use of phosphorus-modified $\gamma-\mathrm{Al}_{2} \mathrm{O}_{3}\left(\mathrm{P}-\mathrm{Al}_{2} \mathrm{O}_{3}\right)$ in $\mathrm{FT}$ synthesis was reported by Bae and co-workers. ${ }^{56}$ They observed weak interactions between cobalt and the phosphorus-modified alumina surface due to the partial transformation of the $\gamma$ $\mathrm{Al}_{2} \mathrm{O}_{3}$ surface to $\mathrm{AlPO}_{4}$, which eventually enhanced the reducibility of $\mathrm{Co}_{3} \mathrm{O}_{4}$ species and inhibited the sintering of metallic cobalt nanocrystallites. The cobalt catalysts on the P$\mathrm{Al}_{2} \mathrm{O}_{3}$ support $(1-2$ wt $\% \mathrm{P}$ ) exhibited higher $\mathrm{CO}$ conversion (ca. $40 \%$ vs $22 \%$ ), $\mathrm{C}_{5+}$ selectivity (ca. $74 \%$ vs $81 \%$ ), and stability compared with their counterparts on bare $\mathrm{Al}_{2} \mathrm{O}_{3}$ in a fixed-bed FT synthesis $\left(20\right.$ wt $\% \mathrm{Co}, 220^{\circ} \mathrm{C}, 20 \mathrm{bar}, \mathrm{H}_{2} / \mathrm{CO}=$ 2 ). The observed higher catalytic performance was attributed to the good homogeneous dispersion of cobalt species with high reducibility. The $\mathrm{P}-\mathrm{Al}_{2} \mathrm{O}_{3}$ support also significantly suppressed the migration of cobalt particles to the outer pore mouths by forming thermally stable $\mathrm{Co}-\mathrm{P}$ oxo species on the $\mathrm{Al}_{2} \mathrm{O}_{3}$ surface during the $\mathrm{FT}$ synthesis reaction, thus helping to enhance the catalytic stability and activity. ${ }^{57}$ Furthermore, the cobalt catalysts supported on phosphorusmodified $\gamma-\mathrm{Al}_{2} \mathrm{O}_{3}$ tested in a slurry-phase $\mathrm{FT}$ synthesis reaction displayed higher catalytic activity and stability. Modification of 
alumina by phosphorus not only suppressed the hydrophilic properties and enhanced the hydrothermal stability of $\gamma-\mathrm{Al}_{2} \mathrm{O}_{3}$ but also reduced the deposition of polymeric carbons on the catalytic surface formed during FT synthesis. ${ }^{58-60}$

2.2.2. Surface Modifications with Carbon/Organic Molecules. The carbon interlayer in carbon-covered aluminasupported cobalt catalysts is known to weaken the detrimental metal-support interactions, thereby avoiding the formation of catalytically inactive species. ${ }^{61}$ Jean-Marie et al. ${ }^{62}$ demonstrated that pretreatment of alumina with sorbitol resulted in enhanced cobalt dispersion, but at the cost of the formation of smaller cobalt oxide particles that possess lower reducibility. The cobalt catalysts supported on alumina pretreated with sorbitol exhibited a significant increase in the FT reaction rate $\left(52.5 \times 10^{-3}\right.$ vs $18.9 \times 10^{-3} \mathrm{~mol} \mathrm{~h}^{-1} \mathrm{~g}^{-1}$; FT reaction conditions: 15 wt $\% \mathrm{Co}, 212{ }^{\circ} \mathrm{C}, 20$ bar, $\mathrm{H}_{2} / \mathrm{CO}=2$ ) compared with their counterparts on unmodified alumina. The effect on the catalyst structure and catalytic performance was less pronounced when sorbitol was introduced during impregnation of the cobalt precursor or catalyst posttreatment. These differences were attributed to different mechanisms of decomposition of the cobalt precursor and crystallization of the $\mathrm{Co}_{3} \mathrm{O}_{4}$ phase in the presence of sorbitol in alumina-supported cobalt catalysts. When $\beta$-cyclodextrin was added in very small amounts to the cobalt nitrate impregnating solutions during the preparation of active alumina-supported cobalt catalysts, their catalytic activity in FT synthesis was almost 4 times higher than without the use of $\beta$-cyclodextrin. ${ }^{63}$ The increase in the activity was credited to enhancement of the cobalt dispersion. Carefully choosing the organic molecules or even biopolymers in right amounts with definite functional groups that coat the support material and interact with metal precursors via specific functional groups on the organic moieties would provide a pathway to disperse metals homogeneously on the support surface.

2.2.3. Silylation of $\gamma$-Alumina. The presence of a significant concentration of hydroxyl groups on the surface of $\gamma-\mathrm{Al}_{2} \mathrm{O}_{3}$ makes it hydrophilic in nature, and furthermore, its surface also exhibits Lewis acidic and Brønsted acidic characteristics. ${ }^{29}$ Rytter and co-workers chemically modified the surface of $\gamma$ $\mathrm{Al}_{2} \mathrm{O}_{3}$ using organosilanes containing chloro or methoxy active ligands to make the surface of alumina hydrophobic in nature and investigated the effect of surface acidity and hydrophobicity in FT synthesis $\left(20\right.$ wt $\% \mathrm{Co}, 210{ }^{\circ} \mathrm{C} ; 20$ bar; $\mathrm{H}_{2}$ / $\mathrm{CO}=2.1) .{ }^{64}$ They found that preimpregnation with chloro- or methoxyalkylsilanes led to silylation of the $\gamma-\mathrm{Al}_{2} \mathrm{O}_{3}$ support, yielding a hydrophobic surface and preventing the formation of highly dispersed cobalt oxide interacting with alumina. However, postimpregnation (i.e., impregnation of silane on the calcined $\gamma-\mathrm{Al}_{2} \mathrm{O}_{3}$-supported cobalt catalyst) showed no detectable silylation of the support surface, and the reduction of the catalysts was more challenging because a considerable amount of silanes remained inside the pores. The catalysts supported on $\gamma-\mathrm{Al}_{2} \mathrm{O}_{3}$ preimpregnated with silane provided the possibility to improve the selectivity for higher hydrocarbons in FT synthesis. It was hypothesized that silylation of $\gamma-\mathrm{Al}_{2} \mathrm{O}_{3}$ yielded a support surface that resembles $\alpha-\mathrm{Al}_{2} \mathrm{O}_{3}$ and played a role in improving the chain growth probability $\left(\alpha_{\mathrm{C}_{2+}}\right)$.

The effects of alumina surface modifications on the activity and selectivity of cobalt-based FT catalysts are summarized in Table 1. Certainly, the organic or inorganic modifiers play a significant role in altering the direct metal-support interaction,
Table 1. Effects of Surface Modifiers on the Activity and Selectivity of Cobalt Catalysts Supported on Alumina

\begin{tabular}{|c|c|c|c|}
\hline modifier & catalyst & effects & $\operatorname{ref}(s)$ \\
\hline $\mathrm{Mg}$ & $\mathrm{Co} / \mathrm{Mg} / \mathrm{Al}_{2} \mathrm{O}_{3}$ & $\begin{array}{l}\text { - decreases } \mathrm{Co}-\mathrm{Al}_{2} \mathrm{O}_{3} \text { interaction } \\
\text { - increases Co reduction } \\
\text { - increases CO hydrogenation for } \\
<1 \text { wt } \% \text { magnesia addition }\end{array}$ & $42-44$ \\
\hline $\mathrm{Ba}$ & $\mathrm{Co} / \mathrm{Ba} / \mathrm{Al}_{2} \mathrm{O}_{3}$ & $\begin{array}{l}\text { - facilitates Co reduction for } \leq 2 \\
\text { wt } \% \mathrm{BaO} \text { addition } \\
\text { - enhancement in } \mathrm{CO} \text { conversion } \\
\text { and } \mathrm{C}_{5+} \text { selectivity }\end{array}$ & 46 \\
\hline $\mathrm{Zr}$ & $\mathrm{Co} / \mathrm{Zr} / \mathrm{Al}_{2} \mathrm{O}_{3}$ & $\begin{array}{l}\text { - decreases } \mathrm{Co}-\mathrm{Al}_{2} \mathrm{O}_{3} \text { interaction } \\
(0-15 \text { wt \%) } \\
\text { - improves CO conversion and } \\
\mathrm{C}_{5+} \text { selectivity }\end{array}$ & 47,49 \\
\hline $\mathrm{Ti}$ & $\mathrm{Co} / \mathrm{Ti} / \mathrm{Al}_{2} \mathrm{O}_{3}$ & $\begin{array}{l}\text { - alters surface acidic site density } \\
\text { - increases Co dispersion and } \\
\text { reducibility } \\
\text { - increases CO conversion and } \\
\mathrm{C}_{5+} \text { selectivity }(0.2-0.5 \text { wt } \%)\end{array}$ & 50 \\
\hline $\mathrm{La}$ & $\mathrm{Co} / \mathrm{La} / \mathrm{Al}_{2} \mathrm{O}_{3}$ & $\begin{array}{l}\text { - reduces the amount of cobalt } \\
\text { aluminate species and maximizes } \\
\text { Co dispersion }(10 \mathrm{wt} \%) \\
\text { - increases } \mathrm{C}_{5+} \text { selectivity }\end{array}$ & $52-54$ \\
\hline $\mathrm{P}$ & $\mathrm{Co} / \mathrm{P} / \mathrm{Al}_{2} \mathrm{O}_{3}$ & $\begin{array}{l}\text { - limits cobalt aluminate } \\
\text { formation and aggregation of Co } \\
\text { particles }(\leq 2 \mathrm{wt} \%) \\
\text { - increases thermal stability and } \\
\text { CO conversion }\end{array}$ & 56,57 \\
\hline sorbitol (C) & $\mathrm{Co} / \mathrm{C} / \mathrm{Al}_{2} \mathrm{O}_{3}$ & $\begin{array}{l}\text { - enhances Co dispersion }(\mathrm{Co} / \\
\text { sorbitol = 6) } \\
\text { - limits Co reducibility } \\
\text { - increases CO conversion }\end{array}$ & 62 \\
\hline silanes $(\mathrm{Si})$ & $\mathrm{Co} / \mathrm{Si} / \mathrm{Al}_{2} \mathrm{O}_{3}$ & $\begin{array}{l}\text { - modifies the hydrophobility of } \\
\text { the catalyst } \\
\text { - leads to smaller Co particles } \\
\text { - improves the chain growth } \\
\text { probability }\left(\alpha_{\mathrm{C}_{2+}}\right)\end{array}$ & 64 \\
\hline
\end{tabular}

which affects the Co reducibility, dispersion, and acid/base properties of the catalyst, thereby influencing the catalytic activity and selectivity.

2.3. Acidity/Basicity of the Oxide Support. The surface acidity/basicity of supported Co catalysts was known to modify the adsorption strengths of $\mathrm{CO}$ and $\mathrm{H}_{2}$ on Co particles, which in turn affected the behavior in FT synthesis. ${ }^{65}$ Surface basicity seemed to increase the electron density of supported $\mathrm{Co}$, thereby strengthening the $\mathrm{Co}-\mathrm{CO}$ bonds, whereas, surface acidity appeared to decrease the electron density of supported $\mathrm{Co}$, thus strengthening the $\mathrm{Co}-\mathrm{H}$ bonds. Studies of cobalt supported on $\gamma$-alumina possessing different textural properties showed that the support with low acidity displayed higher activity, higher $\mathrm{C}_{5+}$ hydrocarbon selectivity, and lower methane selectivity in FT synthesis. ${ }^{66}$ The better catalytic performance of the support with low acidity was attributed to the weaker interaction between metallic cobalt and the support, better reducibility of cobalt, and higher intensity of bridge-mode $\mathrm{CO}$ adsorption, which usually favors the dissociation of $\mathrm{CO}$ and chain growth of $-\mathrm{CH}_{2}-$ fragments. In order to fully understand the impact of the chemical nature of the support material on the catalytic performance, it is required to decouple this effect from other influential elements such as support texture, extent of Co reduction, and particle size. In this direction, Prieto and co-workers coated a high-surface-area $\gamma-\mathrm{Al}_{2} \mathrm{O}_{3}$ (AO) support with a monolayer content of various transition metal $\left(\mathrm{YO}_{x}, \mathrm{TiO}_{x}, \mathrm{TaO}_{x}, \mathrm{WO}_{x}\right)$ and lanthanide $\left(\mathrm{SmO}_{x}\right)$ oxides $\left(\mathrm{MO}_{x}\right)$ to obtain support materials $\left(\mathrm{MO}_{x} @\right.$ 
Table 2. Physicochemical Properties of Oxide Support Materials ${ }^{67}$

\begin{tabular}{|c|c|c|c|c|c|c|c|}
\hline \multirow[b]{2}{*}{ support } & \multicolumn{2}{|c|}{ composition } & \multicolumn{4}{|c|}{ textural properties } & \multirow[b]{2}{*}{ acid/base character $\eta^{f}(\mathrm{eV})$} \\
\hline & metal loading (wt \%) & $\delta^{a}\left(\right.$ atoms $\left./ \mathrm{nm}^{2}\right)$ & $S_{\mathrm{BET}}^{b}\left(\mathrm{~m}^{2} / \mathrm{g}\right)$ & $V_{\mathrm{p}}^{c}\left(\mathrm{~cm}^{3} / \mathrm{g}\right)$ & $V_{\mathrm{p}}^{d}\left(\mathrm{~cm}^{3} / \mathrm{g}_{\mathrm{Al}_{2} \mathrm{O}_{3}}\right)$ & $\mathrm{PD}^{e}\left(\mathrm{~cm}^{3} / \mathrm{g}\right)$ & \\
\hline $\mathrm{AO}$ & - & - & 205 & 0.52 & 0.52 & 8.9 & 2.49 \\
\hline $\mathrm{SmO}_{x} @ \mathrm{AO}$ & $18.7^{g}$ & $4.7^{g}$ & 155 & 0.39 & 0.50 & 7.9 & 2.38 \\
\hline $\mathrm{YO}_{x} @ \mathrm{AO}$ & $12.1^{h}$ & $4.7^{h}$ & 174 & 0.44 & 0.52 & 7.9 & 2.46 \\
\hline $\mathrm{TiO}_{x} @ \mathrm{AO}$ & 6.2 & 4.2 & 192 & 0.46 & 0.51 & 8.0 & 2.50 \\
\hline $\mathrm{TaO}_{x} @ \mathrm{AO}$ & 23.5 & 5.3 & 176 & 0.34 & 0.47 & 7.0 & 2.53 \\
\hline WO $@ \mathrm{AO}$ & 24.0 & 5.5 & 178 & 0.37 & 0.53 & 7.0 & 2.61 \\
\hline
\end{tabular}

${ }^{a}$ Surface coverage of the alumina surface with $\mathrm{M}$ atoms. ${ }^{b} S_{\mathrm{BET}}$ is the Brunauer-Emmett-Teller specific surface area. ${ }^{c}$ Total specific pore volume.

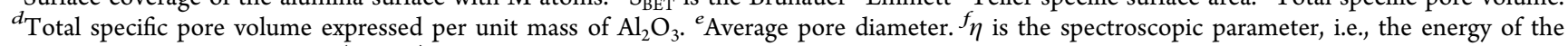
intramolecular charge transfer (IMCT) band of adsorbed alizarin as measured by diffuse-reflectance UV-vis spectroscopy, which gives the Lewis acid/base character. ${ }^{g}$ Nominal values. ${ }^{h}$ Determined by X-ray fluorescence spectrometry.

Table 3. Physicochemical Properties of CoRu/ $\mathrm{MO}_{x} @ \mathrm{Al}_{2} \mathrm{O}_{3}$ Catalysts $^{67}$

\begin{tabular}{|c|c|c|c|c|c|c|c|c|}
\hline \multirow[b]{2}{*}{ catalyst } & \multicolumn{2}{|c|}{$\begin{array}{c}\text { metal } \\
\text { contents } \\
(\text { wt \%) }\end{array}$} & \multicolumn{2}{|c|}{ textural properties } & \multicolumn{4}{|c|}{ metal dispersion } \\
\hline & Co & $\mathrm{Ru}$ & $S_{\mathrm{BET}}{ }^{a}\left(\mathrm{~m}^{2} / \mathrm{g}_{\mathrm{Al}_{2} \mathrm{O}_{3}}\right)$ & $V_{\mathrm{p}}^{b}\left(\mathrm{~cm}^{3} / \mathrm{g}_{\mathrm{Al}_{2} \mathrm{O}_{3}}\right)$ & $d\left(\mathrm{Co}_{3} \mathrm{O}_{4}\right)_{\mathrm{XRD}}{ }^{c}(\mathrm{~nm})$ & $d(\mathrm{Co})_{\mathrm{TEM}}{ }^{d}(\mathrm{~nm})$ & $\mathrm{H}_{2}$ uptake $^{e}(\mu \mathrm{mol} / \mathrm{g})$ & $d(\mathrm{Co})_{\mathrm{H}}{ }^{f}(\mathrm{~nm})$ \\
\hline $\mathrm{CoRu} / \mathrm{AO}$ & 22.1 & 0.3 & 260 & 0.52 & 17.3 & & 144 & 12.5 \\
\hline $\mathrm{CoRu} / \mathrm{SmO}_{x} @ \mathrm{AO}$ & 21.8 & 0.3 & 292 & 0.49 & 12.7 & 13.6 & 126 & 14.1 \\
\hline 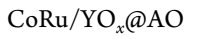 & 21.4 & 0.2 & 271 & 0.45 & 10.5 & & 162 & 10.8 \\
\hline $\mathrm{CoRu} / \mathrm{TiO}_{x} @ \mathrm{AO}$ & 22.8 & 0.2 & 261 & 0.44 & 13.3 & 13.0 & 132 & 14.1 \\
\hline CoRu/TaO $x @ \mathrm{AO}$ & 22.1 & 0.2 & 265 & 0.53 & 17.4 & & 124 & 14.6 \\
\hline CoRu/WO WAO $_{x}$ & 19.9 & 0.2 & 258 & 0.47 & 13.1 & 16.3 & 41 & 39.7 \\
\hline
\end{tabular}

${ }^{a} \mathrm{BET}$ specific surface area expressed per unit mass of $\mathrm{Al}_{2} \mathrm{O}_{3} \cdot{ }^{b}$ Total specific pore volume expressed per unit mass of $\mathrm{Al}_{2} \mathrm{O}_{3} \cdot{ }^{c} \mathrm{Co}_{3} \mathrm{O}_{4}$ crystallite size after air calcination. ${ }^{d}$ Surface-averaged Co particle size distribution as determined by transmission electron microscopy on the reduced and passivated catalysts. ${ }^{e}$ Total hydrogen uptake as determined after in situ reduction. ${ }^{f}$ Apparent Co average particle size as derived from the total $\mathrm{H}_{2}$ chemisorption uptake.
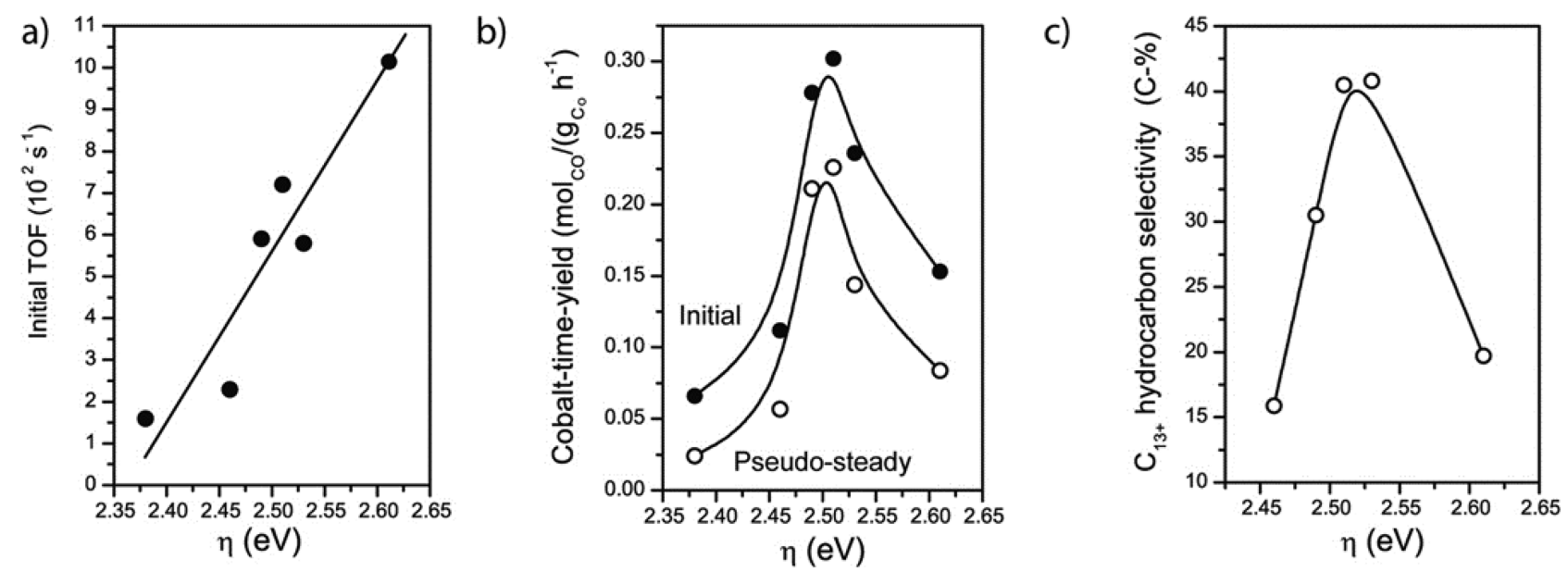

Figure 2. Evolution of (a) the initial turnover frequency (per surface metal atom), (b) the initial (solid symbols) and pseudosteady (open symbols) cobalt time yields, and (c) the $\mathrm{C}_{13+}$ hydrocarbon selectivity obtained with $\mathrm{CoRu} / \mathrm{MO}_{x} @ \mathrm{AO}$ catalysts as a function of the acid/base character of the support material, represented by the spectroscopic parameter $\eta$ (see the text). Reaction conditions: $20 \mathrm{wt} \% \mathrm{Co}, T=220{ }^{\circ} \mathrm{C}, 20 \mathrm{bar}, \mathrm{H}_{2} / \mathrm{Co}=2$, initial gas hourly space velocity (GHSV) $=6.9 \mathrm{~L}_{\text {syngas }} \mathrm{g}_{\text {cat }}{ }^{-1} \mathrm{~h}^{-1}$. Data included in (c) correspond to the steady state after adjustment of the GHSV to achieve a CO conversion level of $40 \pm 5 \%$ in all cases. Data for $\mathrm{CoRu} / \mathrm{SmO}_{x} @ \mathrm{AO}$ are not included in this panel, as the intrinsically lower activity of this catalyst prevented achieving the mentioned $\mathrm{CO}$ conversion level. Lines serve as guides to the eye.

AO) with similar textural properties and vastly different surface acid/base characters (Table 2). ${ }^{67}$ The energy of the lowest intramolecular charge transfer (IMCT)-band of adsorbed 1,2dihydroxy-9,10-anthracenedione (alizarin) as measured by diffuse-reflectance UV-vis spectroscopy gives the Lewis acid/base character of the material and is denoted as $\eta$, the spectroscopic parameter. ${ }^{68}$ Accordingly, $\mathrm{SmO}_{x} @ \mathrm{AO}$ possesses marked basic character whereas $\mathrm{WO}_{x} @ \mathrm{AO}$ exhibits strong
Lewis acid character, and the remaining support materials showed intermediate acid/base characters. Of all the supports, only the $\mathrm{WO}_{x} @ \mathrm{AO}$ support displayed partial reduction at temperatures beyond $830{ }^{\circ} \mathrm{C}$. From temperature-programmed reduction measurements it was concluded that all of the CoRu/MO $\mathrm{MO}_{x} @ \mathrm{AO}(20$ wt \% Co, 0.5 wt \% Ru) catalysts were quantitatively reduced to metallic $\mathrm{Co}$ and $\mathrm{Ru}$ after the reduction treatment preceding the catalytic test. Only in the 
case of the $\mathrm{CoRu} / \mathrm{WO}_{x} @ \mathrm{AO}$ catalyst was partial coverage of the metal surface by $\mathrm{WO}_{x}$ observed, as concluded from X-ray photoelectron spectroscopy analysis; such a phenomenon is usually termed strong metal-support interaction (SMSI) and is observed for cobalt catalysts supported on partially reducible oxides. ${ }^{69}$ For catalysts supported on relatively reducible oxides such as $\mathrm{TaO}_{x} @ \mathrm{AO}$ and $\mathrm{TiO}_{x} @ \mathrm{AO}$, such effects were minimal. Thus, they ensured that there was no or minimal influence of structural properties such as the support texture, extent of Co reduction, and particle size (in all cases the $\mathrm{Co}^{0}$ size was $>10$ $\mathrm{nm}$, for which no particle size effects on the catalytic activity are expected) (Table 3 ).

The catalytic test results showed that the initial TOF (per surface $\mathrm{Co}^{0}$ atom) increased linearly with increasing acidity of the oxide support $(\eta)$ (Figure $2 \mathrm{a}$ ). In contrast, the metalspecific catalytic activity (cobalt time yield) (Figure 2b) and selectivity for $\mathrm{C}_{13+}$ hydrocarbons (Figure 2c) showed a volcano-type dependence with $\eta$, where a maximum was reached for supports of intermediate acid/base character. Furthermore, supports with intermediate acid/base character $(\eta=2.49-2.53 \mathrm{eV})$ exhibited comparable $\mathrm{CH}_{4}$ selectivities of ca. $15 \%$. For a more basic oxide support ( $\left.\mathrm{YO}_{x} @ \mathrm{AO}\right)$, the $\mathrm{CH}_{4}$ selectivity decreased to ca. $10 \%$, while for a markedly acidic oxide support ( $\mathrm{WO}_{x} @ \mathrm{AO}$ ), the $\mathrm{CH}_{4}$ selectivity increased to ca. $20 \%$. The volcano-type dependence of the metal-specific activity with the nature of the support was attributed to the interplay between the number of surface-exposed cobalt sites and their intrinsic activity. Furthermore, it was inferred from in situ CO FTIR analysis that in the case of basic oxide supports (e.g., $\mathrm{SmO}_{x} @ \mathrm{AO}$ ), few atoms from the basic oxide caused selective blockage on the surface of the metallic Co nanoparticles after reduction, which strengthened $\mathrm{CO}$ adsorption and significantly decreased CO hydrogenation; the blocked sites were most likely step edges, which are essential for $\mathrm{CO}$ hydrogenation. On the other hand, for stronger Lewis acidic and more reducible oxide supports (e.g., $\left.\mathrm{WO}_{x} @ \mathrm{AO}\right)$, unselective site blockage via decoration of metallic Co nanoparticles with oxide patches (termed SMSI) effected a decrease in the number of Co sites available for catalysis. This model study that attempted to delineate structural effects from electronic effects should serve as a guide to develop next-generation catalysts in FT synthesis.

The alumina support is the most extensively studied support in FT synthesis, and the above-discussed surface modification techniques help to improve either the activity or selectivity or both in FT synthesis. For further improvements, studying surface modification with a combination of organic and inorganic species to tune the dispersion and electronic effects of the active phase and performing FT catalytic tests for long duration (time on stream) to establish the catalytic stability would enable their implementation in industry.

\section{SILICA-SUPPORTED CATALYSTS}

Next to alumina, silica is another widely used support in cobalt-based FT catalysts, as it possesses suitable chemical and physical properties to serve as a perfect support. The nature of hydroxyl groups (silanols) and their concentration and distribution on the silica surface play vital roles in the dispersion of cobalt particles. The high surface area of silica favors moderately high metal dispersion at reasonably high metal loadings. Furthermore, its surface chemistry enables high reducibility of cobalt precursors to the metallic state under favorable conditions. It was reported that the degree of cobalt reduction was higher on silica compared with other supports, i.e., $\mathrm{SiO}_{2}>\mathrm{TiO}_{2}>\alpha-\mathrm{Al}_{2} \mathrm{O}_{3}>\gamma-\mathrm{Al}_{2} \mathrm{O}_{3}{ }^{70}$ Though metalsupport interactions are weaker on silica compared with alumina, the preparation and pretreatment conditions must be carefully chosen to avoid the formation of cobalt silicate $\left(\mathrm{Co}_{2} \mathrm{SiO}_{4}\right)$, which is inactive in $\mathrm{FT}$ synthesis and can be reduced to metallic cobalt only at temperatures above 700$800{ }^{\circ} \mathrm{C} . .^{71-74}$ The interaction between cobalt and silica that yields cobalt silicate was stronger for the catalysts prepared in basic media than for those prepared in acidic media. ${ }^{74}$ The ease of reduction to metal species on silica supports was found to decrease with decreasing $\mathrm{Co}_{3} \mathrm{O}_{4}$ particle size. ${ }^{75}$ Noble metal promoters such as $\mathrm{Ru}, \mathrm{Pt}$, or $\mathrm{Pd}$ were added to cobalt catalysts supported on $\mathrm{SiO}_{2}$ to improve the reducibility and/or dispersion of cobalt. ${ }^{76}$ In the following sections, the effects of the textural properties, surface modification with different metal oxides or organic molecules, and acid/base properties of silica on the catalytic activity/selectivity in FT synthesis are discussed.

3.1. Effect of Textural Properties of the Silica Support. Cobalt catalysts supported on silica carriers with varying mean pore diameter $(4,6,10$, or $20 \mathrm{~nm})$ tested in the FT reaction $\left(10-12\right.$ wt $\% \mathrm{Co}, 202{ }^{\circ} \mathrm{C}, 20$ bar, $\mathrm{H}_{2} / \mathrm{CO}=2.5$ ) showed a decrease in $\mathrm{CH}_{4}$ selectivity with increasing pore diameter. ${ }^{77}$ This study revealed that the product distribution was affected by the porosity of the support, which was due to the variation in the ratio of chemisorbed $\mathrm{CO}$ and $\mathrm{H}_{2}$ on the catalyst surface, i.e., the $\mathrm{H}_{2}$ uptake decreased with decreasing pore diameter, but the $\mathrm{CO}$ uptake remained almost similar irrespective of the pore diameter. Another study found that the metal crystallite size and degree of cobalt reduction increased with increasing pore diameter of the silica support (mean pore diameter of $4,6,10$, or $15 \mathrm{~nm}) .{ }^{78}$ Furthermore, the $\mathrm{C}_{5+}$ and methane selectivities passed through a maximum and minimum, respectively, in FT synthesis (20 wt \% Co, 200$220{ }^{\circ} \mathrm{C}, 15$ bar, $\mathrm{H}_{2} / \mathrm{CO}=2$ ) for a cobalt catalyst supported on a silica support having a pore diameter of $10 \mathrm{~nm}$. Song and $\mathrm{Li}^{79}$ also reported that cobalt catalysts supported on silica with pore sizes of $6-10 \mathrm{~nm}$ exhibited higher activity and higher $\mathrm{C}_{5+}$ selectivity in FT synthesis, which were attributed to the moderate Co particle size (ca. $5 \mathrm{~nm}$ ) and moderate $\mathrm{CO}$ adsorption on the catalysts. These studies on silica clearly demonstrated the effect of pore size on controlling the particle size and avoiding diffusional limitations of long-chain hydrocarbons, consequently leading to variation in the uptake of $\mathrm{CO}$ and $\mathrm{H}_{2}$ molecules, which in turn affects the product distribution in FT synthesis.

3.2. Effect of Surface Modifications on the Silica Support. 3.2.1. Surface Modification with Inorganic Oxides. 3.2.1.1. Modification with Zirconia. Modification of the silica support with zirconia appeared to positively influence the performance of cobalt catalysts in FT synthesis, particularly when zirconia was added before the impregnation of cobalt. ${ }^{80}$ The addition of zirconia to the silica support during the preparation of the supported cobalt catalyst was found to weaken the $\mathrm{Co}-\mathrm{SiO}_{2}$ interaction by the formation of weaker $\mathrm{Co}-\mathrm{ZrO}_{2}$ interactions that favored the reduction of cobalt at lower temperatures. ${ }^{81,82}$ Consequently, it was found that $\mathrm{Zr}$ modified silica-supported cobalt catalysts exhibited increased steady-state conversion of $\mathrm{CO}$, increased $\mathrm{C}_{5+}$ hydrocarbon selectivity, and decreased $\mathrm{CH}_{4}$ selectivity compared with the unmodified catalysts in FT synthesis $\left(10\right.$ wt \% Co, $230{ }^{\circ} \mathrm{C}, 8$ bar, $\mathrm{H}_{2} / \mathrm{CO}=2$, tested for $\left.240 \mathrm{~h}\right) .{ }^{82}$ Before the steady-state 


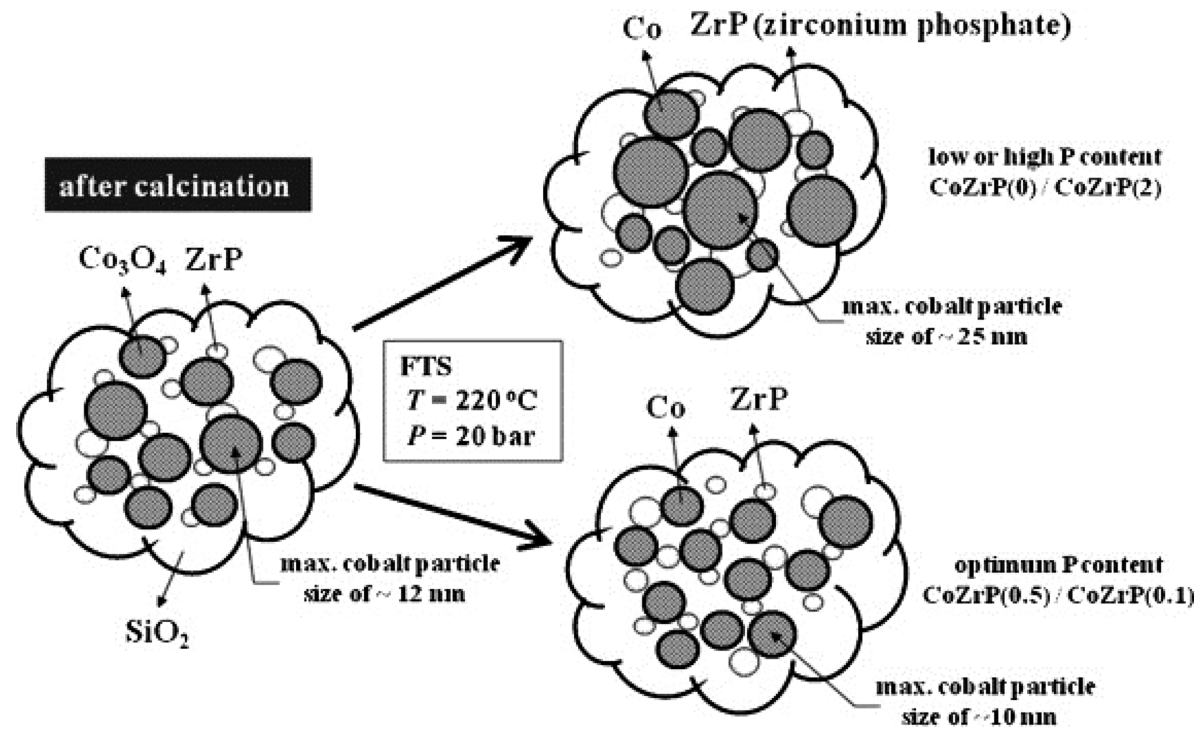

Figure 3. Proposed mechanism of cobalt aggregation in the presence of $\mathrm{ZrP}$ particles on the $\mathrm{SiO}_{2}$ surface. Reprinted with permission from ref 83 . Copyright 2011 John Wiley and Sons.

conversion on Zr-modified cobalt catalysts was reached, an initial drop in the activity was observed. Bae and co-workers improved the stability of $\mathrm{Zr} / \mathrm{SiO}_{2}$-based catalysts by adding appropriate amounts of a phosphorus component, yielding zirconium phosphate-modified $\mathrm{SiO}_{2}\left(\mathrm{ZrP} / \mathrm{SiO}_{2}\right){ }^{83,84}$ The cobalt catalysts supported on $\mathrm{ZrP} / \mathrm{SiO}_{2}$ showed a high activity and a low deactivation rate resulting from prevention of aggregation of cobalt particles in FT synthesis, specifically when the $\mathrm{P} /(\mathrm{Zr}+\mathrm{P})$ molar ratio was in the range of 0.134$0.290{ }^{83}$ The role of $\mathrm{ZrP}$ particles on the $\mathrm{SiO}_{2}$ surface for Co catalysts is schematically depicted in Figure 3. In fact, the enhanced catalytic stability attained using the $\mathrm{ZrP} / \mathrm{SiO}_{2}$ support was attributed to the homogeneous distribution of cobalt clusters, whose mobility was suppressed because the clusters were confined in thermally stable zirconium phosphate matrices on the $\mathrm{SiO}_{2}$ surface.

Jiang et al. $^{85}$ reported that cobalt catalysts supported on zirconium-modified silica treated using dielectric-barrier discharge (DBD) plasma instead of the conventional thermal calcination step exhibited significantly enhanced cobalt reducibility and increased cobalt dispersion compared with the catalysts on unmodified silica. As a result, plasma-treated cobalt catalysts supported on $\mathrm{Zr} / \mathrm{SiO}_{2}$ displayed higher $\mathrm{CO}$ conversions and hydrocarbon chain growth ability in FT synthesis $\left(20 \mathrm{wt} \% \mathrm{Co}, 230{ }^{\circ} \mathrm{C}, 20 \mathrm{bar}, \mathrm{H}_{2} / \mathrm{CO}=2\right)$.

3.2.1.2. Modification with Titania. Titania-modified silica showed decreased size of the supported cobalt particles due to the stronger interactions of cobalt oxide species with the titania than with the silica support, consequently increasing the cobalt dispersion without affecting the reducibility of cobalt too much. ${ }^{86}$ The cobalt catalysts supported on titania-modified silica displayed higher activity in FT synthesis (ca. $65 \%$ vs $50 \%$ CO conversion, $\left.10 \mathrm{wt} \% \mathrm{Co}, 240{ }^{\circ} \mathrm{C}, 10 \mathrm{bar}, \mathrm{H}_{2} / \mathrm{CO}=2\right)$ than its counterparts on pristine silica. The high activity of titaniamodified catalysts was attributed to the increased cobalt dispersion and increased bridge-type adsorbed $\mathrm{CO}$ that was more easily dissociated to carbon and oxygen. ${ }^{87}$
3.2.1.3. Modification with Niobia. In the direction of combining the selectivity-promoting properties of niobia with a highly porous support, den Otter et al. ${ }^{88}$ prepared niobiamodified silica $(\mathrm{Nb} / \mathrm{Si}$ atomic ratio $=0.02-0.12)$ by the incipient wetness impregnation method and applied it as a support for cobalt catalysts. They found that at low $\mathrm{Nb}$ loadings, $\mathrm{Nb}$ existed as small niobia particles or mixed $\mathrm{Nb}-\mathrm{Si}$ species. However, polymerization occurred at a higher $\mathrm{Nb}$ loading $(\mathrm{Nb} / \mathrm{Si}=0.12)$ and calcination temperature $\left(900{ }^{\circ} \mathrm{C}\right)$, forming a niobia layer on $\mathrm{SiO}_{2}$, and eventually 15-20 nm nanocrystals were observed that partially migrated to the exterior surface of the silica grains. Niobia modification of silica did not significantly influence the final cobalt particle size. The cobalt catalysts supported on niobia-modified silica and promoted with platinum yielded an increase in the cobaltmass-normalized activity in FT synthesis (9-21 wt \% Co, 220 ${ }^{\circ} \mathrm{C}, 1$ or 20 bar, $\mathrm{H}_{2} / \mathrm{CO}=2.0$ ) by a factor of $2-3$ in the case of amorphous niobia (obtained for a calcination temperature of $550{ }^{\circ} \mathrm{C}$ ) and by a factor of 3-4 with niobia nanocrystals (obtained for a calcination temperature of $900{ }^{\circ} \mathrm{C}$ ). The increase in catalytic activity was attributed to an increased number of active sites and an increased cobalt-surface-specific activity. At lower pressure ( 1 bar), the $C_{5+}$ selectivity in FT synthesis increased by about $50-65 \%$ upon niobia modification, but at high pressure $(20 \mathrm{bar})$ it was found to slightly decrease by about $1-4 \%$. The pressure-dependent $\mathrm{C}_{5+}$ selectivity of niobia promotion was presumed to be related to a higher intrinsic CO coverage at elevated pressures.

3.2.1.4. Modification with Phosphorus. Cobalt catalysts supported on phosphorus (1 wt \%)-modified silica displayed enhanced dispersion of cobalt oxide nanocrystallites and minimized cobalt silicate formation on silica compared with their counterparts on unmodified silica. ${ }^{89}$ Phosphorusmodified silica-supported cobalt catalysts showed higher $\mathrm{CO}$ conversions ( $>60 \%$ vs ca. $55 \%$ ), lower methane selectivity (ca. $7 \%$ vs $10 \%)$, improved olefin selectivity, and higher $\mathrm{C}_{5+}$ selectivity (ca. $87 \%$ vs ca. $84 \%$ ) in comparison with the catalysts supported on unmodified silica (20 wt \% Co, $220{ }^{\circ} \mathrm{C}$, 


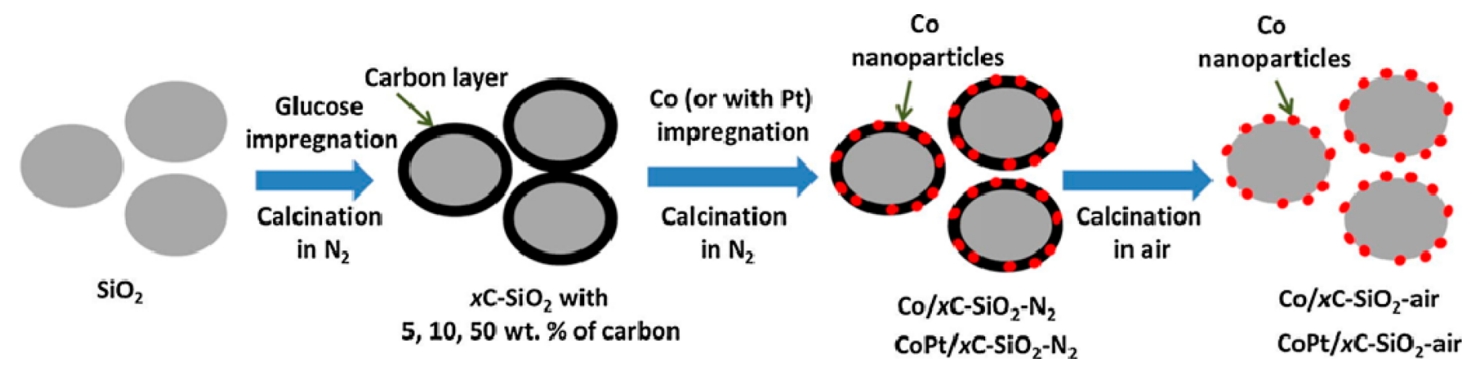

Figure 4. Scheme of the catalyst synthesis on carbon-coated silica. Reprinted with permission from ref 93. Copyright 2016 Elsevier.

20 bar, $\mathrm{H}_{2} / \mathrm{CO}=2$ ). The enhanced catalytic performance was attributed to the increased cobalt dispersion caused by the altered surface interactions of cobalt with the hydroxyl groups on silica. It was found that the cobalt particles interact with phosphate ions, thereby anchoring Co particles to the support and limiting the cobalt sintering rate. ${ }^{90}$

3.2.1.5. Surface Modification with Carbon/Organic Molecules. Pretreatment of the silica support with an organic solvent such as acetic acid, ethanol, 1-propanol, or 1-butanol before impregnation of cobalt modified the surface properties of silica without altering its textural properties. ${ }^{91}$ The pretreatment of silica with acetic acid or alcohols increased the number of isolated silanol $(\mathrm{SiOH})$ groups on the silica surface and hindered the reactivity of $\mathrm{H}$-bonded $\mathrm{SiOH}$ moieties with cobalt species, which led to the formation of smaller cobalt particles. Furthermore, pretreatment of silica with organic solvents changed the isoelectric point compared with pristine silica, which resulted in surplus negative charge on the pretreated silica surface that interacts with $\mathrm{Co}^{2+}$ ions, yielding improved cobalt dispersion. The cobalt catalysts supported on pretreated supports exhibited higher catalytic activity than their counterparts without pretreatment, which was attributed to the high dispersion and high degree of reduction of the supported cobalt. Among all of the catalysts, the cobalt catalyst supported on silica pretreated with acetic acid showed the highest $\mathrm{CO}$ conversion and the lowest $\mathrm{CH}_{4}$ selectivity. Chen et al. $^{92}$ demonstrated modification of the silica surface with ethylene glycol, which enhanced the cobalt dispersion. Cheng and co-workers showed that coating the silica support with carbon $(5,10$, or $50 \mathrm{wt} \%)$ by impregnation of silica with glucose and subsequent calcination $\left(450^{\circ} \mathrm{C}, 4 \mathrm{~h}\right)$ led to stabilization of highly dispersed cobalt oxide particles with partial cobalt reduction during the thermal treatment in an inert $\left(\mathrm{N}_{2}\right)$ atmosphere (Figure 4). ${ }^{93}$ The sizes of the cobalt oxide nanoparticles on the carbon (50 wt \%)-coated silicasupported catalysts $(5-8 \mathrm{~nm})$ were considerably smaller than those of the counterparts without carbon coating $(10-15 \mathrm{~nm})$. The FT activity of catalysts prepared with higher carbon content, calcined in nitrogen followed by air, and containing smaller cobalt particles was almost 2 times higher compared with the reference uncoated catalysts $\left(15 \mathrm{wt} \% \mathrm{Co}, 220^{\circ} \mathrm{C}, 20\right.$ bar, $\mathrm{H}_{2} / \mathrm{CO}=2$ ). Furthermore, higher selectivity for longchain hydrocarbons and low methane selectivity were also observed. It was speculated that the selectivity effects might arise from different factors such as the formation of cobalt nanoparticles with fewer defects in the presence of carbon, selective poisoning of methanation sites by residual carbon, higher cobalt reducibility, and lower content of cationic cobalt silicate species.

The effects of surface modifications of the silica support on the activity and selectivity of cobalt-based FT catalysts are summarized in Table 4. As observed in the case of alumina, silica surface modifiers exhibit a significant role in altering the

Table 4. Effects of Surface Modifiers on the Activity and Selectivity of Cobalt Catalysts Supported on Silica

\begin{tabular}{|c|c|c|c|}
\hline modifier & catalyst & effects & $\operatorname{ref}(s)$ \\
\hline $\mathrm{Zr}$ & $\mathrm{Co} / \mathrm{Zr} / \mathrm{SiO}_{2}$ & $\begin{array}{l}\text { - limits } \mathrm{Co}-\mathrm{SiO}_{2} \text { interactions } \\
\text { - favors weak } \mathrm{Co}-\mathrm{Zr} \\
\text { interactions } \\
\text { - increases Co reducibility } \\
\text { - enhances } \mathrm{CO} \text { conversion and } \\
\mathrm{C}_{5+} \text { selectivity }(2-10 \text { wt } \%)\end{array}$ & $80-82$ \\
\hline $\mathrm{ZrP}$ & $\mathrm{Co} / \mathrm{ZrP} / \mathrm{SiO}_{2}$ & $\begin{array}{l}\text { - prevents Co particle } \\
\text { aggregation } \\
\text { - increases steady-state CO } \\
\text { conversion and catalytic } \\
\text { stability (with } \mathrm{P} /(\mathrm{Zr}+\mathrm{P}) \\
\text { molar ratio of } 0.029-0.134)\end{array}$ & 83,84 \\
\hline $\mathrm{Ti}$ & $\mathrm{Co} / \mathrm{Ti} / \mathrm{SiO}_{2}$ & $\begin{array}{l}\text { - enhances Co dispersion } \\
\text { - modifies Co reducibility } \\
\text { - increases CO conversion (2- } \\
10 \text { wt \%) }\end{array}$ & 86 \\
\hline $\mathrm{Nb}$ & $\mathrm{Co} / \mathrm{Nb} / \mathrm{SiO}_{2}$ & $\begin{array}{l}\text { - increases the number of active } \\
\text { sites } \\
\text { - improves the cobalt-mass- } \\
\text { normalized activity }(\mathrm{Nb} / \mathrm{Si} \\
\text { atomic ratio }=0.02-0.12)\end{array}$ & 88 \\
\hline $\mathrm{P}$ & $\mathrm{Co} / \mathrm{P} / \mathrm{SiO}_{2}$ & $\begin{array}{l}\text { - limits Co sintering } \\
\text { - improves catalyst stability } \\
\text { - increases Co conversion ( } \leq 1 \\
\text { wt } \%)\end{array}$ & 89,90 \\
\hline $\begin{array}{l}\text { organic } \\
\text { molecules } \\
\text { (C) }\end{array}$ & $\mathrm{Co} / \mathrm{C} / \mathrm{SiO}_{2}$ & $\begin{array}{l}\text { - facilitates Co dispersion and } \\
\text { reducibility } \\
\text { - increases CO conversion and } \\
\mathrm{C}_{5+} \text { selectivity }(\leq 10 \mathrm{wt} \%)\end{array}$ & 91,93 \\
\hline
\end{tabular}

detrimental cobalt silicate formation as well as the Co reducibility and dispersion, consequently influencing the catalytic activity and selectivity.

\section{MESOPOROUS SILICA-SUPPORTED CATALYSTS}

Periodic mesoporous silicate materials prepared using surfactant-templated hydrothermal synthetic procedures are evolving as promising support materials for catalytic metal precursors because of their characteristics such as narrow pore size distributions, high surface areas and pore volumes, and controllable acid/base properties. ${ }^{94}$ These properties usually lead to higher metal dispersion in the supported metal catalysis, which eventually leads to an increase in the surface density of active metal sites. MCM-41 and SBA-15 are the two most common types of periodic silicas used as catalytic carriers. MCM-41 exhibits a unidimensional and hexagonal arrangement of mesopores with dimensions in the range of 20 


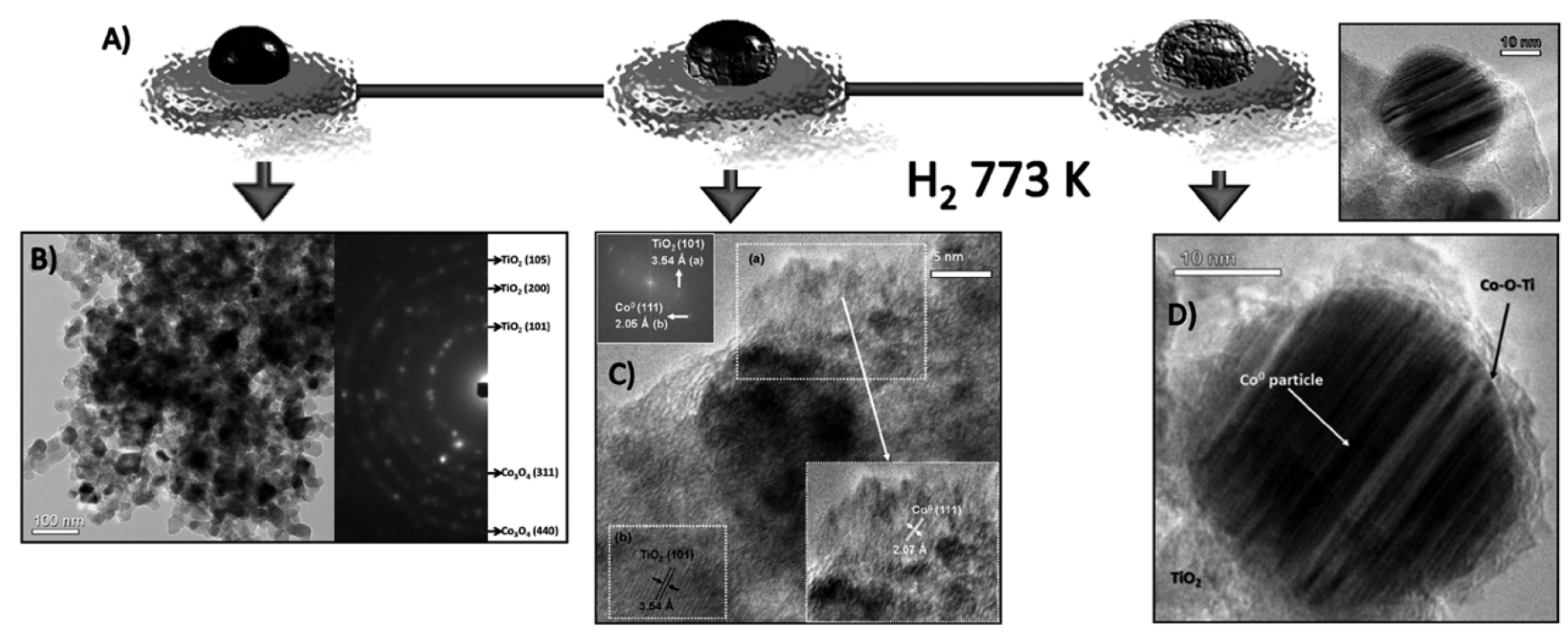

Figure 5. (A) Scheme of the SMSI encapsulation effect. (B) TEM image and electron diffraction pattern for a Co10-ct sample (calcined Co catalyst on $\mathrm{TiO}_{2}$ ). (C) HRTEM image and its Fourier transform for Co10-ctr (reduced Co catalyst on $\mathrm{TiO}_{2}$ ): (a) cobalt nanoparticles over TiO 2 (the reconstructed image corresponding to fcc- $\mathrm{Co}(111)$ is shown at the bottom right); (b) lattice fringes for $\mathrm{TiO}_{2}$. (D) HRTEM images of a Co10-ctr sample depicting the decoration of $\mathrm{Co}$ metal nanoparticles with an amorphous $\mathrm{TiO}_{2}$ layer. Republished with permission from ref 103 . Copyright 2011 Royal Society of Chemistry.

$\AA$ to greater than $100 \AA$ that are tuned by varying the alkyl chain length of the surfactant template and the synthesis conditions. ${ }^{95}$ SBA-15 contains two-dimensional hexagonally ordered mesopores with pore sizes of up to $300 \AA$ that are obtained using a variety of poly(alkylene oxide) triblock copolymers and by the addition of cosolvent organic molecules. ${ }^{96}$ SBA-15 mesoporous material also displays good thermal, mechanical, and chemical resistance properties, which are essential characteristics for a material to be used as a catalyst carrier. Conventional catalyst carriers usually exhibit broad pore size distributions, making it difficult to draw unambiguous conclusions about the influence of catalyst pore sizes on FT reaction rates and selectivities. The tailored pore size distributions in periodic mesoporous silicas such as MCM41 and SBA-15 make these materials suitable to be used as model catalytic supports in evaluating the effects of pore size in FT synthesis. ${ }^{97,98}$ The small, narrow pores present in MCM-41 materials lead to the formation of smaller cobalt oxide particles that are quite difficult to reduce. Consequently, smaller Co species located in the narrow-pore silicas displayed much lower activities in FT synthesis with higher methane selectivities than larger cobalt particles in the wide-pore supports. SBA-15-type periodic mesoporous silicas with a very narrow pore size distribution (ca. $9.1 \mathrm{~nm}$ ) exhibited higher cobalt dispersion over commercial silicas with a broad pore size distribution (ca. $33 \mathrm{~nm}$ ), even at higher cobalt surface densities (5-15 Co/ $\mathrm{nm}^{2}$ ) that resulted in higher cobalt time yields in FT synthesis. ${ }^{99}$ At high cobalt surface densities, commercial silicas exhibited sintering of $\mathrm{Co}_{3} \mathrm{O}_{4}$, but on SBA-15, high cobalt dispersion remained intact. Despite the advantages offered by these mesoporous materials, there are some limitations. For example, aqueous impregnation of MCM-41 with the cobalt precursor followed by drying leads to the loss of long-range ordering of the hexagonal mesoporous structure and to a significant decrease in the surface area and pore volume.' However, the SBA-15 mesoporous structure seemed to remain almost intact after introduction of significant amounts of cobalt (up to 20\%). The difference in structural stability of these two mesoporous silicas was attributed to the different pore wall thicknesses in MCM-41 and SBA-15. Further work is needed to establish its long-term stability in FT synthesis by its surface modification with inorganic and/or organic species.

\section{TITANIA-SUPPORTED CATALYSTS}

Titania usually exhibits relatively low specific surface areas (ca. 60 and ca. $10 \mathrm{~m}^{2} \mathrm{~g}^{1}$ for the anatase and rutile allotropes, respectively) compared with alumina and silica supports. This limits the cobalt loading in FT catalyst formulations to maintain high metal dispersion. Furthermore, $\mathrm{TiO}_{2}$ is known to exhibit the SMSI effect, as first reported by Touster et al. ${ }^{100}$ This type of SMSI is different from the other types of solidstate metal-support interactions, where the metal precursor chemically reacts with the support to form catalytically inactive (refractory) species. SMSIs altered the $\mathrm{H}_{2}$ and $\mathrm{CO}$ chemisorption properties of group VIII metals when these elements were supported on titania. The SMSI effect could be explained via electron transfer from the support to the metal (electronic factor) $)^{101}$ or by the formation of intermetallic phases. ${ }^{102}$ In the case of titania (anatase)-supported cobalt catalysts $\left(\mathrm{Co} / \mathrm{TiO}_{2}\right)$, during reduction of the cobalt oxide particles, partial reduction of the $\mathrm{TiO}_{2}$ support takes place, giving rise to $\mathrm{TiO}_{x}$ suboxide species $(x<2)$ that migrate onto the surface of cobalt particles and encapsulate or decorate the metallic cobalt particles. The evolution of the SMSI decoration effect, as illustrated by high-resolution transmission electron microscopy (HRTEM) images, is depicted in Figure 5. ${ }^{103,104}$ Under similar conditions, the catalytic performance of $\mathrm{Co} /$ $\mathrm{TiO}_{2}$ for $\mathrm{CO}$ hydrogenation was very low $(<5 \%)$ compared with $\mathrm{Co} / \mathrm{SiO}_{2}$ (ca. 30\%) (10 wt \% Co, $230{ }^{\circ} \mathrm{C}, 40$ bar, $\mathrm{H}_{2} / \mathrm{CO}$ $=2) \cdot{ }^{103}$ Its low activity in FT synthesis was attributed to blocking of the active $\mathrm{Co}^{0}$ phase caused by the migration of $\mathrm{Ti}$ species during the reduction step. Despite the active-phase blocking effect, $\mathrm{TiO}_{2}$-supported cobalt catalysts were reported to display high selectivity for long-chain hydrocarbons $\left(\mathrm{C}_{5+}\right)$ compared with their counterparts on alumina. ${ }^{105-107}$ 
Carbon coverage and crystallization

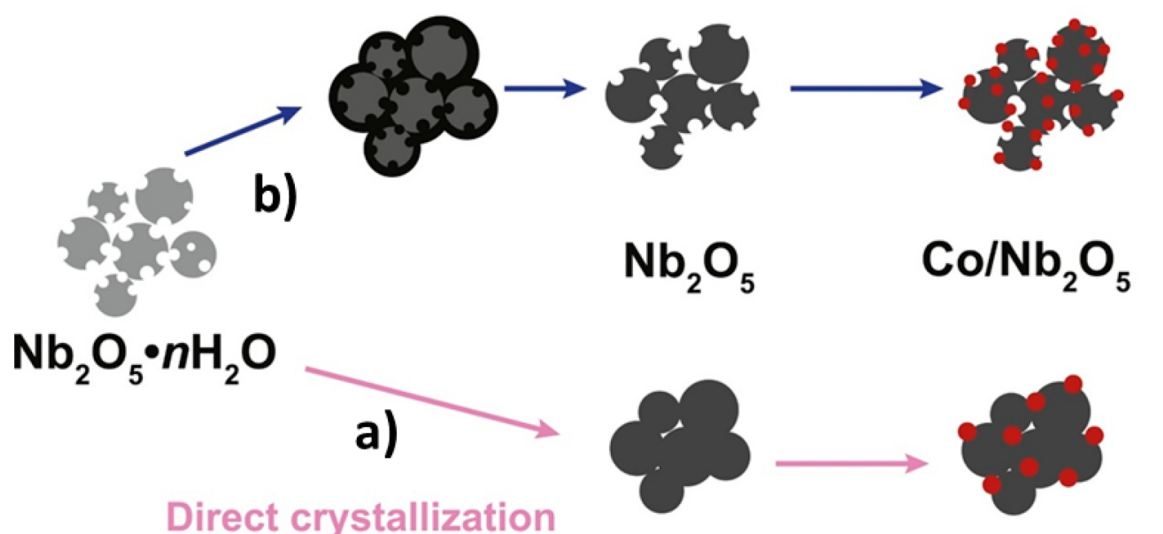

Highly active Fischer-Tropsch

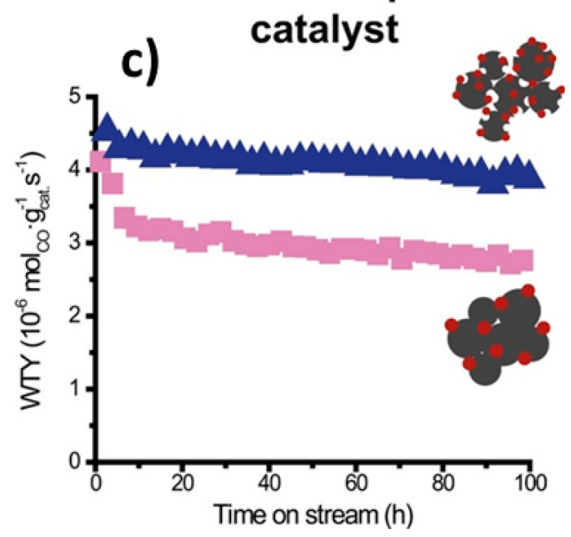

Figure 6. (a) Dense $\mathrm{Nb}_{2} \mathrm{O}_{5}$ obtained by calcination at $600{ }^{\circ} \mathrm{C}$. (b) Porous $\mathrm{Nb}_{2} \mathrm{O}_{5}$-MC obtained by sucrose impregnation, pyrolysis, and calcination. (c) Activity of $\mathrm{Nb}_{2} \mathrm{O}_{5}$-supported cobalt catalysts (blue triangles, $10 \mathrm{wt} \% \mathrm{Co} / \mathrm{Nb}_{2} \mathrm{O}_{5}$ - $\mathrm{MC}$ catalyst; pink squares, $6 \mathrm{wt} \% \mathrm{Co} / \mathrm{Nb}_{2} \mathrm{O}_{5}$ ) normalized by catalyst mass (weight time yield, WTY). Reproduced from ref 116, published by Elsevier.

Iglesia et al. ${ }^{87}$ demonstrated that the addition of $\mathrm{Ru}$ to $\mathrm{Co} /$ $\mathrm{TiO}_{2}(\mathrm{Ru} / \mathrm{Co}$ atomic ratio $<0.008)$ increased both the turnover rate and $\mathrm{C}_{5+}$ selectivity in $\mathrm{FT}$ synthesis. The improved activity was attributed to the higher cobalt site density, enhanced reduction of cobalt oxide species, and inhibition of carbon deposition reactions resulting from the intimate mixing between $\mathrm{Co}$ and $\mathrm{Ru}$. Moreover, Eschemann and co-workers demonstrated that the addition of noble metals such as $\mathrm{Pt}, \mathrm{Ru}, \mathrm{Re}$, and $\mathrm{Ag}$ resulted in decreased reduction temperatures of cobalt oxide supported on $\mathrm{TiO}_{2}$, eventually leading to increases in the $\mathrm{CO}$ hydrogenation activity in FT synthesis. ${ }^{108}$ Cobalt catalysts supported on $\mathrm{TiO}_{2}$ whose surface was modified with boron (0.05 wt \%) showed slightly increased syngas conversion only at higher space times $\left(>0.33 \mathrm{~h} \mathrm{~g}_{\text {cat }} / \mathrm{NL}\right)$, but the product selectivity in FT synthesis remained the same. ${ }^{109}$ Conventionally, FT catalysts are reduced under a hydrogen atmosphere before testing in FT synthesis, but Jalama and co-workers demonstrated that the activation of a titania-supported cobalt catalyst with syngas yielded a catalyst that showed higher stability, higher activity, and better product selectivity $\left(\mathrm{C}_{5+}\right.$ and $\mathrm{C}_{3}-\mathrm{C}_{5}$ olefin to paraffin ratio) in FT synthesis than its counterpart activated with hydrogen gas $\left(20\right.$ wt $\% \mathrm{Co}, 220{ }^{\circ} \mathrm{C}, 20$ bar, $\left.\mathrm{H}_{2} / \mathrm{CO}=2\right)$ .$^{110}$ The enhanced performance of the catalyst activated with syngas was attributed to increased active-site density resulting from improved catalyst reduction and dispersion. Furthermore, it was proposed that $\mathrm{CO}$ prevented the formation of inactive Co species that interact strongly with the support. ${ }^{111}$

\section{NIOBIA-SUPPORTED CATALYSTS}

Niobium oxide $\left(\mathrm{Nb}_{2} \mathrm{O}_{5}\right)$ is known to be a water-tolerant solid acid catalyst, and furthermore, its calcination or pretreatment temperature plays a key role in determining its acidic and catalytic properties. ${ }^{112}$ As observed in the case of titania, $\mathrm{Nb}_{2} \mathrm{O}_{5}$ as a reducible catalytic carrier also exhibits SMSI that is more efficient than that of titania. ${ }^{113}$ Furthermore, $\mathrm{Nb}_{2} \mathrm{O}_{5}$ supported cobalt catalysts were reported to display high selectivity for heavy hydrocarbons $\left(\mathrm{C}_{5+}\right.$ selectivity ca. $\left.49 \%\right)$ in FT synthesis at atmospheric pressure ( 5 wt $\% \mathrm{Co}, 260{ }^{\circ} \mathrm{C}, 1$ bar, $\left.\mathrm{H}_{2} / \mathrm{Co}=2\right)$ compared with its counterparts supported on alumina $\left(\mathrm{C}_{5+}\right.$ selectivity ca. $\left.11 \%\right) .{ }^{113}$ The chain-growthpromoting effect of $\mathrm{Nb}_{2} \mathrm{O}_{5}$ as a support material was attributed to partial reduction of the support and SMSI. ${ }^{114}$ The $\mathrm{C}_{5+}$ selectivity of $\mathrm{Nb}_{2} \mathrm{O}_{5}$-supported cobalt catalysts was also reported to be very high, i.e., up to $90 \mathrm{wt} \% \mathrm{C}_{5+}$ under industrial working conditions $\left(5-20 \mathrm{wt} \% \mathrm{Co}, 220{ }^{\circ} \mathrm{C}, 20 \mathrm{bar}\right.$, $\left.\mathrm{H}_{2} / \mathrm{Co}=2\right) .{ }^{11}$ It was found that $5 \mathrm{wt} \% \mathrm{Co} / \mathrm{Nb}_{2} \mathrm{O}_{5}$ (operated at ca. $250{ }^{\circ} \mathrm{C}$ ) and 25 wt $\% \mathrm{Co} / \gamma-\mathrm{Al}_{2} \mathrm{O}_{3}$ (operated at ca. 210 ${ }^{\circ} \mathrm{C}$ ) have identical activities per unit mass of catalyst at similar $\mathrm{C}_{5+}$ selectivities (ca. $80 \mathrm{wt} \%$ ), and consequently, the activity per unit mass of cobalt was 4 times higher for the $\mathrm{Nb}_{2} \mathrm{O}_{5^{-}}$ supported catalyst. However, it should be noted that the catalysts supported on $\mathrm{Nb}_{2} \mathrm{O}_{5}$ required a higher operating reaction temperature, i.e., $40{ }^{\circ} \mathrm{C}$ higher than their $\mathrm{Al}_{2} \mathrm{O}_{3}$ counterparts. Furthermore, when 6 wt $\% \mathrm{Co} / \mathrm{Nb}_{2} \mathrm{O}_{5}$ catalysts were promoted with platinum ( $\mathrm{Co} / \mathrm{Pt}$ atomic ratio ca. 140), the cobalt-mass-normalized activity in FT synthesis (6 wt \% Co, $220{ }^{\circ} \mathrm{C}, 20$ bar, $\mathrm{H}_{2} / \mathrm{Co}=2$ ) increased by a factor of 2.4 , while the high $\mathrm{C}_{5+}$ selectivity ( $85 \mathrm{wt} \%$ ) was maintained. ${ }^{115}$ The increase in the activity of Pt-promoted $\mathrm{Co} / \mathrm{Nb}_{2} \mathrm{O}_{5}$ catalysts was tentatively credited to the more efficient promotion of Co by $\mathrm{NbO}_{x}(x<2.5)$ species resulting from the reduction of $\mathrm{Nb}_{2} \mathrm{O}_{5}$ and to an increase in the number of catalytically active sites by a factor of 1.7 as evidenced from $\mathrm{CO}$ chemisorption experiments. ${ }^{115}$

Multiple impregnations on crystalline $\mathrm{Nb}_{2} \mathrm{O}_{5}$ to achieve cobalt loadings higher than 6 wt \% usually led to larger cobalt particles, reduced interaction of cobalt with $\mathrm{Nb}_{2} \mathrm{O}_{5}$, and subsequently decreased activity per unit mass of cobalt and $\mathrm{C}_{5+}$ selectivity. ${ }^{116}$ Preparation of $\mathrm{Nb}_{2} \mathrm{O}_{5}$-supported catalysts with higher cobalt loadings and dispersion is very challenging because of the very low specific pore structure of crystalline $\mathrm{Nb}_{2} \mathrm{O}_{5}$ compared with commercial FT supports such as silica and alumina. In the direction of circumventing this challenge, Hernández Mejia and co-workers reported the preparation of mesoporous crystalline $\mathrm{Nb}_{2} \mathrm{O}_{5}\left(\mathrm{Nb}_{2} \mathrm{O}_{5}-\mathrm{MC}\right)$ with tailored porosity by carbon deposition via sucrose pyrolysis (Figure $6 a, b) .{ }^{116}$ Deposition of carbon derived from sucrose during the crystallization step restricted the collapse of the $\mathrm{Nb}_{2} \mathrm{O}_{5} \cdot n \mathrm{H}_{2} \mathrm{O}$ porous structure. The larger specific pore volume of $\mathrm{Nb}_{2} \mathrm{O}_{5^{-}}$ $\mathrm{MC}$ enabled those authors to achieve higher cobalt loading (10 wt \%) in a single impregnation step. The higher cobalt loadings in $\mathrm{Co} / \mathrm{Nb}_{2} \mathrm{O}_{5}$-MC led to an increased catalyst-massnormalized activity in FT synthesis (Figure 6c). The porosity 

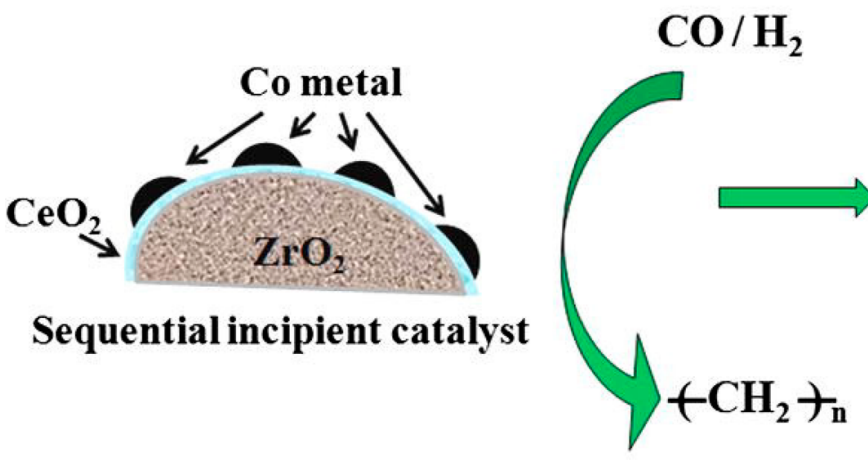
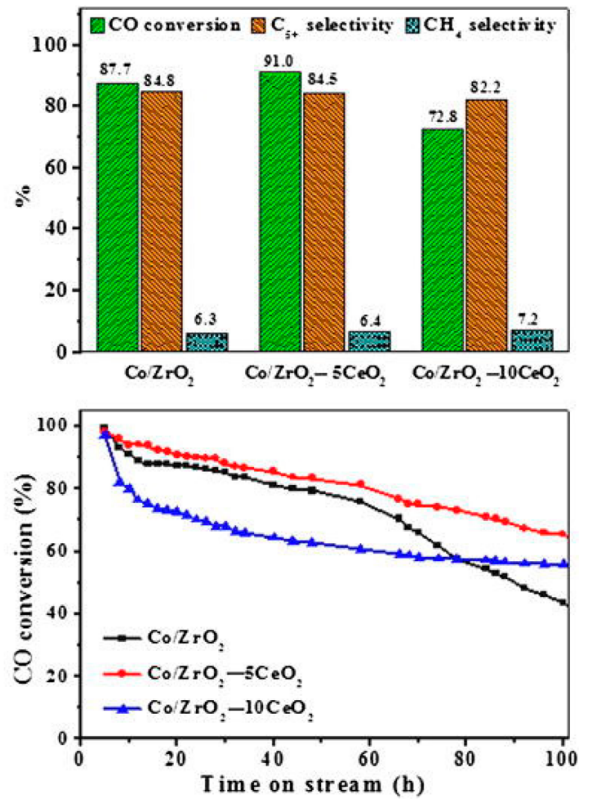

Figure 7. Cobalt catalysts supported on $\mathrm{ZrO}_{2}$ and $\mathrm{CeO}_{2}$-modified $\mathrm{ZrO}_{2}$ prepared by the sequential incipient impregnation method and their activity and hydrocarbon selectivity results in FT synthesis. Reprinted with permission from ref 122. Copyright 2016 Elsevier.

of $\mathrm{Nb}_{2} \mathrm{O}_{5}$-MC prevented sintering of the cobalt particles, resulting in relatively stable catalysts.

\section{ZIRCONIA-SUPPORTED CATALYSTS}

Zirconia is drawing considerable interest on account of its potential use as a catalyst support due to its chemical inertness, redox properties, and acid/base characteristics. ${ }^{117}$ A $\mathrm{ZrO}_{2}$ support was found to promote the formation of amorphous hexagonal metallic cobalt during the reduction step in the catalyst preparation. Furthermore, the direct reduction of cobalt nitrate leads to weaker metal-support interactions than observed in the case of calcined catalysts, consequently increasing the quantity of amorphous or poorly crystalline hexagonal metallic cobalt, which has been proved to be more active than cubic cobalt in FT synthesis. ${ }^{118} \mathrm{ZrO}_{2}$-supported cobalt catalysts exhibited better Co reducibility and capability of hydrogen adsorption via a spillover mechanism compared with conventional alumina-supported Co catalysts. ${ }^{10}$ These properties resulted in a higher catalytic activity ( $\mathrm{CO}$ conversion, $45 \%$ vs $36 \%$ ) and an increase in the chain growth probability $\left(\mathrm{C}_{5+}, 57 \%\right.$ vs $\left.48 \%\right)$ in the $\mathrm{FT}$ synthesis (10.5 wt \% Co, $230{ }^{\circ} \mathrm{C}, 5$ bar, $\left.\mathrm{H}_{2} / \mathrm{CO}=9\right)$. Commercially available micrometer-sized $\left(50 \mathrm{~m}^{2} / \mathrm{g}\right)$ - and nanosized $\left(78 \mathrm{~m}^{2} / \mathrm{g}\right) \mathrm{ZrO}_{2}$ usually possess medium specific surface areas. Panpranot et al. demonstrated the preparation of nanocrystalline $\mathrm{ZrO}_{2}$ by decomposition of zirconium tetra $n$-propoxide in 1,4 butanediol that exhibited a high specific surface area (170 $\left.\mathrm{m}^{2} / \mathrm{g}\right) .{ }^{119}$ Glycothermal-derived nanocrystalline $\mathrm{ZrO}_{2}$-supported cobalt catalysts displayed higher activity, higher selectivity for $\mathrm{C}_{4}-\mathrm{C}_{6}$ hydrocarbons, and lower selectivity for methane compared with the commercial micrometer-sized and nanosized $\mathrm{ZrO}_{2}$ in FT synthesis ( 8 wt \% Co, $220{ }^{\circ} \mathrm{C}, 1 \mathrm{bar}$, $\mathrm{H}_{2} / \mathrm{CO}=10$ ). The better catalytic performance was attributed to higher cobalt dispersion and the presence of highly stable and pure tetragonal-phase zirconia. Liu and co-workers reported the preparation of mesoporous zirconia with different pore sizes possessing the characteristics of both zirconia and mesoporous material. ${ }^{120}$ The cobalt catalysts supported on mesoporous zirconia exhibited enhanced average crystalline sizes and degrees of reduction of $\mathrm{Co}_{3} \mathrm{O}_{4}$, and in addition, the strength of the $\mathrm{Co}-\mathrm{ZrO}_{2}$ interaction decreased with increasing pore diameter ( 5.3 to 6.1 to $8.9 \mathrm{~nm}$ ). The catalytic test results displayed enhanced activity, higher $\mathrm{C}_{5+}$ selectivity, and decreased methane selectivity in FT synthesis with increasing pore size. The enhanced catalytic activity was attributed to the improved mass transfer derived from the large pore size and narrow pore size distribution of the mesoporous zirconia, and the improved $\mathrm{C}_{5+}$ selectivity was derived from the use of zirconia as the catalytic support.

7.1. Effect of Surface Modifications on the Zirconia Support. Cobalt catalysts supported on lanthanum (10 mol \%)-modified $\mathrm{ZrO}_{2}\left(\mathrm{La}-\mathrm{ZrO}_{2}\right)$ were prepared by mechanical mixing and exhibited higher cobalt dispersion and enhanced cobalt reducibility, consequently yielding higher catalytic activity in FT synthesis than those supported on the pure oxides $\left(\mathrm{La}_{2} \mathrm{O}_{3}\right.$ and $\left.\mathrm{ZrO}_{2}\right)$ and other La-modified $\mathrm{ZrO}_{2}$. ${ }^{121}$ The other $\mathrm{La}-\mathrm{ZrO}_{2}$ was prepared by coprecipitation and impregnation, causing intimate contact between $\mathrm{La}_{2} \mathrm{O}_{3}$ and $\mathrm{ZrO}_{2}$ and incorporated $\mathrm{La}$ atoms in $\mathrm{ZrO}_{2}$, which in turn induced stronger interactions between cobalt and the support and lowered the catalytic activity in FT synthesis. Another study showed that cobalt catalysts supported on ceria (5 wt \%)-modified $\mathrm{ZrO}_{2}$ $\left(5 \mathrm{CeO}_{2}-\mathrm{ZrO}_{2}\right)$ prepared by the sequential incipient impregnation method (Figure 7) also had enhanced cobalt oxide dispersion, cobalt reducibility, and number of cobalt active sites compared with those supported on unmodified $\mathrm{ZrO}_{2}{ }^{122}$ Subsequently, the $\mathrm{Co} / 5 \mathrm{CeO}_{2}-\mathrm{ZrO}_{2}$ catalysts displayed higher activity in FT synthesis ( 15 wt \% Co, $220{ }^{\circ} \mathrm{C}, 20$ bar, $\mathrm{H}_{2} / \mathrm{CO}$ $=2$ ). The better catalytic performance was attributed to the cyclic redox process of $\mathrm{CeO}_{2}$, which can effectively inhibit the oxidation of $\mathrm{Co}^{0}$ to $\mathrm{Co}^{2+}$. However, the $\mathrm{C}_{5+}$ selectivities on the $\mathrm{CeO}_{2}$-modified and unmodified catalysts were the same (ca. $85 \%)$. Addition of an excessive amount of $\mathrm{CeO}_{2}$ (10 wt \%) resulted in decreased activity in FT synthesis, which was ascribed to rapid catalyst deactivation in the initial stages of the 
reaction caused by diffusional limitations of the reactants/ products (liquid waxes) in the smaller pores.

\section{ZEOLITE-SUPPORTED CATALYSTS}

Zeolites are crystalline microporous aluminosilicates with frameworks assembled from tetrahedral units having a cation such as $\mathrm{Si}$ or $\mathrm{Al}$ at the center and oxygen atoms at the corners. The utility of zeolites as catalytic supports is generating considerable interest in heterogeneous catalysis because of their shape-selective characteristics, well-defined pore structure, high porosity, and acidic nature. ${ }^{123}$ Zeolites can be synthesized with various structures and pore dimensions. To simplify the notation of diverse zeolite structures, a structuretype code was introduced by IUPAC (e.g., a zeolite containing 10 -membered-ring pore systems that form a three-dimensional network is named ZSM-5). The acidic nature of the zeolites can be tuned by varying the silica-to-alumina ratio. The surface acidic nature of zeolites tends to display FT product selectivity for lighter and branched hydrocarbons and even aromatics, thus deviating with respect to Anderson-Schulz-Flory (ASF) distributions for cobalt catalysts in FT synthesis. ${ }^{124-126}$ Furthermore, zeolite-supported cobalt catalysts serve as a bifunctional catalyst composition in which metallic cobalt drives the growth of long-chain hydrocarbons, which undergo further reaction at the zeolite acid sites to yield more-branched hydrocarbons with limited chain length and aromatics. ${ }^{127}$ ZSM-5-supported cobalt catalysts showed good selectivity for gasoline-type products in FT synthesis due to the characteristic properties of ZSM-5 such as surface acidity (which promotes secondary reactions like oligomerization, isomerization, cracking, and aromatization), pore structure (which provides selectivity for limiting the hydrocarbon chain growth length), resistance to coke formation, and stability under FT reaction conditions. ${ }^{13,128-130}$ It was found that the presence of secondary porosity, cages, and three-dimensional channel systems with large micropores in zeolites (e.g., USY) mediates higher accessibility of reactants/products to the catalytic sites, thereby favoring the formation of long hydrocarbons. ${ }^{131}$

$\beta$-Zeolite is classified as a large-pore zeolite that possesses two types of 12 -membered pores and a three-dimensional structure with both micro- and mesopores. ${ }^{132}$ The cobalt catalysts supported on mesostructured $\beta$-zeolite showed higher activity and lower methane selectivity in FT synthesis than those supported on $\beta$-zeolite, which was ascribed to the better reducibility of larger cobalt particles that exhibit weaker interactions with the support. ${ }^{133}$ In another study, cobalt catalysts $(7.5,10,15$, or $20 \mathrm{wt} \%)$ supported on nanometric $\beta$ zeolite composed of $\beta$-zeolite crystallites of nanometric dimensions and a $\mathrm{SiO}_{2} / \mathrm{Al}_{2} \mathrm{O}_{3}$ molar ratio of about 50 were reported. ${ }^{134}$ These catalysts exhibited bifunctional character with a maximum activity at a specific concentration of cobalt (15 wt \%) and $\mathrm{Co}_{3} \mathrm{O}_{4}$ particle size (ca. 9). However, the selectivity for isoparaffins from isomerization reactions was strongly influenced by the support's acid functionality. A recent study found that the catalytic activity and product selectivity of cobalt supported on $\beta$-zeolite in FT synthesis strongly depends on the catalyst preparation method, i.e., impregnation (IM), incipient wetness (IW), physical mixing (PM), or precipitation (PT). ${ }^{135}$ The activities of the catalysts were ranked in the following order: IW > IM > PT > PM. The selectivities for isoparaffins were placed in the following order: $\mathrm{PT}>\mathrm{PM}>\mathrm{IM}$ $>$ IW.
Generally, most types of zeolite material consist of pore sizes and cavities in the microporous regime, which hampers the transport of reactants and products during FT synthesis. In the direction of overcoming this limitation, hierarchical zeolites were developed that combine the advantages of mesoporous materials and zeolite crystals. ${ }^{136}$ The cobalt catalysts supported on hierarchical zeolite $\mathrm{Y}$ displayed increased activity and $\mathrm{C}_{5-11}$ selectivity in FT synthesis ( 10 wt $\% \mathrm{Co}, 260{ }^{\circ} \mathrm{C}, 10 \mathrm{bar}, \mathrm{H}_{2} /$ $\mathrm{CO}=2$ ) compared with their counterparts supported on pristine zeolite Y (Figure 8). ${ }^{137}$ The better catalytic perform-

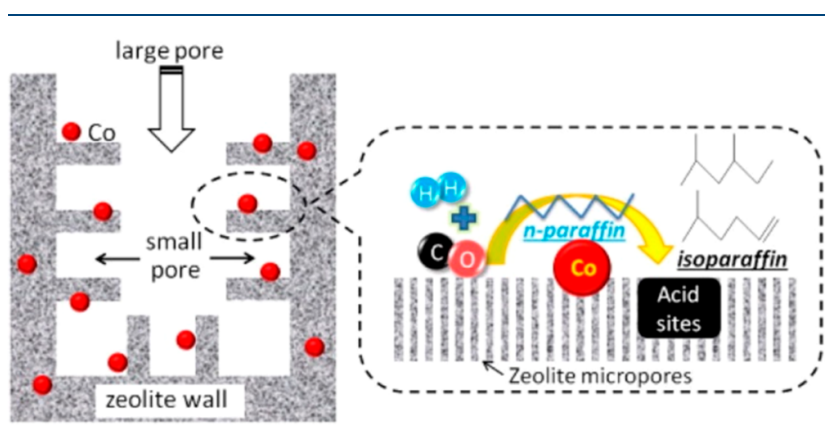

Figure 8. Schematic depiction of the hierarchical zeolite and its use as a catalytic support in FT synthesis. Republished with permission from ref 137. Copyright 2015 Elsevier.

ance was attributed to the optimized hydrocracking and isomerization function derived from the hierarchical zeolite $\mathrm{Y}$ with the strong Brønsted acid/Lewis acid (B/L) ratio and effective textural properties. In a different study, a hierarchically spherical Co-based zeolite catalyst with an aggregated nanorod structure prepared by in situ self-assembly crystallization of Co/SBA-15 also exhibited improved activity and enhanced the isoparaffin selectivity in FT synthesis. ${ }^{138}$

$\mathrm{Lu}$ et al. ${ }^{139}$ demonstrated a new method of preparing $\mathrm{H}$ USY-zeolite-supported nanocobalt bifunctional catalysts by a physical sputtering process (Figure 9). In this process, the

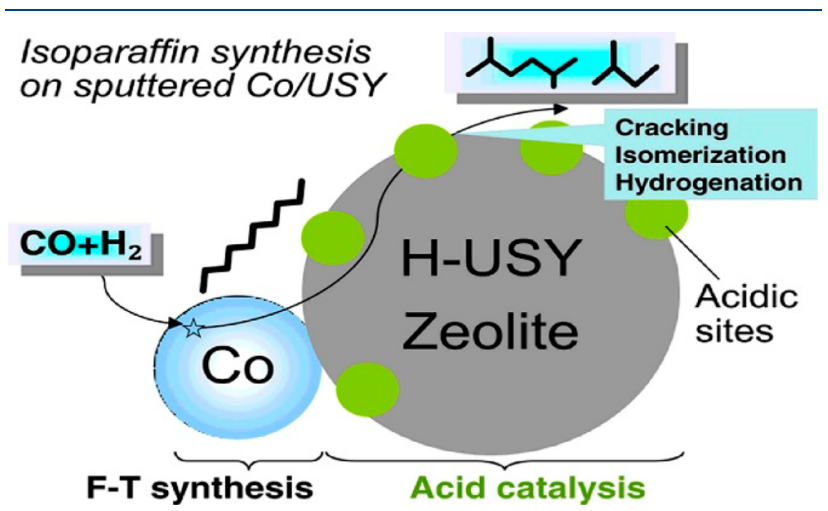

Figure 9. Schematic of the tandem reaction including FT synthesis and acid catalysis achieved on the sputtered Co/USY bifunctional catalyst. Republished with permission from ref 139. Copyright 2015 Elsevier.

particles of sputtered cobalt exist at the nanolevel and were well-dispersed on the acidic USY zeolite. The nanocobalt loaded on the support was easily activated in a lowtemperature $\left(260{ }^{\circ} \mathrm{C}\right)$ hydrogen reduction atmosphere. The sputtered Co metallic nanoparticles wedged on zeolite form only weak physical interactions between the metal and the support, thus leading to a facile metal reduction process in this 
case, in contrast to the strong interaction between the impregnated metal and the support. Consequently, the sputtered bifunctional Co/USY catalyst exhibited much higher $\mathrm{CO}$ conversion and higher isoparaffin selectivity than the conventional impregnated catalyst $\left(7 \mathrm{wt} \% \mathrm{Co}, 260{ }^{\circ} \mathrm{C}, 10 \mathrm{bar}\right.$, $\mathrm{H}_{2} / \mathrm{CO} \approx 2$ ). This method might be useful in heterogeneous catalysis where detrimental SMSI effects are observed.

\section{CERIA-SUPPORTED CATALYSTS}

$\mathrm{CeO}_{2}$ is an interesting choice for use as a catalyst support, considering its redox properties, reducible nature, and surface affinity for both $\mathrm{CO}$ and $\mathrm{H}_{2}$ molecules. Furthermore, it can also function as a structural and electronic promoter in heterogeneous catalysis. ${ }^{140}$ Usually, under typical FT synthesis conditions using cobalt catalysts supported on conventional supports ( 5 wt $\% \mathrm{Co}, 220{ }^{\circ} \mathrm{C}, 20 \mathrm{bar}, \mathrm{H}_{2} / \mathrm{CO}=2$ ), the formation of oxygenates is often neglected. However, it was observed that $\mathrm{CeO}_{2}$-supported cobalt (ca. 5 wt \%) catalysts prepared by the incipient wetness impregnation method exhibited high selectivities for oxygenates (ca. 7\%) and $\mathrm{C}_{2}-$ $\mathrm{C}_{4}$ hydrocarbons (ca. 38\%) and low selectivity for $\mathrm{C}_{5+}$ hydrocarbons $(44 \%)$ in the FT synthesis process (5 wt \% $\left.\mathrm{Co}, 250{ }^{\circ} \mathrm{C}, 20 \mathrm{bar}, \mathrm{H}_{2} / \mathrm{CO}=2\right) .{ }^{12}$ Though it might be argued that the temperature was slightly higher $\left(250 \mathrm{vs} \mathrm{ca} .220^{\circ} \mathrm{C}\right)$ in the above study, the selectivity for oxygenates was still remarkable. Gnanamani et al. ${ }^{141}$ proposed a likely pathway for alcohol formation based on $\mathrm{Co}-\mathrm{CeO}_{2}$ interfacial catalysis, in which $\mathrm{FT}$ reaction intermediates at the cobalt metal sites diffuse from the cobalt metal particles across the $\mathrm{Co}-\mathrm{CeO}_{2}$ junction to react with active bridging $\mathrm{OH}$ groups on partially reduced ceria $\left(\mathrm{Ce}^{3+}\right)$ groups to form oxygenates. Furthermore, it was found that $\mathrm{CeO}_{2}$-supported $\mathrm{Co}(5,15$, or $25 \mathrm{wt} \%)$ catalysts promoted with $\mathrm{Pt}$ exhibit higher selectivities for linear alcohols (14.8\%) at lower cobalt loadings ( $5 \mathrm{wt} \% \mathrm{Co}, 220^{\circ} \mathrm{C}$, $\left.20 \mathrm{bar}, \mathrm{H}_{2} / \mathrm{CO}=2\right)$. Increasing the cobalt content led to a decrease in the selectivity for oxygenates $(8.9 \%$ and $4.5 \%$ for 15 and 25 wt \% Co loading, respectively) because the on-top surface area of cobalt increased at the expense of the interfacial area at the $\mathrm{Co}-\mathrm{CeO}_{2}$ junction.

\section{CARBON-SUPPORTED CATALYSTS}

Carbon-based materials such as carbon nanofibers (CNFs), carbon nanotubes (CNTs), carbon spheres (CSs), and mesoporous carbons have drawn interest as catalyst supports in FT synthesis because of their diverse merits such as high surface areas with diverse pore structures, high purity, high mechanical strength and thermal stability, good electrical conductivity, resistance to acidic and basic conditions, low cost, good recycling characteristics, low density, and superior chemical inertness under FT reaction conditions. ${ }^{142,143}$ In general, carbon is classified into two types: amorphous carbon, which comprises activated and templated carbon, and crystalline carbon, which comprises graphite, fullerenes, CNTs, carbine, and diamond. The chemical inertness of pristine carbon materials helps in circumventing the strong detrimental interactions between the active metal and the support, thereby enabling studies of the catalytic behavior of the metal with respect to its structure, size, and shape in the absence of support effects. The articles reporting on cobaltbased carbon catalysts prior to the year 2015 were summarized in two reviews. In the first one, progress on carbon support structure effects, the influence of surface modification of the carbon pore structure by $\mathrm{O}$ and $\mathrm{N}$ doping, and the effects of cobalt intrinsic properties and promoters on carbon-supported cobalt catalysts for FT synthesis were presented. ${ }^{143}$ In the second one, the features and surface properties of several shaped carbon materials, including carbon black, activated carbon, CNTs, CNFs, CSs, ordered mesoporous carbon, graphene, and diamond and their utility as catalytic supports in FT synthesis and higher alcohol synthesis were discussed and summarized. ${ }^{144}$ In the following paragraphs, only the important findings and the articles from 2015 to the present are discussed.

The effect of Co particle size on traditional oxides in FT synthesis is still not very well established because of the varying degrees of interaction between the support and the metal. In the absence of strong interactions between Co and CNFs, it was found that cobalt particle sizes of $6-8 \mathrm{~nm}$ are preferred for obtaining both higher TOF and $\mathrm{C}_{5+}$ selectivity. ${ }^{145,146}$ The lower TOF of $<6 \mathrm{~nm}$ Co particles was attributed to blocking of edge/corner sites and lower intrinsic activity at the small terraces. ${ }^{147}$ Though the reducibility of cobalt oxide species is improved on carbon material supports, the preparation of highly dispersed and stable cobalt catalysts still requires at least intermediate interactions between the support and the Co precursor. Modification of surface chemical properties of carbon materials by $\mathrm{O}$ or $\mathrm{N}$ doping was found to be essential to increase their ability to anchor cobalt species. Oxygencontaining groups (e.g., carboxylic acid/anhydride, lactone, and phenolic hydroxyl) were introduced on the surface of carbon by treatment with nitric acid, thus increasing the surface acidity and adsorption ability to anchor Co particles. ${ }^{148}$ The acid-treated CNTs yielded a decrease in cobalt particle size and an increase in cobalt dispersion, consequently positively affecting the activity in FT synthesis. ${ }^{149,150}$ Nitrogen functional groups were introduced on the surface of carbon by treatment with ammonia or aniline, thereby altering the defect and electronic structure of the support. ${ }^{142}$ The N-functionalized CNTs as a cobalt catalyst support exhibited increased metal-support interactions, Co dispersion, and reducibility of cobalt oxides, and these observed properties led to a distinct shift to lower-molecular-weight hydrocarbons and provided excellent stability to the $\mathrm{N}$-functionalized CNT-supported cobalt catalyst. ${ }^{151}$ It was also found that $\mathrm{N}$ doping of CSs not only improved the cobalt particle distribution but also influenced the reduction ability of carbon. Thus, N-doped CS-supported Co catalysts autoreduced by the carbon support showed higher $\mathrm{CO}$ conversion than that obtained by $\mathrm{H}_{2}$ reduction. ${ }^{132}$ CNTs are distinguished from other carbon materials by their graphite layers and tubular morphology, which impart remarkable electronic and mechanical properties. ${ }^{153}$ The channels in CNTs restricted cobalt particle growth inside the tubes (confinement effect), and as a result, particles inside the tubes were smaller than the particles attached to the outer surfaces. ${ }^{154}$ Furthermore, it was found that the sintering rate of the particles located on the outer surface of the CNTs was significantly higher than that of particles on the inner surface because of the electron deficiency of the inner walls of the CNTs and the stronger interaction between the cobalt oxides and the support. The confinement of the reactant and reaction intermediates inside the channels increases the contact time of these reaction species with the active phase, leading to increased production of heavier hydrocarbons (higher $\mathrm{C}_{5+}$ selectivity). ${ }^{155}$ On the contrary, the cobalt particles located outside the CNT channels exhibited lower activity and 
$\mathrm{C}_{5+}$ selectivity in the FT reaction. ${ }^{150}$ Comparison of the FT synthesis rates using graphene- and CNT-supported cobalt catalysts showed that the former increased the rate by $22 \%$, shifted the product distribution to the long-chain hydrocarbons, and exhibited higher stability compared with the latter. ${ }^{156}$ These properties were attributed to the better dispersion of cobalt clusters and an increase in the degree of reduction of $\mathrm{Co}$ at relatively lower temperatures in the graphene-supported catalyst.

Eschemann and co-workers demonstrated that by the choice of an appropriate solvent (alcohol) and drying procedure (under nitrogen flow) during the catalyst preparation step, clustering of supported nanoparticles could be avoided, yielding well-dispersed supported cobalt oxide nanoparticles. ${ }^{157}$ It was found that the CNT-supported cobalt catalysts prepared by this method showed a superior cobalt-mass-based activity in FT synthesis compared with those prepared from an aqueous solution, as the cobalt particles had grown less during reduction and the catalytic test, leading to higher specific active metal surface area. CNT-supported cobalt catalysts exhibit superior activity and $\mathrm{C}_{5+}$ selectivity compared with their counterparts supported on $\gamma-\mathrm{Al}_{2} \mathrm{O}_{3}$ due to decreased Co particle size and increased cobalt reducibility, dispersion, and active metal surface area on CNTs. ${ }^{158}$ Phaahlamohlaka et al. ${ }^{159}$ utilized mesoporous hollow carbon spheres (MHCSs) as a model support to study the influence of $\mathrm{Ru}$ nanoparticle location relative to $\mathrm{Co}_{3} \mathrm{O}_{4}$ nanoparticles on the reduction behavior and activity of Co catalysts in FT synthesis. In this study, $\mathrm{Ru}$ nanoparticles were loaded both inside and outside the MHCSs, while $\mathrm{Co}_{3} \mathrm{O}_{4}$ particles were loaded on the outside of the MHCSs (Figure 10). Greater reducibility at low

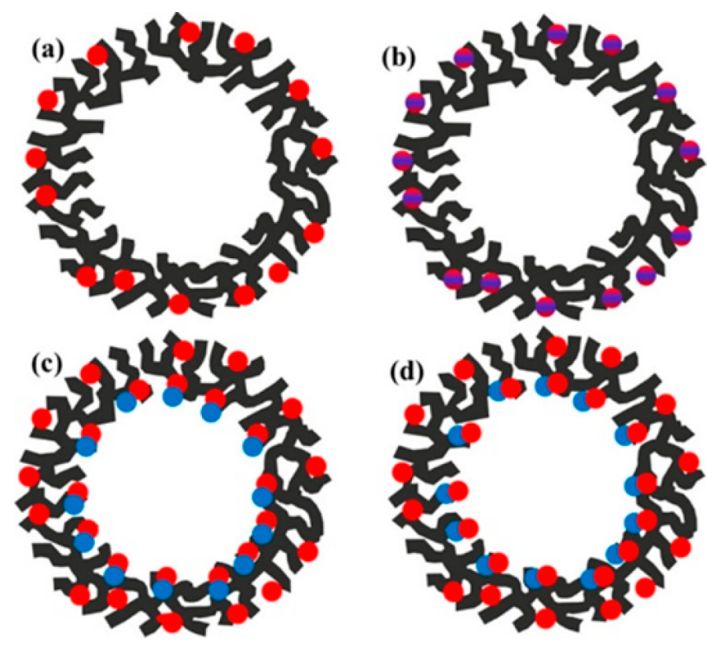

Figure 10. Schematic showing likely Co (red) and Ru (blue) particle distributions on the MHCS support: (a) Co/MHCS; (b) CoRu/ MHCS; (c) 0.2\% Ru@MHCS@Co; (d) 0.5\% Ru@MHCS@Co. ${ }^{159}$

temperatures and higher activity were observed for catalysts where the $\mathrm{Co}$ and $\mathrm{Ru}$ metals were in close proximity to each other (CoRu/MHCS, Figure $10 \mathrm{~b}$ ) as a result of a primary hydrogen spillover effect that enhanced the cobalt oxide reduction, leading to a highly active Co catalyst. In case of $\mathrm{Ru} @$ MHCS@Co, where the Co and Ru were separated by a carbon shell (Figure 10c,d), secondary hydrogen spillover induced complete reduction of cobalt oxide to metallic Co at a lower temperature compared with unpromoted catalyst.
In the direction of decreasing the multitude of parameters in the multistep FT catalytic preparation technique, plasma technology was implemented by Aluha and co-workers, enabling them to prepare C-supported nanometric Co catalysts in a single step. ${ }^{160-166}$ It was shown that C-supported nanometric Co catalysts synthesized by plasma spraying in a single step displayed superior catalytic activity ( $\mathrm{CO}$ conversion: $20 \%$ vs $7 \%$; process conditions: $40 \mathrm{wt} \% \mathrm{Co}, 230{ }^{\circ} \mathrm{C}$, 30 bar, $\mathrm{H}_{2} / \mathrm{CO}=1.88$ ) over the conventional multistep catalyst production by precipitation or impregnation. ${ }^{160}$ This approach to catalyst preparation resulted in nonporous catalysts and aided in improving the dispersion of cobalt compared with the impregnation or precipitation technique: the average Co cluster size in plasma-synthesized $\mathrm{Co} / \mathrm{C}$ was ca. $12 \mathrm{~nm}$, compared with 37 and $22 \mathrm{~nm}$ using the impregnation and precipitation techniques, respectively. The lower process temperature $\left(220^{\circ} \mathrm{C}\right)$ was more beneficial for the selectivity of the $\mathrm{Co} / \mathrm{C}$ catalyst toward the gasoline $\left(\mathrm{C}_{4}-\mathrm{C}_{12}\right)$ and diesel $\left(C_{13}-C_{20}\right)$ range fractions, with $C O$ conversion of about $42 \%$. Increasing the process temperature to $260{ }^{\circ} \mathrm{C}$ resulted in complete $\mathrm{CO}$ conversion at the cost of producing highly prevalent undesired products such as $\mathrm{CO}_{2}$ and $\mathrm{CH}_{4}{ }^{161-163}$

Extensive studies using carbon support materials derived directly from lignocellulosic biomass in FT synthesis are still missing. Such studies would help to identify suitable biomass resources from its diverse and heterogeneous pool of raw material. Furthermore, the presence of inorganic species in biomass-derived carbon supports might play a role in enhancing the activity in FT synthesis.

\section{SILICON CARBIDE-SUPPORTED CATALYSTS}

The reactions involved in the FT synthesis are highly exothermic and cause adiabatic temperature rises of up to $1477{ }^{\circ} \mathrm{C}$ (simply estimated as $\Delta H_{\mathrm{r}} / C_{p}$,reactants $) .{ }^{167}$ Therefore, heat transfer and recovery is very important, especially when using a fixed-bed reactor. A local temperature rise in the reactor can form a hot spot in the catalytic bed that might lead to losses of activity and selectivity, sintering, and deactivation of the catalyst. For this reason, the Sasol I plant in South Africa used a small reactor tube with an internal diameter of $5 \mathrm{~cm}$. The traditional FT catalytic supports such as alumina, silica, and titania have mediocre thermal conductivity and thus might not prevent the formation of hot spots within the catalyst bed. ${ }^{33,168} \beta$-SiC $(\mathrm{SiC})$ is a covalent material made up of tetrahedral structural units. It is a newly emerging catalytic support material with very interesting properties such as chemical inertness, high thermal conductivity, and high mechanical strength along with surface area and surface nature that can be tuned by doping and open porosity consisting mostly of meso- and macropores. ${ }^{169}$ Furthermore, it combines the best properties of both oxide- and carbon-based supports and circumvents many of their disadvantages. ${ }^{170}$ The thermal conductivity of $\mathrm{SiC}$ gives rise to improved heat transfer in catalytic processes by reducing the formation of local hotspots as well as temperature gradients across the catalyst bed, making it a promising support material for FT catalysts. Furthermore, the chemical inertness of $\mathrm{SiC}$ leads to easy recovery of both the active phase and the support. ${ }^{171}$

Lacroix and co-workers evaluated the cobalt-based catalyst supported on a medium-surface-area $\mathrm{SiC}$ foam ceramic in $\mathrm{FT}$ synthesis $\left(30 \mathrm{wt} \% \mathrm{Co}, 220^{\circ} \mathrm{C}, 40 \mathrm{bar}, \mathrm{H}_{2} / \mathrm{CO}=2\right)$ in a fixedbed reactor with no catalyst diluent. ${ }^{14}$ The catalytic test results for these catalysts were compared with those obtained on a 
reference $\mathrm{Co} / \mathrm{Al}_{2} \mathrm{O}_{3}$ foam catalyst. It was found that at medium isoconversion $(<50 \%)$ the two catalysts displayed similar $\mathrm{C}_{5+}$ selectivities. However, when the $\mathrm{CO}$ conversion was increased to $70 \%$, a significant difference between the two catalysts in terms of the $\mathrm{C}_{5+}$ selectivity was observed ( $80 \%$ with $\mathrm{Co} / \mathrm{SiC}$ vs $54 \%$ with $\mathrm{Co} / \mathrm{Al}_{2} \mathrm{O}_{3}$ ). The selectivity difference was ascribed to the high efficiency of the thermally conductive $\mathrm{SiC}$ to evacuate heat generated during the course of the reaction and also to the presence of meso- and macroporosity in the $\mathrm{SiC}$ support. Furthermore, the hydrocarbon chain growth probability $(\alpha)$ obtained on the SiC-based catalyst (0.91) was higher than that of the counterpart on alumina (0.88) with preference to wax formation (Figure 11). Furthermore, the high chemical

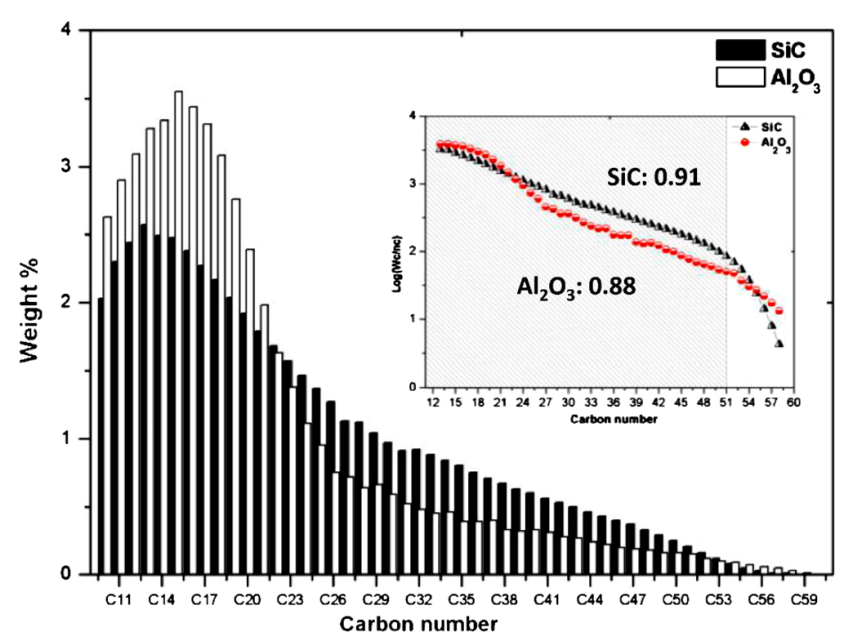

Figure 11. Distributions of liquid hydrocarbons obtained on the $\mathrm{Co} /$ $\mathrm{SiC}$ and $\mathrm{Co} / \mathrm{Al}_{2} \mathrm{O}_{3}$ catalysts. The results were obtained from the liquid hydrocarbons trapped at high pressure in the hot trap $\left(85^{\circ} \mathrm{C}\right)$. Republished with permission from ref 14. Copyright 2011 Elsevier.

inertness of the $\mathrm{SiC}$ material allowed the recovery of both the active phase and the support by a simple acid washing. The recovered $\mathrm{SiC}$ impregnated with fresh Co catalyst displayed similar catalytic performance compared to the fresh catalyst. The catalytic activity of $\mathrm{Co} / \mathrm{SiC}$ was further improved by supporting the cobalt phase on $\mathrm{Al}_{2} \mathrm{O}_{3}$-coated $\mathrm{SiC}\left(\mathrm{Co} / \mathrm{Al}_{2} \mathrm{O}_{3}-\right.$ $\mathrm{SiC})$ without compromising its selectivity for $\mathrm{C}_{5+}$ hydrocarbons $(80 \%)$. The improved activity was attributed to the higher cobalt dispersion on the $\mathrm{Al}_{2} \mathrm{O}_{3}-\mathrm{SiC}$ support compared with unmodified $\mathrm{SiC}$.

In another study, $\mathrm{Co} / \mathrm{SiC}$ catalysts promoted with $\mathrm{Ru}$ (to enhance Co reducibility) were evaluated in FT synthesis in a platelet-structured millireactor (PSR) at different gas hourly space velocities (GHSVs), and the catalytic results were compared with those obtained in the "conventional" microtubular fixed-bed reactor (TR). ${ }^{172}$ The PSR containing an open $\mathrm{SiC}$ cell foam morphology allowed easier operation under different GHSVs without problems of pressure drop or reactor plugging. The PSR displayed a better activity in FT synthesis ( 30 wt $\% \mathrm{Co}, 220^{\circ} \mathrm{C}, 10$ bar, $\mathrm{H}_{2} / \mathrm{CO}=2$ ) compared with that obtained in the TR, and the activity steadily increased with increasing GHSV. The improved catalytic activity with increasing GHSV in the PSR was ascribed to the efficient removal of the liquid hydrocarbon formed on the catalytic surface, ensuring better accessibility of the reactant to the active phase. Furthermore, the PSR yielded a narrower hydrocarbon distribution profile (between $\mathrm{C}_{7}$ and $\mathrm{C}_{17}$ ) compared with the TR, which generated longer-chain hydrocarbons under similar reaction conditions. Of the cobalt precursors supported on $\mathrm{SiC}$, namely, cobalt nitrate $(\mathrm{CoN})$, cobalt acetate (CoA), cobalt chloride $(\mathrm{CoCl})$, and Co citrate (CoCit), it was found that $\mathrm{CoN} / \mathrm{SiC}$ showed the best activity in FT synthesis. ${ }^{173}$ This was attributed to the larger Co particle size, the ease of Co reduction, and the basicity of $\mathrm{CoN} / \mathrm{SiC}$.

Diaz et al. ${ }^{174}$ demonstrated that pretreatment of $\beta$-SiC with the pore agent and acidic treatment improved the catalytic activity of the resulting cobalt catalysts in the FT synthesis $\left(13-15\right.$ wt $\% \mathrm{Co}, 220{ }^{\circ} \mathrm{C}, 20$ bar, $\left.\mathrm{H}_{2} / \mathrm{CO}=2\right)$. The acid treatment resulted in $\mathrm{SiC}$ with lower metal impurities that were left behind during its preparation and also increased the number of acid sites. The pore agent treatment led to changes in the pore size distribution of $\mathrm{SiC}$ by increasing the macropore volume, which favored evacuation of the FT products, keeping the active sites available for reactants. Both these pretreatments enhanced the reducibility of cobalt particles with increased numbers of active sites, resulting in an improvement in the catalytic activity. Alternatively, Liu and co-workers evaluated cobalt catalysts supported on titaniadecorated silicon carbide $(\beta-\mathrm{SiC})$ in FT synthesis $(10 \mathrm{wt} \% \mathrm{Co}$, $230{ }^{\circ} \mathrm{C}, 40$ bar; $\left.\mathrm{H}_{2} / \mathrm{CO}=2\right) .{ }^{175}$ The catalytic test results showed that the cobalt time yield of the catalyst after $\mathrm{TiO}_{2}$ modification $\left(7.5 \times 10^{-5} \mathrm{~mol}_{\mathrm{CO}} \mathrm{g}_{\mathrm{Co}}^{-1} \mathrm{~s}^{-1}\right)$ was about $42 \%$ higher than that of the counterpart on the bare support $(5.3 \times$ $\left.10^{-5} \mathrm{~mol}_{\mathrm{CO}} \mathrm{g}_{\mathrm{Co}}^{-1} \mathrm{~s}^{-1}\right)$. However, the $\mathrm{C}_{5+}$ selectivities of the two catalysts were the same (ca. 91\%). Two-dimensional (2D) elemental maps deduced by $2 \mathrm{D}$ energy-filtered TEM and ${ }^{59} \mathrm{Co}$ NMR analysis revealed that the nanoscale introduction of $\mathrm{TiO}_{2}$ into the $\beta$-SiC matrix significantly enhanced the formation of small and medium-sized cobalt particles. Furthermore, the proper metal-support interaction between cobalt nanoparticles and $\mathrm{TiO}_{2}$ led to the formation of smaller cobalt particles $(<15 \mathrm{~nm})$, resulting in a large fraction of surface atoms and, consequently, a great enhancement of the catalytic activity.

\section{MISCELLANEOUS SUPPORTS}

In addition to the supports discussed above, ceria, aluminum phosphate, hydrotalcites, and metal-organic frameworks (MOFs) as potential supports for cobalt-based catalysts have also been reported. In the following sections, the activities and selectivities of these catalysts in the FT reaction are discussed.

12.1. Aluminum Phosphate-Supported Catalysts. The surface of aluminum phosphate possesses acidic sites that are capable of participating in the catalytic process, and it could also be used as a catalytic carrier. ${ }^{176}$ Amorphous $\mathrm{AlPO}_{4}$ is built of tetrahedral $\mathrm{AlO}_{4}$ and $\mathrm{PO}_{4}$ units and is structurally similar to silica. ${ }^{177}$ Furthermore, it exhibits a high surface area and large average pore size, which are beneficial characteristics of a support. Cobalt catalysts supported on $\mathrm{AlPO}_{4}$ prepared from cobalt nitrate as the precursor displayed better catalytic performance but a slightly lower $\mathrm{C}_{5+}$ selectivity in $\mathrm{FT}$ synthesis compared with the corresponding $\mathrm{Co} / \mathrm{Al}_{2} \mathrm{O}_{3}$ catalyst. ${ }^{178}$ The enhanced activity was attributed to the improvement in the degree of Co reduction (at low temperature), with a high surface area of metallic cobalt containing proper electronic states that aid in the dissociative adsorption of $\mathrm{CO}$, homogeneous dispersion of cobalt on $\mathrm{AlPO}_{4}$, and decreased cobalt aluminate formation compared with the pristine $\mathrm{Al}_{2} \mathrm{O}_{3}$ support. The $\mathrm{Co} / \mathrm{AlPO}_{4}$ catalysts showed a rapid decrease in activity in the initial period, which was attributed to carbon 
deposition, including filamentous carbons; however, the catalytic activity was still higher than that of $\mathrm{Co} / \mathrm{Al}_{2} \mathrm{O}_{3}$.

12.2. Hydrotalcite-Supported Catalysts. Hydrotalcitelike compounds (HTls), denoted by the empirical formula $\left[\mathrm{M}^{2+}{ }_{1-x} \mathrm{M}^{3+}{ }_{x}(\mathrm{OH})_{2}\right]^{x+}\left[\mathrm{A}^{n-}{ }_{x / n}\right]^{x-} \cdot m \mathrm{H}_{2} \mathrm{O}$, where $\mathrm{M}^{2+}$ is a divalent cation such as $\mathrm{Co}^{2+}, \mathrm{Mg}^{2+}, \mathrm{Zn}^{2+}, \mathrm{Ni}^{2+}$, or $\mathrm{Cu}^{2+} ; \mathrm{M}^{3+}$ is a trivalent cation such as $\mathrm{Al}^{3+}, \mathrm{Cr}^{3+}, \mathrm{Fe}^{3+}$, or $\mathrm{Ga}^{3+} ; \mathrm{A}^{n-}$ is an anion of charge $n-$; and $m$ is the molar content of cointercalated water, belong to the large class of anionic clays. In most cases, $\mathrm{M}^{2+}$ and $\mathrm{M}^{3+}$ are $\mathrm{Mg}^{2+}$ and $\mathrm{Al}^{3+}$, respectively. HTls exhibit interesting properties for support materials such as high surface area, basic properties, and stability during thermal treatments. ${ }^{179}$ Krylova et al. ${ }^{180}$ demonstrated the use of synthetic MgAl-HTls $\left(\mathrm{Mg}_{6} \mathrm{Al}_{2}\left(\mathrm{CO}_{3}\right)\right.$ $\left.(\mathrm{OH})_{16} \cdot 4 \mathrm{H}_{2} \mathrm{O}\right)$ as supports for Co $(30 \mathrm{wt} \%)$ catalysts $(\mathrm{Co} /$ MgAl-HTls) that are highly selective with respect to the formation of paraffins $(\alpha=0.9-0.94)$ in FT synthesis (30 wt \% $\left.\mathrm{Co}, 170-230{ }^{\circ} \mathrm{C}, 10 \mathrm{bar}, \mathrm{H}_{2} / \mathrm{CO}=2\right)$. Another study found that Co (10 wt \%) catalysts supported on commercial MgAlHTls displayed the highest catalytic activity and better $\mathrm{C}_{5+}$ selectivity than those supported on $\mathrm{Al}_{2} \mathrm{O}_{3}$ or $\mathrm{MgO}$ in FT synthesis $\left(10\right.$ wt $\% \mathrm{Co}, 230{ }^{\circ} \mathrm{C}, 2$ bar, $\left.\mathrm{H}_{2} / \mathrm{CO}=2\right) .{ }^{181}$ The better catalytic performance of $\mathrm{Co} / \mathrm{MgAl}-\mathrm{HTl}$ s was ascribed to the effects of the relatively higher total surface area, high reducibility, and smaller cobalt particle size. However, Co catalysts supported on calcined $\left(500{ }^{\circ} \mathrm{C}\right) \mathrm{MgAl}-\mathrm{HTls}$ displayed very poor activity, which was attributed to possible changes in the layered structure of HTls, with the formation of $\mathrm{Mg}(\mathrm{Al})$ mixed oxide modifying the surface basicity and a much stronger interaction of $\mathrm{Mg}(\mathrm{Al})$ oxide with cobalt particles. Di Fronzo et al. ${ }^{182}$ introduced ternary $\mathrm{HTlc}$, with the general formula $\left[\mathrm{Co}_{x} \mathrm{Zn}_{(1-x-y)} \mathrm{Al}_{y}(\mathrm{OH})_{2}\right]\left(\mathrm{NO}_{3}\right)_{y} \cdot 0.5 \mathrm{H}_{2} \mathrm{O}$, synthesized by a modified urea method (Co-Zn-Al-HTls with $5-35$ wt \% Co loading), as catalysts in FT synthesis. These are a new kind of catalyst, as the active metal is part of the structural core of the HTlc, as opposed to the conventional supported-cobalt catalysts. Cobalt was found to be uniformly dispersed in Co$\mathrm{Zn}-\mathrm{Al}-\mathrm{HTl}$, and the reduction of cobalt was achieved at temperatures lower than $350{ }^{\circ} \mathrm{C}$. These catalysts were tested for about $24 \mathrm{~h}$ and found to be active in FT synthesis ( $5 \mathrm{wt} \%$ Co, $220-240{ }^{\circ} \mathrm{C}, 20$ bar, $\mathrm{H}_{2} / \mathrm{CO}=2$ ), with $\mathrm{CO}$ conversions of about $80 \%$ and $\mathrm{C}_{7+}$ selectivities of up to ca. $93 \%$. Although this is a new method of preparing Co-based FT catalysts, their long-term stability and the effect of cobalt loading in terms of morphology/size of Co crystallites must be established.

12.3. MOF-Supported Catalysts. MOFs are new class of porous organic-inorganic hybrid materials constructed by linking of metal ions or clusters with multidentate organic linkers. The tunable structure, topology, surface area, pore size, pore volume, and functionality of MOFs make them an interesting material for applications in the field of heterogeneous catalysis. ${ }^{183,184}$ Isaeva et al. ${ }^{185}$ reported a cobalt $(5-15$ wt \%)-containing $\mathrm{Al}^{3+}$-derived microporous MOF (Co-MIL$53(\mathrm{Al})$ ) catalyst prepared by the incipient wetness impregnation method. Although MOFs are known for poor thermal stability (even $<350{ }^{\circ} \mathrm{C}$ ), these catalysts were found to retain their crystallinity even after the catalytic test $(20 \mathrm{~h})$. The CoMIL-53(Al) catalysts exhibited similar activity and slightly higher $\mathrm{C}_{5+}$ selectivity ( $73 \%$ vs $69 \%$ at 15 wt \% Co loading) than those supported on alumina in FT synthesis (5-15 wt \% $\mathrm{Co}, 240{ }^{\circ} \mathrm{C}, 20 \mathrm{bar}, \mathrm{H}_{2} / \mathrm{CO}=2$ ). Though Co nanocrystallites were more highly dispersed on MIL-53( $\mathrm{Al}$ ) than on alumina, there was a significant fraction of small particles $(2-4 \mathrm{~nm})$ that were not catalytically very active on the former support, which explains their similar catalytic performance. In a different study, MOF-derived cobalt catalysts, one containing nitrogen (CoZIF-67) and the other one nitrogen-free (Co-MOF-74), were prepared by incorporating cobalt into the MOF matrix during the synthesis. ${ }^{186}$ Before these catalysts were tested in FT synthesis, they were thermally treated $\left(550{ }^{\circ} \mathrm{C}\right)$ under an argon atmosphere to carbonize the organic ligands that aided in the reduction of cobalt species and to prevent Co aggregation. However, the MOF structure was collapsed after the thermal treatment. The cobalt nanocrystallites embedded in the carbon matrix were well-dispersed in both of these catalysts. The cobalt catalysts derived from nitrogen-free MOFs (Co-C) exhibited better CO conversion (30\% vs $10 \%)$ with higher $\mathrm{C}_{5+}$ selectivity $(65 \%$ vs $31 \%)$, moderate short-chain hydrocarbon selectivity $\left(\mathrm{C}_{2}-\mathrm{C}_{4}, 10 \%\right.$ vs $\left.37 \%\right)$, and similar $\mathrm{CH}_{4}$ selectivity compared with the catalysts derived from nitrogen-containing MOFs (Co-NC) in FT synthesis (30 wt \% Co in Co-C and 52 wt \% Co in Co-NC, $230{ }^{\circ} \mathrm{C}, 30$ bar, $\mathrm{H}_{2} / \mathrm{CO}=2$ ). The difference in the catalytic performances was attributed to the relatively large pore size $(7 \mathrm{~nm}$ in $\mathrm{Co}-\mathrm{C}$ vs 3 $\mathrm{nm}$ in Co-NC), which facilitates the diffusion of hydrocarbons. The high selectivity for short-chain hydrocarbons $\left(\mathrm{C}_{2}-\mathrm{C}_{4}\right)$ using Co-NC was tentatively ascribed to the electronic effects generated by the presence of nitrogen with electron donor capability in the carbon matrix.

Usually, the cobalt phase present in MOF-derived materials is composed solely of fcc Co. However, the hcp Co phase is found to be more active in FT synthesis because $\mathrm{CO}$ molecules bind to and dissociate from the Co-hcp structure more readily than from the Co-fcc phase. ${ }^{118,187}$ Recently it was shown that well-dispersed Co-fcc nanoparticles (ca. $10 \mathrm{~nm}$ ) were obtained on the porous-carbon-supported Co catalysts prepared by pyrolyzing a Co-MOF-71 precursor. ${ }^{188}$ Furthermore, doping of Co-MOF-71 with variable quantities of the $\mathrm{Si}$ precursor $\mathrm{Si}\left(\mathrm{OC}_{2} \mathrm{H}_{5}\right)_{4}$ and subsequent pyrolysis $\left(250{ }^{\circ} \mathrm{C}\right)$ and hydrogenation $\left(350^{\circ} \mathrm{C}\right)$ treatments resulted in catalysts $(\mathrm{Co}-\mathrm{Si}-\mathrm{C})$ with tunable $\mathrm{Co}-\mathrm{fcc}$ nanoparticles that were partially transformed into Co-hcp phase via a $\mathrm{Co}_{2} \mathrm{C}$ intermediate. The $\mathrm{Co}-$ $\mathrm{Si}-\mathrm{C}$ catalysts holding high Co site density $\left(\mathrm{mol}_{\text {active sites }} / \mathrm{g}_{\text {cat }}\right)$ showed very good activity and $\mathrm{C}_{5+}$ selectivity, with diesel fuels being the main constituents in the liquid product. The $\mathrm{C}_{5+}$ space-time yields ( $g_{\text {hydrocarbons }} \mathrm{g}_{\text {cat }}{ }^{-1} \mathrm{~h}^{-1}$ ) of the $\mathrm{Co}-\mathrm{Si}-\mathrm{C}$ catalysts were reported to be relatively higher than those of the conventional Co catalysts, but the tested conditions were different. Therefore, more studies to test the long-term stability and economic viability of preparing these types of catalysts are needed in order to comment on their application at large scale.

12.4. Metal-Foam-Supported Catalysts. Metal foams are a new kind of porous materials with a cellular structure that offer interesting characteristics for use as catalyst carriers, such as high thermal conductivity like that of $\mathrm{SiC}$, limited detrimental metal-support interactions, a low pressure drop due to the presence of voids (macropores) that enhance the mass transfer properties, and low density. ${ }^{189}$ Park et al. ${ }^{190}$ introduced the use of Ni-foam-supported catalysts prepared by coating the cobalt catalyst powder $\left(\mathrm{Co} / \mathrm{Al}_{2} \mathrm{O}_{3}\right)$ on the surface of a Ni foam in FT synthesis (8 wt \% Co, 190-220 ${ }^{\circ} \mathrm{C}, 20 \mathrm{bar}$, $\mathrm{H}_{2} / \mathrm{CO}=2$ ). The thus-prepared $\mathrm{Ni}$ foam catalyst showed low $\mathrm{CH}_{4}$ and $\mathrm{CO}_{2}$ selectivities and high $\mathrm{C}_{5+}$ selectivity compared with the conventional $\mathrm{Co} / \mathrm{Al}_{2} \mathrm{O}_{3}$ catalyst. The enhanced performance was attributed to the better heat and mass transfer properties in the reaction. Furthermore, it was found 
Table 5. Guidance for Support Modifications To Improve Catalytic Performance of Co-Based Catalysts in FT Synthesis $(\otimes$, No; $\sqrt{ }$, Yes

\begin{tabular}{|c|c|c|c|c|c|c|}
\hline \multirow[b]{2}{*}{ support } & \multicolumn{6}{|c|}{ are surface modifications/doping required to improve the support characteristics? } \\
\hline & surface area & reducibility & dispersion & metal-support interactions & acid/base properties & thermal conductivity \\
\hline alumina & $\otimes$ & $\sqrt{ }$ & $\sqrt{ }$ & $\sqrt{ }$ & $\sqrt{ }$ & $\sqrt{ }$ \\
\hline silica & $\otimes$ & $\sqrt{ }$ & $\sqrt{ }$ & $\sqrt{ }$ & $\sqrt{ }$ & $\sqrt{ }$ \\
\hline titania & $\sqrt{ }$ & $\otimes$ & $\sqrt{ }$ & $\sqrt{ }$ & $\sqrt{ }$ & $\sqrt{ }$ \\
\hline niobia & $\sqrt{ }$ & $\otimes$ & $\sqrt{ }$ & $\sqrt{ }$ & $\sqrt{ }$ & $\sqrt{ }$ \\
\hline zirconia & $\sqrt{ }$ & $\sqrt{ }$ & $\sqrt{ }$ & $\otimes$ & $\sqrt{ }$ & $\sqrt{ }$ \\
\hline zeolites & $\otimes$ & $\sqrt{ }$ & $\otimes$ & $\sqrt{ }$ & $\otimes$ & $\sqrt{ }$ \\
\hline carbon materials & $\otimes$ & $\otimes$ & $\sqrt{ }$ & $\otimes$ & $\sqrt{ }$ & $\otimes$ \\
\hline silicon carbide & $\sqrt{ }$ & $\otimes$ & $\sqrt{ }$ & $\otimes$ & $\sqrt{ }$ & $\otimes$ \\
\hline metal foams & $\sqrt{ }$ & $\otimes$ & $\sqrt{ }$ & $\otimes$ & $\sqrt{ }$ & $\otimes$ \\
\hline
\end{tabular}

Table 6. Guidance for the Choice of Support Based on the Product Selectivities of Co-Based Catalysts in FT Synthesis

\begin{tabular}{|c|c|c|c|}
\hline products & support & characteristics that affect the product selectivity & refs \\
\hline \multirow[t]{9}{*}{$\mathrm{C}_{5+}$} & $\mathrm{Al}_{2} \mathrm{O}_{3}$ & $\begin{array}{l}\text { - pore size (ca. } 12-50 \mathrm{~nm}) \\
\text { - Co particle size }\left(7-8 \mathrm{~nm} \text { for } \gamma-\mathrm{Al}_{2} \mathrm{O}_{3}\right) \\
\text { - from different phases of alumina, } \alpha-\mathrm{Al}_{2} \mathrm{O}_{3} \text { is preferred } \\
\text { - catalyst particle size }(50-225 \mu \mathrm{m})\end{array}$ & $35,36,40$ \\
\hline & $\begin{array}{l}\text { surface- } \\
\text { modified } \\
\mathrm{Al}_{2} \mathrm{O}_{3}\end{array}$ & $\begin{array}{l}\text { - modification with inorganic oxides such as } \mathrm{Zr}, \mathrm{Ti} \text {, or } \mathrm{Ta} \\
\text { - alters } \mathrm{H}_{2} / \mathrm{CO} \text { mass transport within the pores } \\
\text { - intermediate acid/base character }(\eta=2.49-2.53 \mathrm{eV} \text {; vide supra })\end{array}$ & 49,67 \\
\hline & $\mathrm{SiO}_{2}$ & $\begin{array}{l}\text { - pore size (ca. } 10 \mathrm{~nm}) \\
\text { - Co particle size (ca. } 9 \mathrm{~nm}) \\
\text { - moderate CO adsorption }\end{array}$ & 78,79 \\
\hline & $\begin{array}{l}\text { surface- } \\
\text { modified } \\
\mathrm{SiO}_{2}\end{array}$ & $\begin{array}{l}\text { - modification with inorganic oxides such as } \mathrm{Zr} / \mathrm{P} \\
\text { - enhances stabilization of the active phase } \\
\text { - selective poisoning of methanation sites by carbon coating (10 wt \%) }\end{array}$ & $\begin{array}{l}81,82,89 \\
93\end{array}$ \\
\hline & $\mathrm{TiO}_{2}$ & $\begin{array}{l}\text { - reducible nature of the support } \\
\text { - average pore size (ca. } 16 \mathrm{~nm} \text { ) favors easy diffusion of long-chain hydrocarbons, leading to high } \mathrm{C}_{5+} \text { selectivity } \\
\text { - close interaction of Co promoted with } \mathrm{Ru} \text { or Re } \\
\text { - reduces blockage of the active site by carbonaceous species }\end{array}$ & $87,107,108$ \\
\hline & $\mathrm{Nb}_{2} \mathrm{O}_{5}$ & $\begin{array}{l}\text { - reducible nature of the support } \\
\text { - electronic effect: possible electron enrichment of surface cobalt atoms by partially reduced } \mathrm{NbO}_{x} \text { species } \\
\text { localized on the cobalt particles favors hydrogenolysis, leading to higher } \mathrm{C}_{5+} \text { selectivity }\end{array}$ & $113-115$ \\
\hline & $\mathrm{ZrO}_{2}$ & $\begin{array}{l}\text { - ability to adsorb hydrogen via a spillover mechanism } \\
\text { - mesoporous } \mathrm{ZrO}_{2} \text { with pore size of ca. } 9 \mathrm{~nm} \text { yields mostly } \mathrm{C}_{12}-\mathrm{C}_{18} \text { (diesel range) }\end{array}$ & 10,120 \\
\hline & carbon & $\begin{array}{l}\text { - Co particle size }(\sim 8 \mathrm{~nm}) \\
\text { - CNTs: confinement of reactants and reaction intermediates within CNTs leads to increased contact time of } \\
\text { reactive species with the active phase, favoring } \mathrm{C}_{5+} \text { selectivity } \\
\text { - graphite: reduces the high } \mathrm{H} \text { adsorption and thus leads to long-chain growth }\end{array}$ & $\begin{array}{l}146,155 \\
156\end{array}$ \\
\hline & $\mathrm{SiC}$ & $\begin{array}{l}\text { - ability to efficiently evacuate heat generated during the FT reaction, } \\
\text { - presence of meso- and macroporosity favors wax formation even at high } \mathrm{CO} \text { conversions } \\
\text { - surface modification with } \mathrm{TiO}_{2} \text { leads to smaller Co particles }(<15 \mathrm{~nm})\end{array}$ & 14,175 \\
\hline $\begin{array}{l}\mathrm{C}_{5}-\mathrm{C}_{10} \\
\quad \text { (gasoline } \\
\text { range) }\end{array}$ & zeolites & $\begin{array}{l}\text { - the acidic nature of the zeolites can be tuned by changing the silica/alumina ratio, which favors short-chain } \\
\text { hydrocarbons } \\
\text { - serve as bifunctional catalysts } \\
\text { - secondary reaction of long-chain hydrocarbons to yield branched hydrocarbons with limited chain length and } \\
\text { aromatics } \\
\text { - preferred zeolites: ZSM-5 or hierarchical Y zeolite }\end{array}$ & $\begin{array}{l}127-130 \\
137\end{array}$ \\
\hline oxygenates & $\mathrm{CeO}_{2}$ & $\begin{array}{l}\text { - redox properties of } \mathrm{CeO}_{2} \\
\text { - alcohol formation based on } \mathrm{Co}-\mathrm{CeO}_{2} \text { interfacial catalysis (vide supra) }\end{array}$ & 12,141 \\
\hline
\end{tabular}

that $\mathrm{CH}_{4}$ formation was effectively minimized even at higher reaction temperatures. However, macroporous metal foams possess low metal surface area, making it difficult to get good dispersion of the active phase. In the direction of circumventing this problem, Harmel ${ }^{191}$ proposed a method of growing cobalt nanowires in the porous network of nickel and copper foams. Interestingly, these Co nanowires constitute Co-hcp phase, which is known to exhibit high activity in FT synthesis. The Ni-foam-supported cobalt catalysts showed high activity and selectivity for $\mathrm{CH}_{4}$, whereas the $\mathrm{Cu}$-foamsupported catalysts exhibited high activity and selectivity for $\mathrm{C}_{5+}$ hydrocarbons. This represents a new method to increase the dispersion of the active phase and enhance the intrinsic activity of cobalt active sites, but the long-term stability of these catalysts and the economic viability of the preparation 
protocol must still be carefully evaluated before they can be implemented in the industrial process.

12.5. Hydroxyapatite: A Potential Support Material. Hydroxyapatite ( $\left.\mathrm{HAP}, \mathrm{Ca}_{10}\left(\mathrm{PO}_{4}\right)_{6}(\mathrm{OH})_{2}\right)$ is a double salt of tricalcium phosphate- and calcium hydroxide-based materials that contains both acidic and basic functionalities. ${ }^{192}$ Furthermore, it exhibits other characteristics such as high thermal stability, extremely low water solubility, and tunable specific surface area with or without mesopores depending on the synthesis conditions. ${ }^{193}$ The $\mathrm{Ca} / \mathrm{P}$ molar ratio in the stoichiometric form of HAP is 1.67. The ionic radii of HAP's component elements ( $\mathrm{Ca}$ and $\mathrm{P}$ ) permit the transfer or loss of ions within its crystal structure, consequently leading to nonstoichiometric HAPs, $\mathrm{Ca}_{10-z}\left(\mathrm{HPO}_{4}\right)_{z}\left(\mathrm{PO}_{4}\right)_{6-z}(\mathrm{OH})_{2-z}(0$ $<z \leq 1)$ with $\mathrm{Ca} / \mathrm{P}$ molar ratios in the range of 1.50 to $1.80{ }^{194}$ The possibility of preparing nonstoichiometric HAPs helps in tuning the density of acidic and basic sites, which is not possible in the case of conventional catalyst carriers. When the $\mathrm{Ca} / \mathrm{P}$ ratio of HAP is about 1.50 , the material behaves as an acidic catalyst. HAP exhibits characters of both acidic and basic catalysts when the $\mathrm{Ca} / \mathrm{P}$ ratio is between 1.50 and 1.67 and acts as a basic catalyst when the $\mathrm{Ca} / \mathrm{P}$ ratio is above $1.67 .^{195}$ Furthermore, the calcium ions in HAP can be easily exchanged with most divalent cations (e.g., $\mathrm{Cu}^{2+}, \mathrm{Pb}^{2+}, \mathrm{Zn}^{2+}, \mathrm{Cd}^{2+}, \mathrm{Co}^{2+}$, etc.) without affecting the stability of the phosphate. ${ }^{196}$ These interesting characteristics of HAPs make them unique support materials in heterogeneous catalysts. ${ }^{197}$ Over the past decade, their potential as catalyst supports has been realized in many different reactions such as methane oxidation, ${ }^{198,199}$ dry reforming of methane, ${ }^{200-203}$ the water-gas shift reaction, ${ }^{204}$ hydrogen production, ${ }^{205}$ and selective oxidation of alcohols. ${ }^{206}$ Considering the properties of HAPs, it is definitely worth utilizing them as catalyst supports in Co-based FT catalysts.

\section{SUMMARY}

On the basis of the above-discussed literature on different aspects of support effects in the FT process, the guidelines for determining the necessity of support surface modifications are given in Table 5, and the choice of support on the basis of the product selectivities of Co-based catalysts in FT synthesis is summarized in Table 6.

\section{CONCLUSIONS AND OUTLOOK}

In general, cobalt precursors experience varying metal-support interactions depending on the type of the support. Oxide supports exhibit medium to strong interactions with cobalt, whereas pristine carbon materials and $\mathrm{SiC}$ display very poor interaction. The type of interaction between the support and the metal plays a pivotal role in the dispersion of cobalt metal precursors, and the strength and type of interaction determines the cobalt reducibility, which in turn determines the activity and selectivity in FT synthesis. Textural properties of the support such as surface area, pore volume, pore size distribution, and crystalline phase of the support have been found to influence both the activity and selectivity. High specific surface area and pore volume are required in order to increase the loading of active metal without compromising its dispersion. The pore size of the mesoporous supports limits the size of cobalt nanocrystallites via the confinement effect. Catalysts containing medium-sized pores exhibit higher selectivity for long-chain hydrocarbons compared with catalysts with small pores.
$\mathrm{Al}_{2} \mathrm{O}_{3}$ has been the most extensively studied support because of its applicability under industrial conditions. Different crystalline phases of alumina exhibit $\mathrm{C}_{5+}$ selectivities in the following order: $\alpha-\mathrm{Al}_{2} \mathrm{O}_{3}>\delta-\mathrm{Al}_{2} \mathrm{O}_{3}>\theta-\mathrm{Al}_{2} \mathrm{O}_{3}>\gamma-\mathrm{Al}_{2} \mathrm{O}_{3}$. Different types of oxides (magnesia, zirconia, titania, phosphorus, lanthana), silanes, and organic molecules (sorbitol, cyclodextrin) have been used to modify the alumina surface to prevent the formation of refractory cobalt aluminates resulting from the direct interaction of cobalt with the alumina support. Porous $\gamma-\mathrm{Al}_{2} \mathrm{O}_{3}$ covered by monolayers of various oxides with identical support textures, extents of Co reduction, and particle sizes showed that the chemical nature of the support (Lewis acid/base character) controls both the catalytic activity and the selectivity for long-chain products.

Silica has been the next most widely studied support, and observations made for alumina in terms of textural properties hold true for silica supports too. Although the interaction of cobalt metal precursors with silica is poor compared with alumina, the formation of cobalt silicates is still observed. Such detrimental interactions are circumvented by surface modifications with inorganic oxides and organic compounds. Mesoporous silicas (MCM-41 and SBA-15) offer the possibility of synthesizing supports with desired narrow-pore size distributions, surface areas, pore volumes, and controllable acid/base properties.

Titania and niobia exhibit strong interactions with cobalt. These supports are partially reduced during the activation step under a hydrogen atmosphere and decorate the surface of the cobalt nanocrystallites. Zirconia shows weaker interactions with cobalt compared with the supports mentioned above and displays the capability of hydrogen adsorption via a spillover mechanism. Supports such as alumina, silica, and $\mathrm{SiC}$ can be surface-modified with titania, niobia, and zirconia to improve cobalt dispersion, reducibility, and stability, consequently enhancing the catalytic performance.

Zeolites with shape-selective characteristics, well-defined pore structures, high porosity, and acidity that can be tuned by changing the silica/alumina ratio. Cobalt catalysts supported on zeolites exhibit bifunctional characteristics that are very useful in directing the selectivity for the desired hydrocarbon fraction (e.g., gasoline vs diesel) through in situ hydrocracking of the wax fraction.

Carbon materials interact very weakly with cobalt, making them ideal supports for use in model catalysts for the rational design of catalysts. $\mathrm{SiC}$ support characteristics such as high thermal conductivity, mechanical strength, and chemical inertness make $\mathrm{SiC}$ a suitable support material for FT catalysts, as the FT reaction is highly exothermic. Advantages of using $\mathrm{SiC}$-supported Co cobalt catalysts include improved heat transfer in FT synthesis, easy recovery of both the active phase and the support, and improved $\mathrm{C}_{5+}$ selectivity.

Significant advances have been realized in understanding the effect of the support in FT synthesis, but the majority of the studies have been performed on alumina and to a certain extent on silica. In order to mask unfavorable properties of the supports, surface modification by coating the support surface with inorganic oxides or organic molecules has been used to get desired properties that improve the activity and/or selectivity in FT synthesis. Parameters such as the cobalt nanocrystallite size, crystal structure (hcp vs fcc), distribution, and reducibility on a support material play a role in determining the activity of supported Co catalysts in FT synthesis. Some of the factors that influence the selectivities for 
various products in FT synthesis are the pore structure and chemical nature of the support, the type of support material (selectivities for $\mathrm{C}_{5+}$ hydrocarbons: $\mathrm{SiC}>$ titania/ $\alpha$-alumina $>$ $\gamma$-alumina/silica), and the acidic character of the support, which induces in situ hydrocracking of long-chain hydrocarbons (e.g., in the case of zeolites). The FT catalysts prepared on unconventional supports such as mesoporous silicas, zeolites, $\mathrm{SiC}, \mathrm{MOF}$, hydrotalcite, and metal foams present enhanced activity and/or selectivity for desired hydrocarbon ranges in FT synthesis. However, to implement these new findings in industry, more work is needed to establish the long-term operational stability, recovery and regenerability, cost effectiveness, and environmental integrity of these catalysts. In particular, through the use of advanced electron microscopy techniques such as cryo-TEM and electron tomography, more detailed information on the distribution of the metal precursors can be obtained at different stages of catalyst preparation with the newly emerging supports. Furthermore, in situ X-ray absorption spectroscopy, $\mathrm{X}$-ray fluorescence spectroscopy, and liquid-cell TEM studies would provide a quantitative picture of the evolution of the diameter, shape, lattice packing, and density of the deposited cobalt particles in real time. In order to design supported catalysts with the desired activity and selectivity, emerging in situ spectroscopy and microscopy techniques under industrial working conditions would help in better understanding the role of electronic and structural effects in the FT reaction. Finally, the development of next-generation supported cobalt catalysts that resist some impurities in syngas derived from biomass and wastes must be intensified. New potential supports such as hydroxyapatite may bring new insights for the design of competitive catalysts versus traditional aluminaor silica-based supports in FT synthesis.

\section{AUTHOR INFORMATION}

\section{Corresponding Author}

*E-mail: rajesh.munirathinam83@gmail.com, rajesh. munirathinam@mines-albi.fr.

\section{ORCID $\odot$}

Rajesh Munirathinam: 0000-0002-9164-9520

Notes

The authors declare no competing financial interest.

\section{REFERENCES}

(1) Anderson, R. B.; Shultz, J. F.; Hofer, L. J. E.; Storch, H. H. Physical Chemistry of the Fischer-Tropsch Synthesis; Bureau of Mines, Bulletin 580; U.S. Department of the Interior: Washington, DC, 1959.

(2) Iglesia, E. Design, Synthesis, and Use of Cobalt-Based FischerTropsch Synthesis Catalysts. Appl. Catal., A 1997, 161 (1-2), 59-78.

(3) Dry, M. E. Fischer-Tropsch Synthesis over Iron Catalysts. Catal. Lett. 1990, 7 (1-4), 241-251.

(4) Davis, B. H. Fischer-Tropsch Synthesis: Comparison of Performances of Iron and Cobalt Catalysts. Ind. Eng. Chem. Res. 2007, 46 (26), 8938-8945.

(5) Khodakov, A. Y.; Chu, W.; Fongarland, P. Advances in the Development of Novel Cobalt Fischer-Tropsch Catalysts for Synthesis of Long-Chain Hydrocarbons and Clean Fuels. Chem. Rev. 2007, 107, 1692-1744.

(6) van de Loosdrecht, J.; Botes, F. G.; Ciobica, I. M.; Ferreira, A.; Gibson, P.; Moodley, D. J.; Saib, A. M.; Visagie, J. L.; Weststrate, C. J.; Niemantsverdriet, J. W. Fischer-Tropsch Synthesis: Catalysts and Chemistry. In Comprehensive Inorganic Chemistry II, 2nd ed.; Reedijk, J., Poeppelmeier, K., Eds.; Elsevier: Amsterdam, 2013; Vol. 7, Chapter 7.20 .
(7) Oukaci, R.; Singleton, A. H.; Goodwin, J. G. Comparison of Patented Co F-T Catalysts Using Fixed-Bed and Slurry Bubble Column Reactors. Appl. Catal., A 1999, 186 (1-2), 129-144.

(8) Sun, B.; Xu, K.; Nguyen, L.; Qiao, M.; Tao, F. F. Preparation and Catalysis of Carbon-Supported Iron Catalysts for Fischer-Tropsch Synthesis. Chem CatChem 2012, 4, 1498-1511.

(9) Khodakov, A. Y.; Zholobenko, V. L.; Bechara, R.; Durand, D. Impact of Aqueous Impregnation on the Long-Range Ordering and Mesoporous Structure of Cobalt Containing MCM-41 and SBA-15 Materials. Microporous Mesoporous Mater. 2005, 79 (1-3), 29-39.

(10) Enache, D. I.; Roy-Auberger, M.; Revel, R. Differences in the Characteristics and Catalytic Properties of Cobalt-Based FischerTropsch Catalysts Supported on Zirconia and Alumina. Appl. Catal., A 2004, 268 (1-2), 51-60.

(11) den Otter, J. H.; de Jong, K. P. Highly Selective and Active Niobia-Supported Cobalt Catalysts for Fischer-Tropsch Synthesis. Top. Catal. 2014, 57 (6-9), 445-450.

(12) Spadaro, L.; Arena, F.; Granados, M. L.; Ojeda, M.; Fierro, J. L. G.; Frusteri, F. Metal-Support Interactions and Reactivity of $\mathrm{Co} /$ $\mathrm{CeO}_{2}$ Catalysts in the Fischer-Tropsch Synthesis Reaction. J. Catal. 2005, 234 (2), 451-462.

(13) Bessell, S. Investigation of Bifunctional Zeolite Supported Cobalt Fischer-Tropsch Catalysts. Appl. Catal., A 1995, 126 (2), 235-244.

(14) Lacroix, M.; Dreibine, L.; De Tymowski, B.; Vigneron, F.; Edouard, D.; Bégin, D.; Nguyen, P.; Pham, C.; Savin-Poncet, S.; Luck, F.; Ledoux, M. J.; Pham-Huu, C. Silicon Carbide Foam Composite Containing Cobalt as a Highly Selective and Re-Usable FischerTropsch Synthesis Catalyst. Appl. Catal., A 2011, 397 (1-2), 62-72.

(15) Diehl, F.; Khodakov, A. Y. Promotion of Cobalt FischerTropsch Catalysts with Noble Metals: A Review. Oil Gas Sci. Technol. 2009, 64 (1), 11-24.

(16) Morales, F.; Weckhuysen, B. M. Promotion Effects in Co-Based Fischer-Tropsch Catalysis. Catalysis 2006, 19, 1-40.

(17) Yang, N.; Bent, S. F. Investigation of Inherent Differences between Oxide Supports in Heterogeneous Catalysis in the Absence of Structural Variations. J. Catal. 2017, 351, 49-58.

(18) Reuel, R. C.; Bartholomew, C. H. The Stoichiometries of $\mathrm{H}_{2}$ and CO Adsorptions on Cobalt: Effects of Support and Preparation. J. Catal. 1984, 85 (1), 63-77.

(19) Jahangiri, H.; Bennett, J.; Mahjoubi, P.; Wilson, K.; Gu, S. A Review of Advanced Catalyst Development for Fischer-Tropsch Synthesis of Hydrocarbons from Biomass Derived Syn-Gas. Catal. Sci. Technol. 2014, 4 (8), 2210-2229.

(20) Zowtiak, J. M.; Bartholomew, C. H. The Kinetics of $\mathrm{H}_{2}$ Adsorption on and Desorption from Cobalt and the Effects of Support Thereon. J. Catal. 1983, 83 (1), 107-120.

(21) Bessell, S. Support Effects in Cobalt-Based Fischer-Tropsch Catalysis. Appl. Catal., A 1993, 96 (2), 253-268.

(22) Bartholomew, C. H.; Reuel, R. C. Cobalt-Support Interactions: Their Effects on Adsorption and $\mathrm{CO}$ Hydrogenation Activity and Selectivity Properties. Ind. Eng. Chem. Prod. Res. Dev. 1985, 24 (1), 56-61.

(23) Bertole, C. J.; Mims, C. A.; Kiss, G. Support and Rhenium Effects on the Intrinsic Site Activity and Methane Selectivity of Cobalt Fischer-Tropsch Catalysts. J. Catal. 2004, 221 (1), 191-203.

(24) Zhang, Q.; Kang, J.; Wang, Y. Development of Novel Catalysts for Fischer-Tropsch Synthesis: Tuning the Product Selectivity. Chem CatChem 2010, 2, 1030-1058.

(25) Rytter, E.; Tsakoumis, N. E.; Holmen, A. On the Selectivity to Higher Hydrocarbons in Co-Based Fischer-Tropsch Synthesis. Catal. Today 2016, 261, 3-16.

(26) Rytter, E.; Holmen, A. On the Support in Cobalt FischerTropsch Synthesis-Emphasis on Alumina and Aluminates. Catal. Today 2016, 275, 11-19.

(27) Ail, S. S.; Dasappa, S. Biomass to Liquid Transportation Fuel via Fischer-Tropsch Synthesis - Technology Review and Current Scenario. Renewable Sustainable Energy Rev. 2016, 58, 267-286. 
(28) Althapp, A.; Degen, W.; Heinl, E.; Rouveirolles, P.; Rudloff, M.; Stöhr, M. Renewable Fuels for Advanced Powertrains (RENEW), EC Contract No. SES6-CT-2003-502705, 2007.

(29) Busca, G. The Surface of Transitional Aluminas: A Critical Review. Catal. Today 2014, 226, 2-13.

(30) Wang, W. J.; Chen, Y. W. Influence of Metal Loading on the Reducibility and Hydrogenation Activity of Cobalt/Alumina Catalysts. Appl. Catal. 1991, 77 (2), 223-233.

(31) Chin, R. L.; Hercules, D. M. Surface Spectroscopic Characterization of Cobalt-Alumina Catalysts. J. Phys. Chem. 1982, 86 (3), 360-367.

(32) Jacobs, G.; Das, T. K.; Zhang, Y.; Li, J.; Racoillet, G.; Davis, B. H. Fischer-Tropsch Synthesis: Support, Loading, and Promoter Effects on the Reducibility of Cobalt Catalysts. Appl. Catal., A 2002, 233 (1-2), 263-281.

(33) Storsæter, S.; Tøtdal, B.; Walmsley, J. C.; Tanem, B. S.; Holmen, A. Characterization of Alumina-, Silica-, and TitaniaSupported Cobalt Fischer-Tropsch Catalysts. J. Catal. 2005, 236 (1), 139-152.

(34) Xiong, H.; Zhang, Y.; Wang, S.; Li, J. Fischer-Tropsch Synthesis: The Effect of $\mathrm{Al}_{2} \mathrm{O}_{3}$ Porosity on the Performance of $\mathrm{Co} /$ $\mathrm{Al}_{2} \mathrm{O}_{3}$ Catalyst. Catal. Commun. 2005, 6 (8), 512-516.

(35) Borg, Ø.; Eri, S.; Blekkan, E. A.; Storsæter, S.; Wigum, H.; Rytter, E.; Holmen, A. Fischer-Tropsch Synthesis over $\gamma$-AluminaSupported Cobalt Catalysts: Effect of Support Variables. J. Catal. 2007, 248 (1), 89-100.

(36) Borg, Ø.; Dietzel, P. D. C.; Spjelkavik, A. I.; Tveten, E. Z.; Walmsley, J. C.; Diplas, S.; Eri, S.; Holmen, A.; Rytter, E. FischerTropsch Synthesis: Cobalt Particle Size and Support Effects on Intrinsic Activity and Product Distribution. J. Catal. 2008, 259 (2), $161-164$.

(37) Schanke, D.; Eri, S.; Rytter, E.; Aaserud, C.; Hilmen, A.-M.; Lindvåg, O. A.; Bergene, E.; Holmen, A. Fischer-Tropsch Synthesis on Cobalt Catalysts Supported on Different Aluminas. Stud. Surf. Sci. Catal. 2004, 147, 301-306.

(38) Phan, X. K.; Yang, J.; Bakhtiary-Davijnay, H.; Myrstad, R.; Venvik, H. J.; Holmen, A. Studies of Macroporous Structured Alumina Based Cobalt Catalysts for Fischer-Tropsch Synthesis. Catal. Lett. 2011, 141 (12), 1739-1745.

(39) Vosoughi, V.; Badoga, S.; Dalai, A. K.; Abatzoglou, N. Modification of Mesoporous Alumina as a Support for Cobalt-Based Catalyst in Fischer-Tropsch Synthesis. Fuel Process. Technol. 2017, $162,55-65$.

(40) Rane, S.; Borg, Ø.; Yang, J.; Rytter, E.; Holmen, A. Effect of Alumina Phases on Hydrocarbon Selectivity in Fischer-Tropsch Synthesis. Appl. Catal., A 2010, 388 (1-2), 160-167.

(41) Liu, Y.; Jia, L.; Hou, B.; Sun, D.; Li, D. Cobalt AluminateModified Alumina as a Carrier for Cobalt in Fischer-Tropsch Synthesis. Appl. Catal., A 2017, 530, 30-36.

(42) Zhang, Y.; Xiong, H.; Liew, K.; Li, J. Effect of Magnesia on Alumina-Supported Cobalt Fischer-Tropsch Synthesis Catalysts. J. Mol. Catal. A: Chem. 2005, 237 (1-2), 172-181.

(43) Chernavskii, P. A.; Pankina, G. A.; Lunin, V. V. The Influence of Oxide-Oxide Interaction on the Catalytic Properties of $\mathrm{Co} / \mathrm{Al}_{2} \mathrm{O}_{3}$ in CO Hydrogenation. Catal. Lett. 2000, 66 (3), 121-124.

(44) Enger, B. C.; Fossan, Å. L.; Borg, Ø.; Rytter, E.; Holmen, A. Modified Alumina as Catalyst Support for Cobalt in the FischerTropsch Synthesis. J. Catal. 2011, 284 (1), 9-22.

(45) Balonek, C. M.; Lillebø, A. H.; Rane, S.; Rytter, E.; Schmidt, L. D.; Holmen, A. Effect of Alkali Metal Impurities on Co-Re Catalysts for Fischer-Tropsch Synthesis from Biomass-Derived Syngas. Catal. Lett. 2010, 138 (1-2), 8-13.

(46) Bao, A.; Li, J.; Zhang, Y. Effect of Barium on Reducibility and Activity for Cobalt-Based Fischer-Tropsch Synthesis Catalysts. J. Nat. Gas Chem. 2010, 19 (6), 622-627.

(47) Xiong, H.; Zhang, Y.; Liew, K.; Li, J. Catalytic Performance of Zirconium-Modified $\mathrm{Co} / \mathrm{Al}_{2} \mathrm{O}_{3}$ for Fischer-Tropsch Synthesis. J. Mol. Catal. A: Chem. 2005, 231 (1-2), 145-151.
(48) Rohr, F.; Lindvåg, O. A.; Holmen, A.; Blekkan, E. A. FischerTropsch Synthesis over Cobalt Catalysts Supported on ZirconiaModified Alumina. Catal. Today 2000, 58 (4), 247-254.

(49) Ma, W.; Jacobs, G.; Gao, P.; Jermwongratanachai, T.; Shafer, W. D.; Pendyala, V. R. R.; Yen, C. H.; Klettlinger, J. L. S.; Davis, B. H. Fischer-Tropsch Synthesis: Pore Size and $\mathrm{Zr}$ Promotional Effects on the Activity and Selectivity of $25 \% \mathrm{Co} / \mathrm{Al}_{2} \mathrm{O}_{3}$ Catalysts. Appl. Catal., A 2014, 475, 314-324.

(50) Park, S. J.; Kim, S. M.; Woo, M. H.; Bae, J. W.; Jun, K. W.; Ha, K. S. Effects of Titanium Impurity on Alumina Surface for the Activity of $\mathrm{Co} / \mathrm{Ti}-\mathrm{Al}_{2} \mathrm{O}_{3}$ Fischer-Tropsch Catalyst. Appl. Catal., A 2012, 419-420 (420), 148-155.

(51) Liu, Y.; Luo, J.; Girleanu, M.; Ersen, O.; Pham-Huu, C.; Meny, C. Efficient Hierarchically Structured Composites Containing Cobalt Catalyst for Clean Synthetic Fuel Production from Fischer-Tropsch Synthesis. J. Catal. 2014, 318, 179-192.

(52) Ledford, J. S.; Houalla, M.; Petrakis, L.; Hercules, D. M. Influence of Lanthanum Oxide on the Surface Structure and Co Hydrogenation Activity of Supported Cobalt Catalysts. Stud. Surf. Sci. Catal. 1987, 31 (C), 433-442.

(53) Cai, Z.; Li, J.; Liew, K.; Hu, J. Effect of $\mathrm{La}_{2} \mathrm{O}_{3}$-Dopping on the $\mathrm{Al}_{2} \mathrm{O}_{3}$ Supported Cobalt Catalyst for Fischer-Tropsch Synthesis. J. Mol. Catal. A: Chem. 2010, 330 (1-2), 10-17.

(54) Brabant, C.; Khodakov, A.; Griboval-Constant, A. Promotion of Lanthanum-Supported Cobalt-Based Catalysts for the FischerTropsch Reaction. C. R. Chim. 2017, 20 (1), 40-46.

(55) Iwamoto, R.; Grimblot, J. Influence of Phosphorus on the Properties of Alumina-Based Hydrotreating Catalysts. Adv. Catal. 1999, 44 (C), 417-503.

(56) Bae, J. W.; Kim, S. M.; Lee, Y. J.; Lee, M. J.; Jun, K. W. Enhanced Fischer-Tropsch Activity on Co/P- $\mathrm{Al}_{2} \mathrm{O}_{3}$ Catalyst: Effect of Phosphorous Content. Catal. Commun. 2009, 10 (9), 1358-1362.

(57) Woo, M. H.; Cho, J. M.; Jun, K. W.; Lee, Y. J.; Bae, J. W. Thermally Stabilized Cobalt-Based Fischer-Tropsch Catalysts by Phosphorous Modification of $\mathrm{Al}_{2} \mathrm{O}_{3}$ : Effect of Calcination Temperatures on Catalyst Stability. ChemCatChem 2015, 7 (9), 1460-1469.

(58) Park, S. J.; Bae, J. W.; Jung, G. I.; Ha, K. S.; Jun, K. W.; Lee, Y. J.; Park, H. G. Crucial Factors for Catalyst Aggregation and Deactivation on $\mathrm{Co} / \mathrm{Al}_{2} \mathrm{O}_{3}$ in a Slurry-Phase Fischer-Tropsch Synthesis. Appl. Catal., A 2012, 413-414, 310-321.

(59) Ha, K. S.; Jung, G. I.; Woo, M. H.; Jun, K. W.; Bae, J. W. Effects of Phosphorus and Saccharide on Size, Shape, and Reducibility of Fischer-Tropsch Catalysts for Slurry Phase and Fixed-Bed Reactions. Appl. Catal., A 2013, 453, 358-369.

(60) Park, S. J.; Bae, J. W.; Lee, Y. J.; Ha, K. S.; Jun, K. W.; Karandikar, P. Deactivation Behaviors of Pt or Ru Promoted Co/P$\mathrm{Al}_{2} \mathrm{O}_{3}$ Catalysts during Slurry-Phase Fischer-Tropsch Synthesis. Catal. Commun. 2011, 12 (6), 539-543.

(61) Vissers, J. P. R.; Mercx, F. P. M.; Bouwens, S. M. A. M.; de Beer, V. H. J.; Prins, R. Carbon-Covered Alumina as a Support for Sulfide Catalysts. J. Catal. 1988, 114 (2), 291-302.

(62) Jean-Marie, A.; Griboval-Constant, A.; Khodakov, A. Y.; Diehl, F. Influence of Sub-Stoichiometric Sorbitol Addition Modes on the Structure and Catalytic Performance of Alumina-Supported Cobalt Fischer-Tropsch Catalysts. Catal. Today 2011, 171 (1), 180-185.

(63) Jean-Marie, A.; Griboval-Constant, A.; Khodakov, A. Y.; Monflier, E.; Diehl, F. $\beta$-Cyclodextrin for Design of Alumina Supported Cobalt Catalysts Efficient in Fischer-Tropsch Synthesis. Chem. Commun. 2011, 47 (38), 10767-10769.

(64) Rytter, E.; Salman, A. u. R.; Tsakoumis, N. E.; Myrstad, R.; Yang, J.; Lögdberg, S.; Holmen, A.; Rønning, M. Hydrophobic Catalyst Support Surfaces by Silylation of $\gamma$-Alumina for $\mathrm{Co} / \mathrm{Re}$ Fischer-Tropsch Synthesis. Catal. Today 2018, 299, 20-27.

(65) Chen, L.; Tian, X.; Fu, Y.; Shen, J. The Effect of Surface Acidic and Basic Properties of Highly Loaded Co Catalysts on the FischerTropsch Synthesis. Catal. Commun. 2012, 28 (3), 155-158.

(66) Zhang, J.; Chen, J.; Ren, J.; Li, Y.; Sun, Y. Support Effect of Co/ $\mathrm{Al}_{2} \mathrm{O}_{3}$ Catalysts for Fischer-Tropsch Synthesis. Fuel 2003, 82 (5), 581-586. 
(67) Prieto, G.; De Mello, M. I. S.; Concepción, P.; Murciano, R.; Pergher, S. B. C.; Martínez, A. Cobalt-Catalyzed Fischer-Tropsch Synthesis: Chemical Nature of the Oxide Support as a Performance Descriptor. ACS Catal. 2015, 5 (6), 3323-3335.

(68) Jeong, N. C.; Lee, J. S.; Tae, E. L.; Lee, Y. J.; Yoon, K. B. Acidity Scale for Metal Oxides and Sanderson's Electronegativities of Lanthanide Elements. Angew. Chem., Int. Ed. 2008, 47 (52), 1012810132.

(69) Soled, S. L.; Iglesia, E.; Fiato, R. A.; Baumgartner, J. E.; Vroman, H.; Miseo, S. Control of Metal Dispersion and Structure by Changes in the Solid-State Chemistry of Supported Cobalt FischerTropsch Catalysts. Top. Catal. 2003, 26 (1-4), 101-109.

(70) Borg, Ø.; Rønning, M.; Storster, S.; van Beek, W.; Holmen, A. Identification of Cobalt Species during Temperature Programmed Reduction of Fischer-Tropsch Catalysts. Stud. Surf. Sci. Catal. 2007, 163, 255-272.

(71) Puskas, I.; Fleisch, T. H.; Hall, J. B.; Meyers, B. L.; Roginski, R. T. Metal-Support Interactions in Precipitated, Magnesium-Promoted Cobalt-Silica Catalysts. J. Catal. 1992, 134 (2), 615-628.

(72) Rosynek, M. P.; Polansky, C. A. Effect of Cobalt Source on the Reduction Properties of Silica-Supported Cobalt Catalysts. Appl. Catal. 1991, 73 (1), 97-112.

(73) Huber, G. W.; Guymon, C. G.; Conrad, T. L.; Stephenson, B. C.; Bartholomew, C. H. Hydrothermal Stability of $\mathrm{Co} / \mathrm{SiO}_{2}$ FischerTropsch Synthesis Catalysts. Stud. Surf. Sci. Catal. 2001, 139, 423430.

(74) Ernst, B.; Libs, S.; Chaumette, P.; Kiennemann, A. Preparation and Characterization of Fischer-Tropsch Active $\mathrm{Co} / \mathrm{SiO}_{2}$ Catalysts. Appl. Catal., A 1999, 186 (1-2), 145-168.

(75) Khodakov, A. Y.; Lynch, J.; Bazin, D.; Rebours, B.; Zanier, N.; Moisson, B.; Chaumette, P. Reducibility of Cobalt Species in SilicaSupported Fischer-Tropsch Catalysts. J. Catal. 1997, 168 (1), 1625.

(76) Tsubaki, N.; Sun, S.; Fujimoto, K. Different Functions of the Noble Metals Added to Cobalt Catalysts for Fischer-Tropsch Synthesis. J. Catal. 2001, 199 (2), 236-246.

(77) Lapszewicz, J. A.; Loeh, H. J.; Chipperfield, J. R. The Effect of Catalyst Porosity on Methane Selectivity in the Fischer-Tropsch Reaction. J. Chem. Soc., Chem. Commun. 1993, No. 11, 913.

(78) Saib, A. M.; Claeys, M.; Van Steen, E. Silica Supported Cobalt Fischer-Tropsch Catalysts: Effect of Pore Diameter of Support. Catal. Today 2002, 71 (3-4), 395-402.

(79) Song, D.; Li, J. Effect of Catalyst Pore Size on the Catalytic Performance of Silica Supported Cobalt Fischer-Tropsch Catalysts. J. Mol. Catal. A: Chem. 2006, 247 (1-2), 206-212.

(80) All, S.; Chen, B.; Goodwin, J. G. Zr Promotion of $\mathrm{Co} / \mathrm{SiO}_{2}$ for Fischer-Tropsch Synthesis. J. Catal. 1995, 157 (1), 35-41.

(81) Feller, A.; Claeys, M.; van Steen, E. Cobalt Cluster Effects in Zirconium Promoted $\mathrm{Co} / \mathrm{SiO}_{2}$ Fischer-Tropsch Catalysts. J. Catal. 1999, 185 (1), 120-130.

(82) Moradi, G. R.; Basir, M. M.; Taeb, A.; Kiennemann, A. Promotion of $\mathrm{Co} / \mathrm{SiO}_{2}$ Fischer-Tropsch Catalysts with Zirconium. Catal. Commun. 2003, 4 (1), 27-32.

(83) Bae, J. W.; Park, S. J.; Woo, M. H.; Cheon, J. Y.; Ha, K. S.; Jun, K. W.; Lee, D. H.; Jung, H. M. Enhanced Catalytic Performance by Zirconium Phosphate-Modified $\mathrm{SiO}_{2}$-Supported $\mathrm{Ru}$, Co Catalyst for Fischer-Tropsch Synthesis. ChemCatChem 2011, 3 (8), 1342-1347. (84) Jang, I. H.; Um, S. H.; Lim, B.; Woo, M. H.; Jun, K. W.; Lee, J. B.; Bae, J. W. Effects of Surface Modification with Zirconium Phosphate on $\mathrm{Ru} / \mathrm{Co} / \mathrm{SiO}_{2}$ Fischer-Tropsch Catalysts Analyzed by XPS and TEM Analyses. Appl. Catal., A 2013, 450, 88-95.

(85) Jiang, Y.; Fu, T.; Lü, J.; Li, Z. A Zirconium Modified Co/SiO 2 Fischer-Tropsch Catalyst Prepared by Dielectric-Barrier Discharge Plasma. J. Energy Chem. 2013, 22 (3), 506-511.

(86) Hinchiranan, S.; Zhang, Y.; Nagamori, S.; Vitidsant, T.; Tsubaki, N. $\mathrm{TiO}_{2}$ Promoted $\mathrm{Co} / \mathrm{SiO}_{2}$ Catalysts for Fischer-Tropsch Synthesis. Fuel Process. Technol. 2008, 89 (4), 455-459.
(87) Iglesia, E.; Soled, S. L.; Fiato, R. A.; Via, G. H. Bimetallic Synergy in Cobalt-Ruthenium Fischer-Tropsch Synthesis Catalysts. J. Catal. 1993, 143 (2), 345-368.

(88) den Otter, J. H.; Nijveld, S. R.; de Jong, K. P. Synergistic Promotion of $\mathrm{Co} / \mathrm{SiO}_{2}$ Fischer-Tropsch Catalysts by Niobia and Platinum. ACS Catal. 2016, 6 (3), 1616-1623.

(89) Gnanamani, M. K.; Jacobs, G.; Graham, U. M.; Pendyala, V. R. R.; Martinelli, M.; MacLennan, A.; Hu, Y.; Davis, B. H. Effect of Sequence of $\mathrm{P}$ and Co Addition over Silica for Fischer-Tropsch Synthesis. Appl. Catal., A 2017, 538, 190-198.

(90) Gnanamani, M. K.; Jacobs, G.; Pendyala, V. R. R.; Graham, U. M.; Hopps, S. D.; Thomas, G. A.; Shafer, W. D.; Sparks, D. E.; Xiao, Q.; Hu, Y.; Davis, B. H. Fischer-Tropsch Synthesis: Anchoring of Cobalt Particles in Phosphorus Modified Cobalt/Silica Catalysts. Appl. Catal., A 2016, 523, 146-158.

(91) Zhang, Y.; Hanayama, K.; Tsubaki, N. The Surface Modification Effects of Silica Support by Organic Solvents for Fischer-Tropsch Synthesis Catalysts. Catal. Commun. 2006, 7 (5), 251-254.

(92) Chen, J.; Zhang, Y.; Tan, L.; Zhang, Y. A Simple Method for Preparing the Highly Dispersed Supported $\mathrm{Co}_{3} \mathrm{O}_{4}$ on Silica Support. Ind. Eng. Chem. Res. 2011, 50 (7), 4212-4215.

(93) Cheng, K.; Subramanian, V.; Carvalho, A.; Ordomsky, V. V.; Wang, Y.; Khodakov, A. Y. The Role of Carbon Pre-Coating for the Synthesis of Highly Efficient Cobalt Catalysts for Fischer-Tropsch Synthesis. J. Catal. 2016, 337, 260-271.

(94) Alothman, Z. A. A Review: Fundamental Aspects of Silicate Mesoporous Materials. Materials 2012, 5 (12), 2874-2902.

(95) Beck, J. S.; Vartuli, J. C.; Roth, W. J.; Leonowicz, M. E.; Kresge, C. T.; Schmitt, K. D.; Chu, C. T.-W.; Olson, D. H.; Sheppard, E. W.; McCullen, S. B.; Higgins, J. B.; Schlenker, J. L. A New Family of Mesoporous Molecular Sieves Prepared with Liquid Crystal Template. J. Am. Chem. Soc. 1992, 114 (27), 10834-10843.

(96) Zhao, D.; Feng, J.; Huo, Q.; Melosh, N.; Fredrickson, G. H.; Chmelka, B. F.; Stucky, G. D. Triblock Copolymer Syntheses of Mesoporous Silica with Periodic 50 to 300 Angstrom Pores. Science 1998, 279 (5350), 548-552.

(97) Khodakov, A. Y.; Griboval-Constant, A.; Bechara, R.; Zholobenko, V. L. Pore Size Effects in Fischer-Tropsch Synthesis over Cobalt-Supported Mesoporous Silicas. J. Catal. 2002, 206 (2), 230-241.

(98) González, O.; Pérez, H.; Navarro, P.; Almeida, L. C.; Pacheco, J. G.; Montes, M. Use of Different Mesostructured Materials Based on Silica as Cobalt Supports for the Fischer-Tropsch Synthesis. Catal. Today 2009, 148 (1-2), 140-147.

(99) Khodakov, A. Y.; Bechara, R.; Griboval-Constant, A. FischerTropsch Synthesis over Silica Supported Cobalt Catalysts: Mesoporous Structure versus Cobalt Surface Density. Appl. Catal., A 2003, 254 (2), 273-288.

(100) Tauster, S. J.; Fung, S. C.; Garten, R. L. Strong MetalSupport Interactions. Group 8 Noble Metals Supported on $\mathrm{TiO}_{2}$. J. Am. Chem. Soc. 1978, 100 (1), 170-175.

(101) Resasco, D. E.; Weber, R. S.; Sakellson, S.; McMillan, M.; Haller, G. L. X-Ray Absorption near-Edge Structure Evidence for Direct Metal-Metal Bonding and Electron Transfer in Reduced Rhodium/Titania Catalysts. J. Phys. Chem. 1988, 92 (1), 189-193.

(102) Beard, B. C.; Ross, P. N. Platinum-Titanium Alloy Formation from High-Temperature Reduction of a Titania-Impregnated Platinum Catalyst: Implications for Strong Metal-Support Interaction. J. Phys. Chem. 1986, 90 (26), 6811-6817.

(103) de la Peña O’Shea, V. A.; Consuelo Álvarez Galván, M.; Platero Prats, A. E.; Campos-Martin, J. M.; Fierro, J. L. G. Direct Evidence of the SMSI Decoration Effect: The Case of $\mathrm{Co} / \mathrm{TiO}_{2}$ Catalyst. Chem. Commun. 2011, 47 (25), 7131.

(104) Cats, K. H.; Andrews, J. C.; Stéphan, O.; March, K.; Karunakaran, C.; Meirer, F.; de Groot, F. M. F.; Weckhuysen, B. M. Active Phase Distribution Changes within a Catalyst Particle during Fischer-Tropsch Synthesis as Revealed by Multi-Scale Microscopy. Catal. Sci. Technol. 2016, 6 (12), 4438-4449. 
(105) Reuel, R. C.; Bartholomew, C. H. Effects of Support and Dispersion on the CO Hydrogenation Activity/Selectivity Properties of Cobalt. J. Catal. 1984, 85 (1), 78-88.

(106) De La Osa, A. R.; De Lucas, A.; Romero, A.; Valverde, J. L.; Sánchez, P. Influence of the Catalytic Support on the Industrial Fischer-Tropsch Synthetic Diesel Production. Catal. Today 2011, 176 (1), 298-302.

(107) Oh, J. H.; Bae, J. W.; Park, S. J.; Khanna, P. K.; Jun, K. W. Slurry-Phase Fischer-Tropsch Synthesis Using $\mathrm{Co} / \gamma-\mathrm{Al}_{2} \mathrm{O}_{3}, \mathrm{Co} / \mathrm{SiO}_{2}$ and $\mathrm{Co} / \mathrm{TiO}_{2}$ : Effect of Support on Catalyst Aggregation. Catal. Lett. 2009, 130 (3-4), 403-409.

(108) Eschemann, T. O.; Oenema, J.; de Jong, K. P. Effects of Noble Metal Promotion for $\mathrm{Co} / \mathrm{TiO}_{2}$ Fischer-Tropsch Catalysts. Catal. Today 2016, 261, 60-66.

(109) Li, J.; Jacobs, G.; Zhang, Y.; Das, T.; Davis, B. H. FischerTropsch Synthesis: Effect of Small Amounts of Boron, Ruthenium and Rhenium on Co/ $\mathrm{TiO}_{2}$ Catalysts. Appl. Catal., A 2002, 223 (1-2), 195-203.

(110) Jalama, K.; Kabuba, J.; Xiong, H.; Jewell, L. L. Co/ $\mathrm{TiO}_{2}$ Fischer-Tropsch Catalyst Activation by Synthesis Gas. Catal. Commun. 2012, 17, 154-159.

(111) Li, J.; Xu, L.; Keogh, R.; Davis, B. Fischer-Tropsch Synthesis. Effect of $\mathrm{CO}$ Pretreatment on a Ruthenium Promoted $\mathrm{Co} / \mathrm{TiO}_{2}$. Catal. Lett. 2000, 70, 127-130.

(112) Chai, S. H.; Wang, H. P.; Liang, Y.; Xu, B. Q. Sustainable Production of Acrolein: Gas-Phase Dehydration of Glycerol over $\mathrm{Nb}_{2} \mathrm{O}_{5}$ catalyst. J. Catal. 2007, 250 (2), 342-349.

(113) Silva, R. R. C. M.; Schmal, M.; Frety, R.; Dalmon, J. A. Effect of the Support on the Fischer-Tropsch Synthesis with $\mathrm{Co} / \mathrm{Nb}_{2} \mathrm{O}_{5}$ Catalysts. J. Chem. Soc., Faraday Trans. 1993, 89 (21), 3975.

(114) Mendes, F. M. T.; Uhl, A.; Starr, D. E.; Guimond, S.; Schmal, M.; Kuhlenbeck, H.; Shaikhutdinov, S. K.; Freund, H. J. Strong Metal Support Interaction on Co/Niobia Model Catalysts. Catal. Lett. 2006, 111 (1-2), 35-41.

(115) den Otter, J. H.; Yoshida, H.; Ledesma, C.; Chen, D.; de Jong, K. P. On the Superior Activity and Selectivity of $\mathrm{PtCo} / \mathrm{Nb}_{2} \mathrm{O}_{5}$ Fischer-Tropsch Catalysts. J. Catal. 2016, 340, 270-275.

(116) Hernández Mejía, C.; den Otter, J. H.; Weber, J. L.; de Jong, K. P. Crystalline Niobia with Tailored Porosity as Support for Cobalt Catalysts for the Fischer-Tropsch Synthesis. Appl. Catal., A 2017, 548, 143-149.

(117) Zhang, Y.; Xiang, H.; Zhong, B.; Wang, Q. $\mathrm{ZrO}_{2}-\mathrm{SiO}_{2}$ Aerogel Supported Cobalt Catalysts for the Synthesis of Long-Chain Hydrocarbon from Syngas. Pet. Sci. Technol. 1999, 17 (9-10), 981-998.

(118) Enache, D. I.; Rebours, B.; Roy-Auberger, M.; Revel, R. In Situ XRD Study of the Influence of Thermal Treatment on the Characteristics and the Catalytic Properties of Cobalt-Based FischerTropsch Catalysts. J. Catal. 2002, 205 (2), 346-353.

(119) Panpranot, J.; Taochaiyaphum, N.; Jongsomjit, B.; Praserthdam, P. Differences in Characteristics and Catalytic Properties of Co Catalysts Supported on Micron- and Nano-Sized Zirconia. Catal. Commun. 2006, 7 (3), 192-197.

(120) Liu, Y.; Chen, J.; Fang, K.; Wang, Y.; Sun, Y. A Large PoreSize Mesoporous Zirconia Supported Cobalt Catalyst with Good Performance in Fischer-Tropsch Synthesis. Catal. Commun. 2007, 8 (6), 945-949.

(121) Soisuwan, S.; Netiworaruksa, B.; Charoendechanukor, C.; Tubcharoen, T.; Panpranot, J.; Praserthdam, P. Characteristics and Catalytic Properties of La-Modified $\mathrm{ZrO}_{2}$ Supported Cobalt Catalysts in CO Hydrogenation. React. Kinet., Mech. Catal. 2011, 103 (2), 367378.

(122) Zhang, X.; Su, H.; Zhang, Y.; Gu, X. Effect of $\mathrm{CeO}_{2}$ Promotion on the Catalytic Performance of $\mathrm{Co} / \mathrm{ZrO}_{2}$ Catalysts for Fischer-Tropsch Synthesis. Fuel 2016, 184, 162-168.

(123) Opanasenko, M. Zeolite Constructor Kit: Design for Catalytic Applications. Catal. Today 2018, 304, 2-11.
(124) McMahon, K. C.; Suib, S. L.; Johnson, B. G.; Bartholomew, C. H., Jr. Dispersed Cobalt-Containing Zeolite Fischer-Tropsch Catalysts. J. Catal. 1987, 106 (1), 47-53.

(125) Bartholomew, C. H. Recent Developments in FischerTropsch Catalysis. Stud. Surf. Sci. Catal. 1991, 64, 158-224.

(126) Fornasari, G.; La, T. M. G.; Vaccari, A.; Bednarova, S.; Jiru, P.; Tvaruzkova, Z. Fischer-Tropsch Synthesis on Zeolite Supported Cobalt Catalysts. Stud. Surf. Sci. Catal. 1991, 61 (C), 333-339.

(127) Udaya, V.; Rao, S.; Gormley, R. J. Bifunctional Catalysis in Syngas Conversions. Catal. Today 1990, 6 (3), 207-234.

(128) Bessell, S. ZSM-5 as a Support for Cobalt Fischer-Tropsch Catalysts. Stud. Surf. Sci. Catal. 1994, 81 (C), 461-466.

(129) Ngamcharussrivichai, C.; Liu, X.; Li, X.; Vitidsant, T.; Fujimoto, K. An Active and Selective Production of Gasoline-Range Hydrocarbons over Bifunctional Co-Based Catalysts. Fuel 2007, 86 (1-2), 50-59.

(130) Dalil, M.; Sohrabi, M.; Royaee, S. J. Application of Nano-Sized Cobalt on ZSM-5 Zeolite as an Active Catalyst in Fischer-Tropsch Synthesis. J. Ind. Eng. Chem. 2012, 18 (2), 690-696.

(131) Zola, A. S.; Bidart, A. M. F.; Fraga, A. d. C.; Hori, C. E.; Sousa-Aguiar, E. F.; Arroyo, P. A. Cobalt Supported on Different Zeolites for Fischer-Tropsch Synthesis. Stud. Surf. Sci. Catal. 2007, 167, 129-134.

(132) Higgins, J. B.; LaPierre, R. B.; Schlenker, J. L.; Rohrman, A. C.; Wood, J. D.; Kerr, G. T.; Rohrbaugh, W. J. The Framework Topology of Zeolite Beta. Zeolites 1988, 8 (6), 446-452.

(133) Pereira, A. L. C.; González-Carballo, J. M.; Pérez-Alonso, F. J.; Rojas, S.; Fierro, J. L. G.; Rangel, M. D. C. Effect of the Mesostructuration of the Beta Zeolite Support on the Properties of Cobalt Catalysts for Fischer-Tropsch Synthesis. Top. Catal. 2011, 54 (1-4), 179-189.

(134) Espinosa, G.; Domínguez, J. M.; Morales-Pacheco, P.; Tobon, A.; Aguilar, M.; Benítez, J. Catalytic Behavior of $\mathrm{Co} /(\mathrm{Nano} \beta$-Zeolite) Bifunctional Catalysts for Fischer-Tropsch Reactions. Catal. Today 2011, 166 (1), 47-52.

(135) Nakanishi, M.; Uddin, M. A.; Kato, Y.; Nishina, Y.; Hapipi, A. M. Effects of Preparation Method on the Properties of Cobalt Supported B-Zeolite Catalysts for Fischer-Tropsch Synthesis. Catal. Today 2017, 291, 124-132.

(136) Meng, X.; Nawaz, F.; Xiao, F. S. Templating Route for Synthesizing Mesoporous Zeolites with Improved Catalytic Properties. Nano Today 2009, 4 (4), 292-301.

(137) Xing, C.; Yang, G.; Wu, M.; Yang, R.; Tan, L.; Zhu, P.; Wei, Q.; Li, J.; Mao, J.; Yoneyama, Y.; Tsubaki, N. Hierarchical Zeolite y Supported Cobalt Bifunctional Catalyst for Facilely Tuning the Product Distribution of Fischer-Tropsch Synthesis. Fuel 2015, 148, $48-57$.

(138) Xing, C.; Yang, G.; Lu, P.; Shen, W.; Gai, X.; Tan, L.; Mao, J.; Wang, T.; Yang, R.; Tsubaki, N. A Hierarchically Spherical Co-Based Zeolite Catalyst with Aggregated Nanorods Structure for Improved Fischer-Tropsch Synthesis Reaction Activity and Isoparaffin Selectivity. Microporous Mesoporous Mater. 2016, 233, 62-69.

(139) Lu, P.; Sun, J.; Zhu, P.; Abe, T.; Yang, R.; Taguchi, A.; Vitidsant, T.; Tsubaki, N. Sputtered Nano-Cobalt on H-USY Zeolite for Selectively Converting Syngas to Gasoline. J. Energy Chem. 2015, 24 (5), 637-641.

(140) Trovarelli, A. Catalytic Properties of Ceria and $\mathrm{CeO}_{2}$ Containing Materials. Catal. Rev.: Sci. Eng. 1996, 38 (4), 439-520.

(141) Gnanamani, M. K.; Ribeiro, M. C.; Ma, W.; Shafer, W. D.; Jacobs, G.; Graham, U. M.; Davis, B. H. Fischer-Tropsch Synthesis: Metal-Support Interfacial Contact Governs Oxygenates Selectivity over $\mathrm{CeO}_{2}$ supported Pt-Co Catalysts. Appl. Catal., A 2011, 393 (12), $17-23$.

(142) Yang, Y.; Chiang, K.; Burke, N. Porous Carbon-Supported Catalysts for Energy and Environmental Applications: A Short Review. Catal. Today 2011, 178 (1), 197-205.

(143) Fu, T.; Li, Z. Review of Recent Development in Co-Based Catalysts Supported on Carbon Materials for Fischer-Tropsch Synthesis. Chem. Eng. Sci. 2015, 135, 3-20. 
(144) Xiong, H.; Jewell, L. L.; Coville, N. J. Shaped Carbons As Supports for the Catalytic Conversion of Syngas to Clean Fuels. ACS Catal. 2015, 5, 2640-2658.

(145) Bezemer, G. L.; van Laak, A.; van Dillen, A. J.; de Jong, K. P. Cobalt Supported on Carbon Nanofibers- a Promising Novel Fischer-Tropsch Catalyst. Stud. Surf. Sci. Catal. 2004, 147, 259-264. (146) Bezemer, G. L.; Bitter, J. H.; Kuipers, H. P. C. E.; Oosterbeek, H.; Holewijn, J. E.; Xu, X.; Kapteijn, F.; van Dillen, A. J.; de Jong, K. P. Cobalt Particle Size Effects in the Fischer-Tropsch Reaction Studied with Carbon Nanofiber Supported Catalysts. J. Am. Chem. Soc. 2006, 128 (12), 3956-3964.

(147) den Breejen, J. P.; Radstake, P. B.; Bezemer, G. L.; Bitter, J. H.; Frøseth, V.; Holmen, A.; de Jong, K. P. On the Origin of the Cobalt Particle Size Effects in Fischer-Tropsch Catalysis. J. Am. Chem. Soc. 2009, 131 (20), 7197-7203.

(148) Trépanier, M.; Tavasoli, A.; Dalai, A. K.; Abatzoglou, N. Fischer-Tropsch Synthesis over Carbon Nanotubes Supported Cobalt Catalysts in a Fixed Bed Reactor: Influence of Acid Treatment. Fuel Process. Technol. 2009, 90 (3), 367-374.

(149) Trépanier, M.; Tavasoli, A.; Dalai, A. K.; Abatzoglou, N. Co, $\mathrm{Ru}$ and $\mathrm{K}$ Loadings Effects on the Activity and Selectivity of Carbon Nanotubes Supported Cobalt Catalyst in Fischer-Tropsch Synthesis. Appl. Catal., A 2009, 353 (2), 193-202.

(150) Fu, T.; Lv, J.; Li, Z. Effect of Carbon Porosity and Cobalt Particle Size on the Catalytic Performance of Carbon Supported Cobalt Fischer-Tropsch Catalysts. Ind. Eng. Chem. Res. 2014, 53 (4), $1342-1350$.

(151) Davari, M.; Karimi, S.; Tavasoli, A.; Karimi, A. Enhancement of Activity, Selectivity and Stability of CNTs-Supported Cobalt Catalyst in Fischer-Tropsch via CNTs Functionalization. Appl. Catal., A 2014, 485, 133-142.

(152) Xiong, H.; Moyo, M.; Rayner, M. K.; Jewell, L. L.; Billing, D. G.; Coville, N. J. Autoreduction and Catalytic Performance of a Cobalt Fischer-Tropsch Synthesis Catalyst Supported on NitrogenDoped Carbon Spheres. ChemCatChem 2010, 2 (5), 514-518.

(153) Su, D. S.; Perathoner, S.; Centi, G. Nanocarbons for the Development of Advanced Catalysts. Chem. Rev. 2013, 113 (8), 5782-5816.

(154) Tavasoli, A.; Trépanier, M.; Dalai, A. K.; Abatzoglou, N. Effects of Confinement in Carbon Nanotubes on the Activity, Selectivity, and Lifetime of Fischer-Tropsch Co/Carbon Nanotube Catalysts. J. Chem. Eng. Data 2010, 55 (8), 2757-2763.

(155) Xing, C.; Yang, G.; Wang, D.; Zeng, C.; Jin, Y.; Yang, R.; Suehiro, Y.; Tsubaki, N. Controllable Encapsulation of Cobalt Clusters inside Carbon Nanotubes as Effective Catalysts for Fischer-Tropsch Synthesis. Catal. Today 2013, 215, 24-28.

(156) Karimi, S.; Tavasoli, A.; Mortazavi, Y.; Karimi, A. Cobalt Supported on Graphene - A Promising Novel Fischer-Tropsch Synthesis Catalyst. Appl. Catal, A 2015, 499, 188-196.

(157) Eschemann, T. O.; Lamme, W. S.; Manchester, R. L.; Parmentier, T. E.; Cognigni, A.; Rønning, M.; de Jong, K. P. Effect of Support Surface Treatment on the Synthesis, Structure, and Performance of Co/CNT Fischer-Tropsch Catalysts. J. Catal. 2015, 328, 130-138.

(158) Ali, S.; Zabidi, N. A. M.; Al-Marri, M. J.; Khader, M. M. Effect of the Support on Physicochemical Properties and Catalytic Performance of Cobalt Based Nano-Catalysts in Fischer-Tropsch Reaction. Mater. Today Commun. 2017, 10, 67-71.

(159) Phaahlamohlaka, T. N.; Kumi, D. O.; Dlamini, M. W.; Forbes, R.; Jewell, L. L.; Billing, D. G.; Coville, N. J. Effects of Co and Ru Intimacy in Fischer-Tropsch Catalysts Using Hollow Carbon Sphere Supports: Assessment of the Hydrogen Spillover Processes. ACS Catal. 2017, 7 (3), 1568-1578.

(160) Aluha, J.; Boahene, P.; Dalai, A.; Hu, Y.; Bere, K.; Braidy, N.; Abatzoglou, N. Synthesis and Characterization of $\mathrm{Co} / \mathrm{C}$ and $\mathrm{Fe} / \mathrm{C}$ Nanocatalysts for Fischer-Tropsch Synthesis: A Comparative Study Using a Fixed-Bed Reactor. Ind. Eng. Chem. Res. 2015, 54 (43), 10661-10674.
(161) Aluha, J.; Braidy, N.; Dalai, A.; Abatzoglou, N. LowTemperature Fischer-Tropsch Synthesis Using Plasma-Synthesized Nanometric $\mathrm{Co} / \mathrm{C}$ and $\mathrm{Fe} / \mathrm{C}$ Catalysts. Can. J. Chem. Eng. 2016, 94 (8), 1504-1515.

(162) Aluha, J.; Abatzoglou, N. Synthetic Fuels from 3- $\varphi$ FischerTropsch Synthesis Using Syngas Feed and Novel Nanometric Catalysts Synthesised by Plasma. Biomass Bioenergy 2016, 95, 330339.

(163) Aluha, J.; Hu, Y.; Abatzoglou, N. Effect of CO Concentration on the $\alpha$-Value of Plasma-Synthesized Co/C Catalyst in FischerTropsch Synthesis. Catalysts 2017, 7 (3), 69.

(164) Aluha, J.; Abatzoglou, N. Promotional Effect of Mo and Ni in Plasma-Synthesized $\mathrm{Co}-\mathrm{Fe} / \mathrm{C}$ Bimetallic Nano-Catalysts for Fischer-Tropsch Synthesis. J. Ind. Eng. Chem. 2017, 50, 199-212.

(165) Aluha, J.; Abatzoglou, N. Gold-Promoted Plasma-Synthesized Ni-Co-Fe/C Catalyst for Fischer-Tropsch Synthesis. Gold Bull. 2017, 50 (2), 147-162.

(166) Aluha, J.; Bere, K.; Abatzoglou, N.; Gitzhofer, F. Synthesis of Nano-Catalysts by Induction Suspension Plasma Technology (SPS) for Fischer-Tropsch Reaction. Plasma Chem. Plasma Process. 2016, 36 (5), 1325-1348.

(167) Zhu, X.; Lu, X.; Liu, X.; Hildebrandt, D.; Glasser, D. Study of Radial Heat Transfer in a Tubular Fischer-Tropsch Synthesis Reactor. Ind. Eng. Chem. Res. 2010, 49 (21), 10682-10688.

(168) Zhu, X.; Lu, X.; Liu, X.; Hildebrandt, D.; Glasser, D. Heat Transfer Study with and without Fischer-Tropsch Reaction in a Fixed Bed Reactor with $\mathrm{TiO}_{2}, \mathrm{SiO}_{2}$, and $\mathrm{SiC}$ Supported Cobalt Catalysts. Chem. Eng. J. 2014, 247, 75-84.

(169) Duong-Viet, C.; Ba, H.; El-Berrichi, Z.; Nhut, J.-M.; Ledoux, M. J.; Liu, Y.; Pham-Huu, C. Silicon Carbide Foam as a Porous Support Platform for Catalytic Applications. New J. Chem. 2016, 40 (5), 4285-4299.

(170) Nguyen, P.; Pham, C. Innovative Porous SiC-Based Materials: From Nanoscopic Understandings to Tunable Carriers Serving Catalytic Needs. Appl. Catal., A 2011, 391 (1-2), 443-454.

(171) Liu, Y.; Ersen, O.; Meny, C.; Luck, F.; Pham-Huu, C. Fischer-Tropsch Reaction on a Thermally Conductive and Reusable Silicon Carbide Support. ChemSusChem 2014, 7 (5), 1218-1239.

(172) Liu, Y.; Edouard, D.; Nguyen, L. D.; Begin, D.; Nguyen, P.; Pham, C.; Pham-Huu, C. High Performance Structured Platelet MilliReactor Filled with Supported Cobalt Open Cell SiC Foam Catalyst for the Fischer-Tropsch Synthesis. Chem. Eng. J. 2013, 222, 265273.

(173) de la Osa, A.; Romero, A.; Dorado, F.; Valverde, J.; Sánchez, P. Influence of Cobalt Precursor on Efficient Production of Commercial Fuels over FTS $\mathrm{Co} / \mathrm{SiC}$ Catalyst. Catalysts 2016, 6 (7), 98.

(174) Díaz, J. A.; Calvo-Serrano, M.; de la Osa, A. R.; GarcíaMinguillán, A. M.; Romero, A.; Giroir-Fendler, A.; Valverde, J. L. $\beta$ Silicon Carbide as a Catalyst Support in the Fischer-Tropsch Synthesis: Influence of the Modification of the Support by a Pore Agent and Acidic Treatment. Appl. Catal., A 2014, 475, 82-89.

(175) Liu, Y.; de Tymowski, B.; Vigneron, F.; Florea, I.; Ersen, O.; Meny, C.; Nguyen, P.; Pham, C.; Luck, F.; Pham-Huu, C. TitaniaDecorated Silicon Carbide-Containing Cobalt Catalyst for FischerTropsch Synthesis. ACS Catal. 2013, 3 (3), 393-404.

(176) Moffat, J. B. Phosphates as Catalysts. Catal. Rev.: Sci. Eng. 1978, 18 (2), 199-258.

(177) Cheung, T. T. P.; Willcox, K. W.; McDaniel, M. P.; Johnson, M. M.; Bronnimann, C.; Frye, J. The Structure of Coprecipitated Aluminophosphate Catalyst Supports. J. Catal. 1986, 102 (1), 10-20.

(178) Bae, J. W.; Kim, S. M.; Kang, S. H.; Chary, K. V. R.; Lee, Y. J.; Kim, H. J.; Jun, K. W. Effect of Support and Cobalt Precursors on the Activity of $\mathrm{Co} / \mathrm{AlPO}_{4}$ Catalysts in Fischer-Tropsch Synthesis. J. Mol. Catal. A: Chem. 2009, 311 (1-2), 7-16.

(179) Cavani, F.; Trifirò, F.; Vaccari, A. Hydrotalcite-Type Anionic Clays: Preparation, Properties and Applications. Catal. Today 1991, 11 (2), 173-301. 
(180) Krylova, M. V.; Kulikov, A. B.; Knyazeva, M. I.; Krylova, A. Yu. Cobalt-Containing Catalysts Made from Layered Double Hydroxides for Synthesis of Hydrocarbon from Carbon Monoxide and Hydrogen. Chem. Technol. Fuels Oils 2008, 44 (5), 339-343.

(181) Tsai, Y.-T.; Mo, X.; Campos, A.; Goodwin, J. G.; Spivey, J. J. Hydrotalcite Supported Co Catalysts for CO Hydrogenation. Appl. Catal., A 2011, 396 (1-2), 91-100.

(182) Di Fronzo, A.; Pirola, C.; Comazzi, A.; Galli, F.; Bianchi, C. L.; Di Michele, A.; Vivani, R.; Nocchetti, M.; Bastianini, M.; Boffito, D. C. Co-Based Hydrotalcites as New Catalysts for the Fischer-Tropsch Synthesis Process. Fuel 2014, 119, 62-69.

(183) Chughtai, A. H.; Ahmad, N.; Younus, H. A.; Laypkov, A.; Verpoort, F. Metal-organic Frameworks: Versatile Heterogeneous Catalysts for Efficient Catalytic Organic Transformations. Chem. Soc. Rev. 2015, 44 (19), 6804-6849.

(184) Liu, J.; Chen, L.; Cui, H.; Zhang, J.; Zhang, L.; Su, C.-Y. Applications of Metal-organic Frameworks in Heterogeneous Supramolecular Catalysis. Chem. Soc. Rev. 2014, 43 (16), 6011-6061.

(185) Isaeva, V. I.; Eliseev, O. L.; Kazantsev, R. V.; Chernyshev, V. V.; Davydov, P. E.; Saifutdinov, B. R.; Lapidus, A. L.; Kustov, L. M. Fischer-Tropsch Synthesis over MOF-Supported Cobalt Catalysts (Co@MIL-53(Al)). Dalton Trans. 2016, 45 (30), 12006-12014.

(186) Qiu, B.; Yang, C.; Guo, W.; Xu, Y.; Liang, Z.; Ma, D.; Zou, R. Highly Dispersed Co-Based Fischer-Tropsch Synthesis Catalysts from Metal-organic Frameworks. J. Mater. Chem. A 2017, 5 (17), $8081-8086$.

(187) Sadeqzadeh, M.; Karaca, H.; Safonova, O. V.; Fongarland, P.; Chambrey, S.; Roussel, P.; Griboval-Constant, A.; Lacroix, M.; Curulla-Ferré, D.; Luck, F.; Khodakov, A. Y. Identification of the Active Species in the Working Alumina-Supported Cobalt Catalyst under Various Conditions of Fischer-Tropsch Synthesis. Catal. Today 2011, 164 (1), 62-67.

(188) Pei, Y.; Li, Z.; Li, Y. Highly Active and Selective Co-Based Fischer-Tropsch Catalysts Derived from Metal-organic Frameworks. AIChE J. 2017, 63 (7), 2935-2944.

(189) Banhart, J. Manufacture, Characterisation and Application of Cellular Metals and Metal Foams. Prog. Mater. Sci. 2001, 46 (6), 559-632.

(190) Park, J. C.; Roh, N. S.; Chun, D. H.; Jung, H.; Yang, J. I. Cobalt Catalyst Coated Metallic Foam and Heat-Exchanger Type Reactor for Fischer-Tropsch Synthesis. Fuel Process. Technol. 2014, $119,60-66$

(191) Harmel, J. Synthèse de Nano-Catalyseurs Hybrides à Base de Cobalt Pour La Catalyse Fischer-Tropsch. Ph.D. Thesis, University of Toulouse, Toulouse, France, 2016.

(192) Narasaraju, T. S. B.; Phebe, D. E. Some Physico-Chemical Aspects of Hydroxylapatite. J. Mater. Sci. 1996, 31 (1), 1-21.

(193) Pham Minh, D.; Galera Martínez, M.; Nzihou, A.; Sharrock, P. Thermal Behavior of Apatitic Calcium Phosphates Synthesized from Calcium Carbonate and Orthophosphoric Acid or Potassium Dihydrogen Orthophosphate. J. Therm. Anal. Calorim. 2013, 112 (3), 1145-1155.

(194) Joris, S. J.; Amberg, C. H. Nature of Deficiency in Nonstoichiometric Hydroxyapatites. II. Spectroscopic Studies of Calcium and Strontium Hydroxyapatites. J. Phys. Chem. 1971, 75 (20), 3172-3178.

(195) Tsuchida, T.; Kubo, J.; Yoshioka, T.; Sakuma, S.; Takeguchi, T.; Ueda, W. Reaction of Ethanol over Hydroxyapatite Affected by Ca/P Ratio of Catalyst. J. Catal. 2008, 259 (2), 183-189.

(196) Wakamura, M.; Kandori, K.; Ishikawa, T. Surface Structure and Composition of Calcium Hydroxyapatites Substituted with $\mathrm{Al}(\mathrm{III}), \mathrm{La}(\mathrm{III})$ and $\mathrm{Fe}(\mathrm{III})$ Ions. Colloids Surf., A 2000, 164 (2-3), 297-305.

(197) Fihri, A.; Len, C.; Varma, R. S.; Solhy, A. Hydroxyapatite: A Review of Syntheses, Structure and Applications in Heterogeneous Catalysis. Coord. Chem. Rev. 2017, 347, 48-76.

(198) Boukha, Z.; Kacimi, M.; Ziyad, M.; Ensuque, A.; BozonVerduraz, F. Comparative Study of Catalytic Activity of Pd Loaded Hydroxyapatite and Fluoroapatite in Butan-2-ol Conversion and
Methane Oxidation. J. Mol. Catal. A: Chem. 2007, 270 (1-2), 205213.

(199) Jun, J. H.; Lee, T.-J.; Lim, T. H.; Nam, S.-W.; Hong, S.-A.; Yoon, K. J. Nickel-Calcium Phosphate/Hydroxyapatite Catalysts for Partial Oxidation of Methane to Syngas: Characterization and Activation. J. Catal. 2004, 221 (1), 178-190.

(200) Rêgo De Vasconcelos, B.; Zhao, L.; Sharrock, P.; Nzihou, A.; Pham Minh, D. Catalytic Transformation of Carbon Dioxide and Methane into Syngas over Ruthenium and Platinum Supported Hydroxyapatites. Appl. Surf. Sci. 2016, 390, 141-156.

(201) Rêgo de Vasconcelos, B.; Pham Minh, D.; Sharrock, P.; Nzihou, A. Regeneration Study of Ni/Hydroxyapatite Spent Catalyst from Dry Reforming. Catal. Today 2018, 310, 107-115.

(202) Boukha, Z.; Kacimi, M.; Pereira, M. F. R.; Faria, J. L.; Figueiredo, J. L.; Ziyad, M. Methane Dry Reforming on Ni Loaded Hydroxyapatite and Fluoroapatite. Appl. Catal., A 2007, 317 (2), 299-309.

(203) Phan, T. S.; Sane, A. R.; Rêgo de Vasconcelos, B.; Nzihou, A.; Sharrock, P.; Grouset, D.; Pham Minh, D. Hydroxyapatite Supported Bimetallic Cobalt and Nickel Catalysts for Syngas Production from Dry Reforming of Methane. Appl. Catal., B 2018, 224, 310-321.

(204) Venugopal, A.; Scurrell, M. S. Hydroxyapatite as a Novel Support for Gold and Ruthenium Catalysts: Behaviour in the Water Gas Shift Reaction. Appl. Catal., A 2003, 245 (1), 137-147.

(205) Yaakob, Z.; Hakim, L.; Kumar, M.; Ismail, M.; Daud, W. Short Communication: Hydroxyapatite Supported Nickel Catalyst for Hydrogen Production. Am. J. Sci. Ind. Res. 2010, 1 (2), 122-126.

(206) Mori, K.; Hara, T.; Mizugaki, T.; Ebitani, K.; Kaneda, K. Hydroxyapatite-Supported Palladium Nanoclusters: A Highly Active Heterogeneous Catalyst for Selective Oxidation of Alcohols by Use of Molecular Oxygen. J. Am. Chem. Soc. 2004, 126 (34), 10657-10666. 